\title{
BRITISH HIV ASSOCIATION \\ GUIDELINES ON THE USE OF \\ VACCINES IN HIV-POSITIVE
}

ADULTS 2015

Writing Group Chair and Editor: Prof Anna Maria Geretti

\section{Writing Group (in alphabetic order):}

Dr Gary Brook, Central Middlesex Hospital, London

Ms Claire Cameron, Public Health England, London

Dr David Chadwick, James Cook University Hospital, Middlesbrough

Prof Neil French, University of Liverpool

Prof Robert Heyderman, University College London

Dr Antonia Ho, University of Liverpool

Dr Michael Hunter, Belfast Health and Social Care Trust

Dr Shamez Ladhani, Public Health England, London

Dr Mark Lawton, Royal Liverpool University Hospital

Dr Eithne MacMahon, Guy's \& St Thomas' NHS Foundation Trust \& King's College London, London

Dr John McSorley, Central Middlesex Hospital, London

Dr Anton Pozniak, Chelsea and Westminster Hospital, London

Dr Alison Rodger, University College London 


\section{Contents}

INTRODUCTION 3

TABLE 1. SUMMARY OF RECOMMENDATIONS 8

ANTHRAX 10

CHOLERA 12

DIPHTHERIA 15

HAEMOPHILUS INFLUENZAE SEROTYPE $b$ 17

HEPATITIS A 20

HEPATITIS B 23

HUMAN PAPILLOMA VIRUS 30

INFLUENZA 37

JAPANESE ENCEPHALITIS 43

MEASLES, MUMPS AND RUBELLA 45

MENINGOCOCCUS 49

PERTUSSIS (WHOOPING COUGH) 52

PNEUMOCOCCUS 54

POLIOMYELITIS 61

RABIES 63

SMALLPOX 68

TETANUS 72

TICK-BORNE ENCEPHALITIS 75

TYPHOID FEVER 77

TUBERCULOSIS 80

VARICELLA ZOSTER VIRUS 82

YELLOW FEVER VIRUS 88 


\section{INTRODUCTION}

\section{The need for updated guidance}

These guidelines provide updated, GRADE-based recommendations on the use of vaccines in HIVpositive adults. Several factors have made the updating of HIV-specific vaccination guidelines important: effective antiretroviral therapy (ART) has substantially modified the natural history of HIV infection, vaccination practices are evolving, and a large number of novel vaccines are becoming available in clinical care. The update contains important new guidance regarding the use of new vaccines against human papillomavirus (HPV), shingles (herpes zoster), and pneumococcus. Further key updates are related to the use of hepatitis $B$, meningococcus, and pertussis vaccines.

Compared with HIV-negative individuals, HIV-positive adults often have an increased risk of infection or experience more severe morbidity following exposure to vaccine-preventable diseases, and therefore a lower threshold for extending indications and offering vaccination may be appropriate relative to the general population. Improved health and prognosis mean that HIV-positive adults are also increasingly likely to engage in travel or occupations that carry a risk of exposure to infectious agents, and these otherwise healthy individuals should not be denied protection or engagement with such activities if evidence indicates vaccination is safe and immunogenic. Immune responses to vaccination are often sub-optimal in HIV-positive patients, and while these improve with ART, they often remain lower and decline more rapidly than in HIV-negative individuals. However, many of these vaccines still afford protection and for some vaccines it is possible to improve immunogenicity by offering modified vaccine schedules, with higher or more frequent doses, without compromising safety.

Non-replicating vaccines (e.g., whole inactivated, polysaccharide, conjugated, and subunit vaccines, or virus-like particles) can be used safely in HIV-positive persons, whereas replicating (live) vaccines have traditionally been contraindicated. However, ART-induced Immunorestoration reduces the risk of adverse events, in many cases shifting the risk-benefit ratio in favour of vaccination, whereby the risk of disease with natural infection becomes greater than the risk of live vaccine-related adverse events. Important examples of replicating vaccines that can be used in HIV-positive persons with good immunity include those for measles, mumps and rubella (MMR), varicella-zoster virus (VZV), and yellow fever. For vaccinated individuals, the importance of infection avoidance and infection control should continue to be emphasised.

It is envisaged that the HIV specialist should provide overall guidance on vaccine use and enlist the help of primary care physicians for vaccine administration. Education of health care providers and good communication are key requirements to ensure successful implementation of this guidance. Despite evidence that HIV-positive persons benefit from vaccination, there are persisting perceptions about disease incidence and burden, and vaccine effectiveness and safety, which affect vaccination practices among health professionals caring for HIV-positive patients. It is hoped that this guidance will help overcoming such barriers. 
Key points: Vaccination of HIV-positive adults

\begin{tabular}{|ll|l|}
\hline - High risk of infection & Lowers threshold for vaccination \\
\hline - & High risk of severe disease & $\begin{array}{l}\text { Lowers threshold for vaccination } \\
\text { Extends indications for vaccination }\end{array}$ \\
\hline - & Improved prognosis & $\begin{array}{l}\text { Allows engagement with exposure-prone occupations and travel } \\
\text { Increases the likely impact of vaccine-preventable infections }\end{array}$ \\
\hline - & Immunorestoration & $\begin{array}{l}\text { Improves vaccine immunogenicity } \\
\text { Overcomes traditional contraindications to replicating vaccines }\end{array}$ \\
\hline - & Reduced immunogenicity & May be overcome with higher and more frequent vaccine doses \\
\hline - & Perceptions & Create barriers to effective vaccination \\
\hline - & Evolving knowledge & $\begin{array}{l}\text { Requires education of health care professionals and effective } \\
\text { communication between primary and specialist care providers }\end{array}$ \\
\hline
\end{tabular}

\section{How to use the guidelines}

- The guidelines are meant to highlight specific aspects of vaccine use that are relevant to HIVpositive adults. They are intended to be complementary to national guidance available through The Green Book [www.gov.uk/government/collections/immunisation-against-infectious-diseasethe-green-book], to which readers should refer for the latest information on available vaccines and vaccination procedures in the United Kingdom (UK)

- For epidemiological information relevant to the use of travel-related vaccines, the reader is invited to consult guidance for health professionals available through the National Travel Health Network and Centre [www.nathnac.org/ds/map_world.aspx]. Country-specific information for travellers is also available from Public Health England [www.gov.uk/government/organisations/public-healthengland]; Health Protection Scotland [www.hps.scot.nhs.uk]; Travax [www.travax.nhs.uk]; and FitForTravel [www.fitfortravel.nhs.uk]

- Table 1 summarises the recommendations contained in the guidelines. The reader should refer to the individual chapters for details

\section{General principles}

\section{Replicating (live) vaccines:}

- HIV-positive adults with CD4 counts $<200$ cells/ $\mu \mathrm{L}$ must not be given replicating vaccines due to a potential risk of vaccine-associated disease; when indicated, vaccination should be postponed until the CD4 cell count has improved on ART (refer to individual chapters for details)

- HIV-positive adults with a CD4 count of 200-350 cells/ $\mu \mathrm{L}$ have moderate immunodeficiency. Clinical judgment should be used to guide the use of replicating vaccines in these patients. Where exposure is likely, natural infection often carries a greater risk of adverse outcomes than vaccination; a suppressed plasma HIV-1 RNA ("viral") load on ART increases the safety and immunogenicity of vaccination in this group

- The co-administration of multiple replicating vaccines is not recommended in HIV-positive adults due to uncertainties over safety, immunogenicity, and efficacy. An interval of at least 4 weeks between vaccinations is recommended [1D]

- Regardless of the CD4 cell count, contraindications to the use of replicating vaccines that apply to the general population (e.g., in relation to the use of immunosuppressive therapy) also apply to 
HIV-positive patients. The reader should refer to The Green Book for details [www.gov.uk/government/collections/immunisation-against-infectious-disease-the-green-book]

- Replicating vaccines (except Yellow Fever) should be administered at least 14 days before or 3 months after the administration of antibody-containing blood products, because passively acquired antibodies may interfere with the response to the vaccine

\section{Patients with CD4 counts $<200$ cells/ $\mu L$ :}

- Replicating (live) vaccines are contraindicated

- Responses to non-replicating vaccines are reduced. Depending on the level of risk, consideration may be given to delaying vaccination until the CD4 cell count has recovered with ART. Because responses to vaccination are observed in a substantial proportion of patients with low CD4 cell counts however, the potential benefit of vaccination should not be denied to persons at risk of exposure. If indicated, the vaccine course can be repeated following immunoreconstitution on ART rather than postponed [1C]

\section{Travel vaccines:}

- Destination, itinerary, length of stay, and planned activities must be considered equally in HIVpositive and HIV-negative travellers when recommending vaccination. However, the consequences of not administering an indicated vaccine may be more severe in people with HIV

- HIV-positive vaccine recipients should be advised that the levels and duration of vaccine-induced protection might be reduced relative to HIV-negative individuals. The importance of additional measures of protection (e.g., hand washing, against insect bites, food hygiene) should be emphasised

\section{Effects of vaccination on viral load:}

- Transient, clinically non-significant increases in viral load have been reported in HIV-positive persons after the administration of several vaccines. Concerns related to the induction of HIV replication are counterbalanced by the benefit of vaccination, and do not preclude vaccination

\section{General contraindications:}

- As a general rule, vaccines are contraindicated in persons with a history of previous severe adverse reaction or allergy to the vaccine or its components. In addition, persons with acute moderate or severe febrile illness should not usually be vaccinated until their symptoms have abated

- Non-replicating vaccines may be used in pregnancy and during breastfeeding if there is a significant risk of infection or other clinical indication. Replicating vaccines are contraindicated in pregnancy, although in most cases the theoretical risk to the developing foetus is expected to be low

\section{Sources of evidence}

Available evidence was obtained from published peer-reviewed studies and from studies presented at international conferences in the last two years. In addition, the following websites were consulted: The Green Book [www.gov.uk/government/collections/immunisation-against-infectious-disease-thegreen-book]; the Centers for Disease Control \& Prevention [www.cdc.gov/vaccines/hcp/acip-recs/index.html]; and the World Health Organization [WHO; www.who.int/en]. The following US guidelines were also reviewed: Recommendations from the Centers for Disease Control and Prevention, the National Institutes of Health, and the HIV Medicine Association of the Infectious Diseases Society of America: Guidelines for the Prevention and Treatment of Opportunistic Infections in HIV-Infected Adults and Adolescent (updated April 2015) [aidsinfo.nih.gov/contentfiles/Ivguidelines/adult_oi.pdf]; Hibberd PL. Immunizations in HIV-infected patients. UpToDate May 2015 [www.uptodate.com] 


\section{Summary of the modified GRADE system}

BHIVA revised and updated the association's guideline development manual in 2011 [1]. BHIVA has adopted the modified Grading of Recommendations Assessment, Development and Evaluation (GRADE) system for the assessment, evaluation, and grading of evidence and the development of recommendations [2,3]. Strong recommendations are graded 1 A-D. Weak recommendations are suggestions graded 2 A-D. Clinicians should follow a strong recommendation unless there is a clear rationale for an alternative approach. Consensus opinion on good practice is indicated as GPP (Good Practice Point).

Summary modified GRADE system

\begin{tabular}{|c|c|c|}
\hline Grade & $\begin{array}{l}\text { Quality of } \\
\text { evidence }\end{array}$ & Benefits, source of evidence, impact of further research, recommendation \\
\hline $1 A$ & High & $\begin{array}{l}\text { - Benefits clearly outweigh risks and burdens, or vice versa } \\
\text { - Consistent evidence from well performed randomised, controlled trials or } \\
\text { overwhelming evidence of some other form } \\
\text { - Further research is unlikely to change confidence in estimate of benefits and risks } \\
\text { - Strong recommendations, can apply to most patients in most circumstances } \\
\text { without reservation }\end{array}$ \\
\hline 1B & Moderate & $\begin{array}{l}\text { - Benefits clearly outweigh risks and burdens, or vice versa } \\
\text { - Evidence from randomised, controlled trials with important limitations } \\
\text { (inconsistent results, methods flaws, indirect or imprecise), or very strong } \\
\text { evidence of some other research design } \\
\text { - Further research may impact on confidence in the estimate of benefits and risks } \\
\text { - Strong recommendation and applies to most patients }\end{array}$ \\
\hline 1C & Low & $\begin{array}{l}\text { - Benefits appear to outweigh risks and burdens, or vice versa } \\
\text { - Evidence from observational studies, unsystematic clinical experience, or from } \\
\text { randomised, controlled trials with serious flaws } \\
\text { - Any estimate of effect is uncertain. Strong recommendation, and applies to most } \\
\text { patients. Some of the evidence base supporting the recommendation is, however, } \\
\text { of low quality }\end{array}$ \\
\hline 1D & Very low & $\begin{array}{l}\text { - Benefits appear to outweigh risks and burdens, or vice versa } \\
\text { - Evidence limited to case studies } \\
\text { - Strong recommendation based mainly on case studies and expert judgment }\end{array}$ \\
\hline $2 A$ & High & $\begin{array}{l}\text { - Benefits closely balanced with risks and burdens } \\
\text { - Consistent evidence from well performed randomised, controlled trials or } \\
\text { overwhelming evidence of some other form } \\
\text { - Further research is unlikely to change confidence in estimate of benefits and risks } \\
\text { - Weak recommendation, best action may differ depending on circumstances, } \\
\text { patients, or societal values }\end{array}$ \\
\hline 2B & Moderate & $\begin{array}{l}\text { - Benefits closely balanced with risks and burdens, some uncertainly in the } \\
\text { estimates of benefits, risks and burdens } \\
\text { - Evidence from randomised, controlled trials with important limitations } \\
\text { (inconsistent results, methods flaws, indirect or imprecise) } \\
\text { - Further research may change the estimate of benefits and risks } \\
\text { - Weak recommendation, alternative approaches likely to be better for some } \\
\text { patients under some circumstances }\end{array}$ \\
\hline $2 \mathrm{C}$ & Low & $\begin{array}{l}\text { - Uncertainty in the estimates of benefits, risks, and burdens; benefits may be } \\
\text { closely balanced with risks and burdens } \\
\text { - Evidence from observational studies, unsystematic clinical experience, or from } \\
\text { randomised, controlled trials with serious flaws }\end{array}$ \\
\hline
\end{tabular}




\begin{tabular}{|l|l|l|}
\hline & & $\begin{array}{l}\text { - Any estimate of effect is uncertain } \\
\text { - Weak recommendation; other alternatives may be reasonable }\end{array}$ \\
\hline 2D & Very low & $\begin{array}{l}\text { - Uncertainty in the estimates of benefits, risks, and burdens; benefits may be } \\
\text { closely balanced with risks and burdens } \\
\text { - Evidence limited to case studies and expert judgment } \\
\text { - Very weak recommendation; other alternatives may be equally reasonable }\end{array}$ \\
\hline
\end{tabular}

\section{References}

1. BHIVA Guideline Development Manual, $13^{\text {th }}$ September 2011. www.bhiva.org

2. Guyatt GH, Oxman AD, Kunz R et al. Going from evidence to recommendations. BMJ 2008;336: 1049-51.

3. The Grading of Recommendations Assessment, Development and Evaluation (short GRADE) Working Group. www.gradeworkinggroup.org 


\section{TABLE 1. SUMMARY OF RECOMMENDATIONS}

\begin{tabular}{|c|c|c|c|c|c|}
\hline Infection/Disease & Vaccine & Replicating & Primary course & Indication & Notes \\
\hline \multicolumn{6}{|c|}{ Vaccines with broad indications in adults } \\
\hline Hepatitis B & Subunit & No & 4 doses & All non-immune & 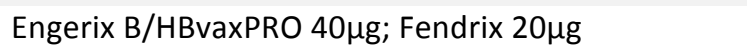 \\
\hline Influenza & Inactivated & No & 1 dose & All yearly & Quadrivalent vaccine preferred \\
\hline Pneumococcus & Conjugated & No & 1 dose & All once & PCV-13 \\
\hline Human papilloma virus & VLP & No & 3 doses & Age and gender related & 4vHPV or 9vHPV preferred \\
\hline Hepatitis A & Inactivated & No & 2-3 doses & At risk & 3 doses if CD4 counts $<350$ cells $/ \mu \mathrm{L}$ \\
\hline Meningococcus & Conjugated & No & 2 doses & Age related, at risk & MenC, MenACWY \\
\hline Meningococcus & Recombinant protein $+\mathrm{OMV}$ & No & 2 doses & Age related, at risk & MenB \\
\hline Pertussis & Acellular multicomponent & No & 1 dose & Pregnant women & Given as combined dTaP/IPV vaccine \\
\hline Pneumococcus & Polysaccharide & No & 1 dose & At risk, once & PPV-23 \\
\hline Measles, Mumps, Rubella & Live attenuated & Yes & 2 doses & All non-immune & Given as combined MMR vaccine, CD4 $>200$ cells $/ \mu \mathrm{L}$ \\
\hline Varicella (chickenpox) & Live attenuated & Yes & 2 doses & All non-immune & CD4 $>200$ cells $/ \mu \mathrm{L}$ \\
\hline Herpes zoster (shingles) & Live attenuated & Yes & 1 dose & All VZV $\operatorname{lgG}{ }^{+}$, age related & CD4 $>200$ cells $/ \mu \mathrm{L}$ \\
\hline \multicolumn{6}{|c|}{ Vaccines with predominantly travel-related indications in adults } \\
\hline Cholera & Inactivated + subunit & No & 2 doses & Selective use & $\mathrm{WC} / \mathrm{rBs}$, oral administration \\
\hline Japanese encephalitis & Vero cell-derived inactivated & No & 2 doses & & \\
\hline Tick-borne encephalitis & Inactivated & No & 3-4 doses & & \\
\hline Tetanus & Toxoid & No & 1 dose & & Given as combined $\mathrm{Td} / \mathrm{IPV}$ vaccine \\
\hline Diphtheria & Toxoid & No & 1 dose & & Given as combined $\mathrm{Td} / \mathrm{IPV}$ vaccine \\
\hline Poliovirus & Inactivated & No & 1 dose & & Given as combined Td/IPV vaccine \\
\hline Rabies & Cell-culture derived & No & 3 doses & & 5 doses for post-exposure prophylaxis \\
\hline Typhoid & Polysaccharide & No & 1 dose & & ViCPS, parenteral \\
\hline Yellow Fever & Live attenuated & Yes & 1 dose & & $<60$ years; CD4 $>200$ cells $/ \mu \mathrm{L}$ \\
\hline \multicolumn{6}{|c|}{ Vaccines with selected indications for at risk adults } \\
\hline Anthrax & Filtrate of bacterial proteins & No & 4 doses & Occupational & AVP \\
\hline Haemophilus Influenzae B & Conjugated & No & 1 dose & At risk & Given as combined vaccines - Hib/MenC \\
\hline Smallpox & MVA & No & 2 doses & Occupational & \\
\hline \multicolumn{6}{|c|}{ Not preferred and contraindicated vaccines } \\
\hline Hepatitis A/B & & No & & Not preferred & Reduced immunogenicity \\
\hline Hepatitis A/typhoid & & No & & Not preferred & Reduced HAV immunogenicity \\
\hline Influenza & Live attenuated & Yes & & Contraindicated & Intranasal \\
\hline Smallpox live & Vaccinia virus & Yes & & Contraindicated & May be considered if CD4 >200 cells/ $\mu \mathrm{L}$ \\
\hline Tuberculosis & BCG & Yes & & Contraindicated & \\
\hline Typhoid & Live attenuated & Yes & & Contraindicated & Oral administration \\
\hline
\end{tabular}


VLP= Virus-like particle; OVM=Outer membrane vesicles; $\mathrm{Td} / \mathrm{IPV}=$ Tetanus/diphtheria/Inactivated Poliovirus; $\mathrm{dTaP} / \mathrm{IPV}=$ diphtheria/Tetanus/acellular Pertussis/Inactivated Poliovirus; VZV= Varicella Zoster Virus; AVP=Anthrax Vaccine Precipitated; MVA=Modified Vaccinia Ankara; ViCPS= Vi capsular polysaccharide vaccine 


\section{ANTHRAX}

1. Infection and disease: Bacillus anthracis is a toxin-producing gram-positive bacterium transmitted through spores that can be found in animal products and can remain viable in the environment for years. The infection occurs primarily in herbivorous mammals. Human infection is rare and occurs almost exclusively after contact with infected animals or animal products. Person-to-person transmission may occur through contact with skin lesions but is unusual [1]. The disease may present as one of three syndromes: cutaneous ( $50 \%$ of cases, rare mortality); respiratory ( $50 \%$ mortality); and gastrointestinal (very rare, $25-60 \%$ mortality). Meningitis may occur and is usually fatal. Provided it is recognized early, anthrax can be treated effectively with antibiotics.

2. Epidemiology: Anthrax occurs in Asia, Africa, and parts of Europe and the Americas. In the UK, human anthrax is rare and is seen almost entirely as an occupational disease in persons handling imported animal products or working with infected animals. Cases have been reported in abattoir workers, tannery/leather workers, farm workers, butchers, engineers, textile workers, and bone meal workers.

3. Anthrax in HIV-positive people: It is not known whether the natural history of anthrax is modified by HIV infection.

4. Anthrax vaccine: The British vaccine - Anthrax Vaccine Precipitated (AVP) - is non-replicating and contains a cell-free filtrate of $B$. anthracis proteins. The product licence (PL 1511/0058) is held by the UK Department of Health. The anthrax vaccine adsorbed (AVA) is licensed for use in humans In the US. AVP is given by parenteral administration. There have been no formal efficacy trials with AVP. Data from the UK and US suggest that anthrax vaccination prevents disease [2,3]. Anthrax vaccination is considered safe [4-13]. Injection site reactions occur in 47\% of AVP recipients [4]. Follow-up data ranging from 3 to 6 years show no overall adverse health effects following receipt of AVP [10].

General indications: Anthrax vaccination is indicated in those with a significant risk of exposure. In the UK, it is available to the Department of Health for occupational health purposes and to the Ministry of Defence to protect service personnel from the use of anthrax as a biological weapon.

5. Anthrax vaccine in HIV-positive adults: No data are available on the immunogenicity, safety, and efficacy of anthrax vaccination in HIV-positive persons.

6. Post-exposure prophylaxis: Following a credible or confirmed exposure to anthrax, post-exposure prophylaxis consists of antibiotic therapy (e.g., oral ciprofloxacin) and may also include the vaccine. Vaccination is recommended because of the uncertainty of when or if the inhaled spores may germinate. Advice must be obtained from Public Health England or other appropriate agencies.

\section{Recommendations for HIV-positive adults}

- We recommend that HIV-positive adults at significant risk of anthrax exposure (typically through occupation) be offered vaccination in accordance with general indications, and regardless of CD4 count, ART use, and viral load [1D]

- We recommend a primary vaccine course consisting of 4 parental doses of the nonreplicating AVP vaccine given at 0, 3 weeks, 6 weeks, and 6 months, with a booster dose given annually to those at continued risk [1D] 
- We recommend that patients with $\mathrm{CD} 4$ count $<200$ cells $/ \mu \mathrm{L}$ be counselled about potential non-response to vaccination and managed accordingly. Deferred or repeat vaccination may be indicated following Immunorestoration on ART [1D]

- We recommend that following a credible or confirmed exposure to anthrax, HIV-positive contacts receive post-exposure prophylaxis with antibiotic therapy and vaccination in accordance with standard recommendations [1D]

\section{References}

1. Holty JE, Bravata DM, Liu H, et al. A century of inhalational Anthrax cases from 1900 to 2005. Ann Intern Med 2006;144:270-80.

2. Brachman PS, Gold H, Plotkin SA et al. Field evaluation of a human anthrax vaccine. Am J Public Health 1962;52:632-45.

3. Hambleton P, Carman JA, Melling J. Anthrax: the disease in relation to vaccines. Vaccine 1984;2:125-32.

4. Hayes SC, World MJ. Adverse reactions to anthrax immunisation in a military field hospital. J R Army Med Corps 2000;146:191-5.

5. Sato PA, Reed RJ, Smith TC, Wang L. Monitoring anthrax vaccine safety in US military service members on active duty: surveillance of 1998 hospitalizations in temporal association with anthrax immunization. Vaccine 2002;20:2369-74.

6. Enstone JE, Wale MC, Nguyen-Van-Tam JS, Pearson JC. Adverse medical events in British service personnel following anthrax vaccination. Vaccine 2003; 21:1348-54.

7. Lange JL, Lesikar SE, Rubertone MV, Brundage JF. Comprehensive systematic surveillance for adverse effects of anthrax vaccine adsorbed, US Armed Forces, 1998-2000. Vaccine 2003;21:16208.

8. Hunter D, Zoutman D, Whitehead J, Hutchings J, Mac-Donald K. Health effects of anthrax vaccination in the Canadian forces. Mil Med 2004;169:833-8.

9. Niu MT, Ball R, Woo EJ, Burwen DR, Knippen M, Braun MM. Adverse events after anthrax vaccination reported to the Vaccine Adverse Event Reporting System (VAERS), 1990-2007. Vaccine 2009;27:290-7.

10. Murphy D, Marteau TM, Wessely S. A longitudinal study of UK military personnel offered anthrax vaccination: informed choice, symptom reporting, uptake and pre-vaccination health. Vaccine 2012;30:1094-100.

11. Sulsky SI, Luippold R, Garman P, et al. Disability among US Army Veterans vaccinated against anthrax. Vaccine 2012;30:6150-6.

12. Stewart B, Rose CE, Tokars Jl, et al. Health-related quality of life in the CDC Anthrax Vaccine Adsorbed Human Clinical Trial. Vaccine 2012;30:5875-9.

13. Ryan MA, Smith TC, Sevick CJ, et al. Birth defects among infants born to women who received anthrax vaccine in pregnancy. Am J Epidemiol 2008;168:434-42. 


\section{CHOLERA}

1. Infection and disease: Vibrio cholerae is a non-invasive toxin-secreting gram-negative bacterium that colonises the small bowel. Classification into over 200 serogroups is based on the $\mathrm{O}$ antigen of the lipopolysaccharide. Cholera epidemics are caused by the $\mathrm{O} 1$ serogroup and more recently by the 0139 serogroup in South and South-East Asia [1]. Infection is acquired primarily by consuming contaminated water or food; person-to-person transmission is rare. Man is the only known host. The disease is characterised by sudden onset of profuse watery diarrhoea and responds to fluid- and electrolytereplacement therapy [1-2]. In extreme cases, hypotension and death can occur within 6-8 hours of the onset of symptoms. Approximately $80 \%$ of infected people have mild diarrhoea or may be asymptomatic. Persons with underlying gastrointestinal disease may be at increased risk of disease.

2. Epidemiology: Seven cholera pandemics have been recorded throughout history. The latest started in 1961 and is still ongoing in over 50 countries in regions of Asia, the Middle East, Africa, and Central and Latin America, with an estimated 3 million cases each year [3]. Large outbreaks are usually caused by a contaminated water supply. In developed countries cases are reported sporadically in travellers, with an overall risk of 5 cases per 100,000 travellers to all destinations [4]. Cholera is rare among UK travellers, and seen predominantly among those who visit the Indian subcontinent. Travellers who follow usual tourist itineraries, use standard tourist accommodation, and observe food safety recommendations while in countries reporting cholera are at little risk. The risk increases for long-term travellers and for those who drink untreated water, eat poorly cooked or raw seafood, or live in unsanitary conditions in disease-endemic areas (e.g. aid workers assisting in disaster relief or refugee camps and adventurous backpackers travelling to remote areas) [4]. Currently, no country requires proof of vaccination against cholera as a condition for entry. Local authorities, however, may require documentation of vaccination.

3. Cholera in HIV-positive people: In cholera-endemic areas, HIV infection is associated with an increased risk for cholera [5]. The risk of severe disease may be increased by immunodeficiency.

4. Cholera vaccine: Several non-replicating oral cholera vaccines are available internationally [6]. The $W C / r B s$ vaccine available in the UK contains inactivated Inaba and Ogawa strains of $V$. cholerae serotype 01, together with recombinant B-subunit of the cholera toxin produced in Inaba strains of $V$. cholerae serotype 01. The replicating, live attenuated CVD 103-HgR vaccine, which has been tested in HIV-positive adults in Mali [7], is currently unavailable. In healthy persons, oral cholera vaccines given as two oral doses 1-6 weeks apart confer $65-86 \%$ protection, starting 10 days after the second dose, and lasting for up to 2 years [8-14]. Interestingly, there is evidence of herd protection from some vaccine campaigns $[12,15]$. The $W C / r B S$ vaccine does not confer protection against $V$. cholerae 0139 . $\mathrm{WC} / \mathrm{rBS}$ appears to provide modest protection against travellers' diarrhoea caused by heat-labile toxin-producing Escherichia coli during the first 3 months following vaccination [4]. However, use for the specific prevention of travellers' diarrhoea is not recommended. There are no major safety concerns with the $\mathrm{WC} / \mathrm{rBS}$ vaccine in immunocompetent individuals from endemic or non-endemic countries $[9-11,13,18]$. The vaccine may cause occasional gastrointestinal symptoms. Systemic symptoms have been reported rarely [4].

General indications: Cholera vaccine is not indicated for most travellers, but is considered for those who are unable to take adequate precautions in highly endemic or epidemic $V$. cholerae 01 settings. These include those assisting in disaster relief or refugee camps; and visitors to remote areas with limited access to healthcare where there are outbreaks. The vaccine should not be co-administered with other oral vaccines.

5. Cholera vaccine in HIV-positive adults: There have been no published reports of the efficacy of the WC/rBS vaccine in HIV-positive travellers. A study conducted in Beira, Mozambique showed $72 \%$ 
protection in a population including approximately $25 \%$ HIV-positive persons [14]. HIV-positive adults with CD4 counts $<100$ cells $/ \mu \mathrm{L}$ may be expected to respond poorly to oral cholera vaccines, whereas those with CD4 counts $>100$ cells/ $\mu \mathrm{L}$ show improved responses after two doses [16]. Intestinal immunogenicity may be preserved [17]. Duration of immunity is unknown. The vaccine is well tolerated in HIV-positive people $[14,16]$.

\section{Recommendations for HIV-positive adults}

- We recommend that HIV-positive adults at significant risk of cholera exposure (typically through specific travel) be offered vaccination in accordance with general indications, and regardless of CD4 count, ART use, and viral load [1B]

- We recommend a primary vaccine course consisting of 2 oral doses of the nonreplicating $\mathrm{WC} / \mathrm{rBS}$ vaccine given 1-6 weeks apart and at least 1 week prior to exposure. If $>6$ weeks elapse between doses, the primary course should be restarted [1B]

- We recommend a single booster dose after 2 years if continued protection is required. If $>2$ years elapse after completion of the primary vaccine course, the full course should be repeated [1B]

\section{References}

1. Harris JB, LaRocque RC, Qadri F, Ryan ET, Calderwood SB. Cholera. Lancet. 2012;379:2466-76.

2. Leibovici-Weissman $Y$, Neuberger A, Bitterman R, Sinclair D, Salam MA, Paul M. Antimicrobial drugs for treating cholera. Cochrane Database Syst Rev 2014;6:CD008625.

3. Ali M, Lopez AL, You YA, Kim YE, Sah B, Maskery B, Clemens J. The global burden of cholera. Bull World Health Organ 2012;90:209-18A.

4. Hill DR, Ford L, Lalloo DG. Oral cholera vaccines: use in clinical practice. Lancet Infect Dis 2006;6:361-73.

5. von Seidlein L, Wang XY, Macuamule A, et al. Is HIV infection associated with an increased risk for cholera? Findings from a case-control study in Mozambique. Trop Med Int Health 2008;13:683-8.

6. Shin S, Desai SN, Sah BK, Clemens JD. Oral vaccines against cholera. Clin Infect Dis 2011;52:1343-9.

7. Perry RT, Plowe CV, Koumare B, et al. A single dose of live oral cholera vaccine CVD 103-HgR is safe and immunogenic in HIV-infected and HIV-noninfected adults in Mali. Bull World Health Organ 1998;76:63-71.

8. Sanchez JL, Vasquez B, Begue RE, et al. Protective efficacy of oral whole-cell/recombinant-Bsubunit cholera vaccine in Peruvian military recruits. Lancet 1994;344:1273-6.

9. Jertborn M, Svennerholm AM, Holmgren J. Evaluation of different immunization schedules for oral cholera B subunit-whole cell vaccine in Swedish volunteers. Vaccine 1993;11:1007-12.

10. Sur D, Lopez AL, Kanungo S, et al. Efficacy and safety of a modified killed-whole-cell oral cholera vaccine in India: an interim analysis of a cluster-randomised, double-blind, placebo-controlled trial. Lancet 2009;374:1694-702.

11. Bhattacharya SK, Sur D, Ali M, et al. 5 year efficacy of a bivalent killed whole-cell oral cholera vaccine in Kolkata, India: a cluster-randomised, double-blind, placebo-controlled trial. Lancet Infect Dis 2013;13:1050-6.

12. Khatib AM, Ali M, von Seidlein $L$, et al. Effectiveness of an oral cholera vaccine in Zanzibar: findings from a mass vaccination campaign and observational cohort study. Lancet Infect Dis 2012;12:83744.

13. Saha A, Chowdhury MI, Khanam F, et al. Safety and immunogenicity study of a killed bivalent (O1 and 0139) whole-cell oral cholera vaccine Shanchol, in Bangladeshi adults and children as young as 1 year of age. Vaccine 2011;29:8285-92.

14. Lucas ME, Deen JL, von Seidlein L, et al. Effectiveness of mass oral cholera vaccination in Beira, Mozambique. N Engl J Med 2005;352:757-67. 
15. Ali M, Emch M, Yunus M, Sack D, Lopez AL, Holmgren J, Clemens J. Vaccine Protection of Bangladeshi infants and young children against cholera: implications for vaccine deployment and person-to-person transmission. Pediatr Infect Dis J 2008;27:33-7.

16. Lewis DJ, Gilks CF, Ojoo S, et al. Immune response following oral administration of cholera toxin $B$ subunit to HIV-1-infected UK and Kenyan subjects. AIDS 1994;8:779-85.

17. Eriksson K, Kilander A, Hagberg L, Norkrans G, Holmgren J, Czerkinsky C. Intestinal antibody responses to oral vaccination in HIV-infected individuals. AIDS 1993;7:1087-91.

18. Legros $D$, Paquet $C$, Perea $W$, et al. Mass vaccination with a two-dose oral cholera vaccine in a refugee camp. Bull World Health Organ 1999;77:837-42.

19. Ortigao-de-Sampaio MB, Shattock RJ, Hayes $P$, et al. Increase in plasma viral load after oral cholera immunization of HIV-infected subjects. AIDS 1998;12:F145-50. 


\section{DIPHTHERIA}

1. Infection and disease: Diphtheria is caused by toxigenic strains of the gram-positive bacteria Corynebacterium diphtheriae and Corynebacterium ulcerans, and affects the upper respiratory tract and occasionally the skin. The infection is transmitted via airborne droplets, generally requiring close contact with symptomatic patients or asymptomatic carriers. Alternative modes of transmission are direct contact with skin lesions or infected cattle and other farm animals (C. ulcerans). Rare human cases have been associated with the consumption of raw unpasteurized dairy products. Lifethreatening complications include cardiac failure and paralysis.

2. Epidemiology: Both $C$. diphtheriae and C. ulcerans cause diphtheria in the UK. Since the 1990s, $C$. ulcerans has been the predominant cause of infection resulting in sporadic deaths [1]. As a result of successful vaccination programmes, the circulation of $C$. diphtheria has virtually ceased in the UK. The majority of cases are now mild infections in partially immunised individuals, or in adults that have been fully immunised but have waning immunity. Susceptibility to diphtheria increases with age. In the UK, approximately $50 \%$ of adults $>30$ years of age are estimated to be susceptible to diphtheria [2]. Diphtheria cases continue to be reported from India, South-east Asia, South America, Africa, former Soviet States, and Eastern Europe; thus there is potential for exposure through travel, and reintroduction of $C$. diphtheriae into the UK may also occur through immigration from these regions.

3. Diphtheria in HIV-positive people: It is not known whether the natural history of diphtheria is modified by HIV infection.

4. Diphtheria vaccine: The diphtheria vaccine is non-replicating and is made from cell-free purified toxin extracted from $C$. diphtheriae and converted into diphtheria toxoid. The vaccine is given to adults in combination with tetanus toxoid and inactivated polio vaccine (Td/IPV) in a preparation containing a lower dosage of diphtheria toxoid than preparations designed for use in childhood. The vaccine is given by parenteral administration. The diphtheria vaccine induces protective antitoxin levels in $95 \%$ of recipients after three doses, and shows a clinical efficacy of over $97 \%[3,4]$. The vaccine is well tolerated. Injection site reactions are common but usually self-limited and may occur more frequently following subsequent doses. Fever and other systemic reactions are uncommon. Severe systemic reactions are rare.

General indications: The aim of the UK national vaccination programme is to ensure that all individuals receive at least 5 vaccine doses. Td/IPV is recommended for vaccination of those aged $\geq 10$ years. Adults who are either unvaccinated or have an uncertain vaccination history are advised to receive primary immunization with three vaccine doses at either monthly intervals or at 0, 1-2 months, and 612 months. Two further doses are scheduled 5 and 10 years after the last dose. Adults who have received partial vaccination are advised to receive the remaining doses, regardless of the interval since the last dose and type of vaccine previously received. It is also recommended that travellers to epidemic and endemic areas should ensure they are fully vaccinated.

5. Diphtheria vaccine in HIV-positive adults: Limited data exist on the immunogenicity and clinical efficacy of the diphtheria vaccine in HIV-positive adults. Vaccine responses may be reduced compared to HIV-negative persons, especially in those with advanced disease and low CD4 cell counts, but improve with ART [5-8]. No increased risk of side effects or adverse reactions to vaccination has been reported in individuals with HIV infection.

6. Post-exposure prophylaxis: Contacts of a case or a carrier of $C$. diphtherium or $C$. ulcerans require antibiotic prophylaxis (e.g., erythromycin). Fully immunised individuals also receive a single reinforcing dose of the vaccine; others are offered to complete the vaccine course. 


\section{Recommendations for HIV-positive adults}

- We recommend that HIV-positive adults that require vaccination against diphtheria, tetanus, or polio be given the parenteral Td/IPV vaccine in accordance with general indications, and regardless of CD4 cell count, ART use, and viral load [1B]

- We recommend that individuals who are either unvaccinated or have an uncertain vaccination history receive 3 vaccine doses at 1 month interval, followed by 2 booster doses after 5 and 10 years; partially vaccinated individuals should complete the 5 -dose vaccine course [1B]

- We recommend that fully vaccinated individuals ( 5 doses) receive a booster dose every 10 years if at risk of exposure, typically through travel [1C]

- We recommend that individuals who may be occupationally exposed to diphtheria (e.g. laboratory workers) be tested for diphtheria antibodies 3 months after vaccination to confirm protective immunity, and be revaccinated if required [1C]

- We recommend that following a credible or confirmed exposure to diphtheria, HIV-positive contacts receive post-exposure prophylaxis with antibiotic therapy and vaccination in accordance with standard recommendations [1C]

\section{References}

1. Wagner KS, White JM, Crowcroft NS, De Martin S, Mann G, Efstratiou A. Diphtheria in the United Kingdom, 1986-2008: the increasing role of Corynebacterium ulcerans. Epidemiol Infect 2010;138:1519-30.

2. Edmunds WJ, Pebody RG, Aggerback $H$ et al. The sero-epidemiology of Diphtheria in Western Europe. Epidemiol Infect 2000;125:113-25.

3. Myers MG, Beckman CW, Vosingh RA, Hankins WA. Primary immunisation with tetanus and diphtheria toxoids: reaction rates and immunogenicity in older children and adults. JAMA 1982; 248:2478-80.

4. Galazka AM, Robertson SE. Immunisation against diphtheria with special emphasis on immunization of adults. Vaccine 1996; 14:845-57.

5. Poland GA, Love KR, Hughes CE. Routine immunizations in the HIV-positive asymptomatic patient. J Gen Inter Med 1990;5:147-52.

6. Kroon FP, Van Dissel JT, Labadie J, Van Loon AM, Van Furth R. Antibody response to diphtheria, tetanus, and poliomyelitis vaccines in relation to the number of CD4 + T lymphocytes in adults Infected with Human Immunodeficiency Virus. Clin Infect Dis 1995;21:1197-203.

7. Valdez $\mathrm{H}$, Smith $\mathrm{KY}$, Landay $\mathrm{A}$ et al. Response to immunization with recall and neoantigens after prolonged administration of an HIV-1 protease inhibitor-containing regimen. AIDS 2000; 14:11-21.

8. Bonetti TC, Succi RC, Weckx LY, Tavares-Lopes L, de Moraes-Pinto MI. Tetanus and diphtheria antibodies and response to a booster dose in Brazilian HIV-1-infected women. Vaccine 2004;22:3707-12. 


\section{HAEMOPHILUS INFLUENZAE SEROTYPE b}

1. Infection and disease: Haemophilus influenzae is a gram-negative coccobacillus that can cause invasive disease in young children and in people with predisposing conditions [1-3]. Hib can colonise the nasopharynx in the absence of symptoms. Transmission occurs through respiratory droplets and close contact with a case or a carrier. Invasive disease is usually caused by one of 6 encapsulated serotypes (a-f), and less commonly by encapsulated non-typable strains. Serotype b (Hib) is the most virulent strain and, prior to the introduction of routine vaccination, was responsible for $>80 \%$ of invasive infections, (primarily meningitis) among children $<5$ years of age. Non-encapsulated strains $(\mathrm{ncHi})$ mainly cause respiratory disease; invasive $\mathrm{ncHi}$ disease is uncommon and usually occurs in pregnant women, newborns, and individuals with underlying conditions (immunosuppression, chronic respiratory disease, head trauma, or neurological disease) [4]. Risk factors for invasive Hib disease are similar to those associated with other encapsulated bacteria. Patients with anatomic or functional asplenia and those with complement deficiencies are at an increased risk of disease.

2. Epidemiology: Hib remains one of the major vaccine-preventable causes of morbidity and mortality worldwide [5]. In industrialised countries, the introduction of Hib conjugate vaccines into national childhood vaccination programmes over the past two decades has resulted in a sustained decline in the incidence of invasive Hib infections across all age-groups, through a combination of direct and indirect (herd) protection [6,7]. In England and Wales, invasive Hib disease is now infrequent [8]. Most cases occur in adults who typically present with pneumonia and often have pre-existing medical conditions, with an overall case-fatality rate of $9 \%$ [8]. Average vaccine coverage remains suboptimal in many developing countries [9].

3. Haemophilus influenzae in HIV-positive adults: In HIV-positive adults, the risk of invasive $H$. influenzae disease is increased compared to the general population $[10,11]$. In one study, cumulative incidence reached 79.6/100,000 among men with AIDS aged 20-49 years; however, only a third of cases were due to the Hib serotype indicating that the Hib vaccine would not be protective. [10]. In countries with established Hib vaccination programmes such as the UK, invasive Hib disease is now uncommon among people with HIV [8].

4. Hib vaccine: The Hib vaccine is non-replicating and contains capsular polysaccharide conjugated to a protein (e.g., tetanus toxoid). It is typically part of multivalent vaccines for use in infants, including the diphtheria/tetanus/acellular pertussis/inactivated polio/Hib vaccine (DTaP/IPV/Hib) and the $\mathrm{Hib} /$ meningococcal group $\mathrm{C}$ vaccine (Hib/MenC). The vaccine is given by parenteral administration. The Hib vaccine is highly immunogenic and efficacious in children [3,5,6,12]; it only protects against invasive Hib disease and offers no protection against other serotypes or against $\mathrm{ncHi}$. Although the duration of protection is unknown, no booster doses are routinely recommended after 12 months of age. The vaccine is well tolerated. Injection site reactions occur in $5-30 \%$ of recipients. Systemic reactions are infrequent.

General indications: The objective of the UK Hib vaccination programme is to protect all individuals $<10$ years of age and older individuals at elevated risk from invasive Hib disease, including individuals who develop asplenia or splenic dysfunction or when complement deficiency is diagnosed.

5. Hib vaccine in HIV-positive adults: The vaccine has been shown to induce protective antibodies in HIV-positive children [13-16] and adults [17-19]. The magnitude and longevity of responses are related to the CD4 cells count and can be reduced relative to HIV-negative individuals. Clinical effectiveness may also be reduced by HIV infection. In South Africa, $47 \%$ of children who developed invasive Hib disease during 2003-2009 despite being fully immunised with the conjugate Hib vaccine were HIVpositive [20]. No safety concerns have emerged in HIV-positive vaccine recipients. 
6. Post-exposure prophylaxis: Household contacts of a Hib case are given antibiotic prophylaxis (e.g., rifampicin), regardless of their immunization status, starting as soon as the index case is diagnosed.

\section{Recommendations for HIV-positive adults}

- Hib vaccination is not recommended routinely in HIV-positive adults, including patients who develop Hib disease. We recommend however that HIV-positive adults with asplenia, splenic dysfunction or complement deficiency (including those receiving complement inhibitor therapy) receive 1 parental dose of a Hib-containing vaccine (e.g., Hib/MenC in the UK) whether or not they were immunised previously, and regardless of CD4 count, ART use, and viral load [1B]

- We recommend that HIV-positive adults who are household contacts of a Hib case are offered antibiotic prophylaxis in accordance with standard recommendations [1C]

\section{References}

1. Ladhani S, Neely F, Heath PT, et al. Recommendations for the prevention of secondary Haemophilus influenzae type b (Hib) disease. J Infect 2009;58:3-14.

2. Ladhani S, Slack MP, Heath PT, von GA, Chandra M, Ramsay ME. Invasive Haemophilus influenzae Disease, Europe, 1996-2006. Emerg Infect Dis 2010;16:455-463.

3. Ladhani SN. Two decades of experience with the Haemophilus influenzae serotype b conjugate vaccine in the United Kingdom. Clin Ther 2012;34:385-99.

4. Gkentzi D, Slack MP, Ladhani SN. The burden of nonencapsulated Haemophilus influenzae in children and potential for prevention. Curr Opin Infect Dis 2012;25:266-72.

5. Watt JP, Wolfson LJ, O'Brien KL, et al. Burden of disease caused by Haemophilus influenzae type b in children younger than 5 years: global estimates. Lancet 2009;374:903-11.

6. Peltola $\mathrm{H}$. Worldwide Haemophilus influenzae type $\mathrm{b}$ disease at the beginning of the 21st century: global analysis of the disease burden 25 years after the use of the polysaccharide vaccine and a decade after the advent of conjugates. Clin Microbiol Rev 2000;13:302-17.

7. Morris SK, Moss WJ, Halsey N. Haemophilus influenzae type $b$ conjugate vaccine use and effectiveness. Lancet Infect Dis. 2008;8:435-43.

8. Collins S, Ramsay M, Campbell H, Slack MP, Ladhani SN. Invasive Haemophilus influenzae type b disease in England and Wales: who is at risk after 2 decades of routine childhood vaccination? Clin Infect Dis 2013;57:1715-21.

9. World Health Organisation (WHO). Haemophilus influenzae type b (Hib) Vaccination WHO position paper: July 2013-Recommendations. Vaccine 2013;31:6168-9.

10. Steinhart R, Reingold AL, Taylor F, Anderson G, Wenger JD. Invasive Haemophilus influenzae infections in men with HIV infection. JAMA 1992;268:3350-2.

11. Selwyn PA, Feingold AR, Hartel D, et al. Increased risk of bacterial pneumonia in HIV-infected intravenous drug users without AIDS. AIDS 1988;2:267-72.

12. Mangtani $P$, Mulholland K, Madhi SA, Edmond K, O'Loughlin R, Hajjeh R. Haemophilus influenzae type $b$ disease in HIV-infected children: a review of the disease epidemiology and effectiveness of Hib conjugate vaccines. Vaccine 2010;28:1677-83.

13. Wenger JD, Pierce R, Deaver KA, Plikaytis BD, Facklam RR, Broome CV. Efficacy of Haemophilus influenzae type $b$ polysaccharide-diphtheria toxoid conjugate vaccine in US children aged 18-59 months. Lancet 1991;338:395-8.

14. Gibb D, Spoulou V, Giacomelli A, et al. Antibody responses to Haemophilus influenzae type b and Streptococcus pneumoniae vaccines in children with human immunodeficiency virus infection. Pediatr Infect Dis J. 1995;14:129-35.

15. Rutstein RM, Rudy BJ, Cnaan A. Response of human immunodeficiency virus-exposed and infected infants to Haemophilus influenzae type $b$ conjugate vaccine. Arch Pediatr Adolesc Med. 1996;150:838-41. 
16. Kale KL, King JC, Jr., Farley JJ, Vink PE, Cimino CO, Paradiso PR. The immunogenicity of Haemophilus influenzae type $b$ conjugate $(\mathrm{HbOC})$ vaccine in human immunodeficiency virusinfected and uninfected infants. Pediatr Infect Dis J. 1995;14:350-4.

17. Steinhoff MC, Auerbach BS, Nelson KE, et al. Antibody responses to Haemophilus influenzae type $B$ vaccines in men with human immunodeficiency virus infection. N Engl J Med. 1991;325:1837-42.

18. Dockrell DH, Poland GA, Steckelberg JM, Wollan PC, Strickland SR, Pomeroy C. Immunogenicity of three Haemophilus influenzae type b protein conjugate vaccines in HIV seropositive adults and analysis of predictors of vaccine response. Vaccine 1999;17:2779-85.

19. De Sousa dos Santos S, Lopes MH, Simonsen V, Caiaffa Filho HH. Haemophilus influenzae type b immunization in adults infected with the human immunodeficiency virus. AIDS Res Hum Retroviruses 2004;20:493-6.

20. von Gottberg GA, Cohen C, Whitelaw A, et al. Invasive disease due to Haemophilus influenzae serotype b ten years after routine vaccination, South Africa, 2003-2009. Vaccine 2012;30:565-71. 


\section{HEPATITIS A}

1. Infection and disease: Hepatitis A virus (HAV) is transmitted faeco-orally through close personal contact, contaminated food and water, and rarely through blood exposure. Person-to-person spread is the most common method of transmission in developed countries. There is evidence that the infection may be spread during sexual contact in men who have sex with men (MSM) [1]. Infection may be asymptomatic, but severity tends to increase with age. Jaundice occurs in $10 \%$ of children below the age of 6 years, $40-50 \%$ of older children and $70-80 \%$ of adults. Fulminant hepatitis is rare ( $<1 \%$ overall) and predominantly occurs in older age groups, but carries a $45 \%$ risk of mortality. Patients with chronic liver disease are at risk of severe complications [2]. Although approximately $15 \%$ of cases show prolonged or relapsing symptoms, chronic HAV infection is not known to occur. Infection is followed by lifelong immunity.

2. Epidemiology: HAV prevalence is low in northern and Western Europe, North America, Australia, New Zealand and Japan, and intermediate to high in Mexico, Central and South America, the Caribbean, Africa, Asia and Eastern Europe. In the UK, those at risk for infection include:

- Household and sexual contacts of infected persons

- Travellers to countries where HAV is common

- Men who have sex with men

- Injecting and non-injecting drug users

- Individuals at risk of infection during outbreaks

- Those with occupational exposure to HAV (e.g. laboratory workers, sewage workers)

- Persons with haemophilia

- Persons with special needs living in residential institutions, and their carers

3. Hepatitis A in HIV-positive adults: Hepatitis A does not appear to be worse in HIV-positive patients when compared to HIV-negative persons, although HAV viraemia may be prolonged $[3,4]$.

4. Hepatitis A vaccine: The HAV vaccine is non-replicating and contains whole inactivated virus. Combined hepatitis $A$ /hepatitis $B$ and hepatitis $A$ /typhoid vaccines are also available. The vaccine is given by parenteral administration. The standard vaccine course comprises two doses given 6-12 months apart. In healthy persons, the HAV vaccine is highly immunogenic and efficacious, without safety concerns. Protective levels of antibodies develop in $97-100 \%$ of individuals within 1 month of the first dose and in virtually $100 \%$ after the second dose. The level of protection against clinical hepatitis is $79-100 \%$ after a single dose. The combined hepatitis $A$ /hepatitis $B$ vaccine is also highly efficacious in health individuals. Successful immunization is thought to confer protection for at least 10 years and possibly for life $[5,6]$.

General indications: The HAV vaccine is indicated for persons at risk of exposure (listed above).

5. HAV vaccine in HIV-positive adults: The rate, magnitude, and longevity of immune responses to HAV vaccination are generally reduced in HIV-positive persons, although they improve with increasing CD4 cells counts and viral load suppression on ART [7-13]. Less than half of vaccine recipients experience seroconversion after a single vaccine dose; responses increase to over $70 \%$ after two doses, while remaining lower than those measured in HIV-negative adults. Further increasing the number of vaccine doses improves antibody levels and the longevity of response but does not significantly improve overall seroconversion rates. In a randomised study, HIV-positive adults were assigned to receive either 2 ( 0 and 6 months) or 3 (0,1, and 6 months) HAV vaccine doses. At week 28 after the first vaccine dose, seroconversion rates were $72 \%$ vs. $88 \%$ respectively in the observed analysis $(p=0.06)$; the 3-dose group had significantly higher antibody titres at week 28 and week 72 [7]. Multivariate analysis indicated that absence of tobacco smoking was an independent predictor of 
response to HAV vaccine (OR 2.92; $95 \% \mathrm{Cl} 1.07,7.97 ; \mathrm{p}=0.04$ ). A prospective cohort study compared responses between HIV-positive MSM receiving two ( 0 and 6 months) or three (0, 1, and 6 months) doses of HAV vaccine and HIV-negative MSM receiving two vaccine doses [12]. At week 48, HAV seroconversion rates were $76 \%, 78 \%$, and $89 \%$ respectively. In HIV-positive MSM, antibody titres were significantly higher with 3 doses than 2 doses. Responses to HAV vaccination also appear to be higher with the monovalent HAV vaccine than for the combined HAV/HBV vaccine, particularly with low CD4 cells counts and detectable viral load, and among patients not completing the vaccine course [13]. Most patients with high CD4 cell counts show a durable response during up to 5 years of follow-up after HAV vaccination [14]. The HAV vaccine is safe and well tolerated in HIV-positive individuals, including those receiving three vaccine doses over 6 months $[7,13]$. Injection site reactions are the most frequent side effect.

6. Post-exposure prophylaxis: Following a high-risk contact (e.g. in the household setting or other intimate contact) HAV vaccine plus human normal immunoglobulin (HNIG) given intramuscularly (at different sites) within 14 days of exposure can prevent or attenuate disease in susceptible persons. Efficacy beyond 14 days of exposure is unknown; disease may be attenuated rather than prevented. In HIV-negative people the clinical efficacy of prophylaxis is in the range 47-87\% $[15,16]$. Early vaccination alone (without HNIG) seems equally effective in HIV-negative people. There are no data on the efficacy of post-exposure prophylaxis in HIV-positive persons.

\section{Recommendations for HIV-positive adults}

- We recommend that HIV-positive adults at risk of hepatitis A exposure (see risk groups) be offered vaccination with the monovalent $H A V$ vaccine $[1 \mathrm{~A}]$

- Patients with CD4 counts $>350$ cells $/ \mu \mathrm{L}$ should be offered 2 vaccine doses at 0 and 6 months $[1 \mathrm{~A}]$

- Patients with CD4 counts $<350$ cells $/ \mu \mathrm{L}$ should receive 3 vaccine doses at 0,1 , and 6 months in order to increase antibody levels and longevity, especially if they are likely to be at continued risk of exposure [1C]

- Pre-vaccination testing for evidence of HAV immunity may be cost-effective in some clinical settings: screening may target those who were born in or lived for extensive periods in geographic areas that have a high to intermediate HAV endemicity, MSM, injecting drug users, and those aged $>50$ years [GPP]

- We recommend that patients at continued risk of exposure receive a boosting vaccine dose every 10 years $[1 \mathrm{C}]$

- We recommend that in circumstance where a profoundly immunocompromised patient (CD4 count $<200 \mathrm{cell} / \mu \mathrm{L}$ ) must be protected from likely exposure to HAV, HNIG may be considered alongside the vaccine for temporary ( 3 weeks) pre-exposure prophylaxis [1D]

- We recommend that following a significant exposure, HIV-positive contacts who are HAV seronegative receive post-exposure prophylaxis with the HAV vaccine, with the first dose given as soon as possible and within 14 days of exposure; if the CD4 count is $<200$ cells $/ \mu \mathrm{L}$ they should also receive HNIG [1C].

- While HAV serostatus should be determined if unknown, prophylaxis should not be delayed while waiting for the results [GPP]

- We suggest that in some circumstances post-exposure prophylaxis may be considered up to 28 days after the contact [2D]

\section{References}

1. Urbanus AT, van Houdt R, van de Laar TJ, Coutinho RA. Viral hepatitis among men who have sex with men, epidemiology and public health consequences. Euro Surveillance: Bulletin Europeen sur les Maladies Transmissibles = European Communicable Disease Bulletin, 2009;14:1025. 
2. Mackinney-Novelo I, Barahona-Garrido J, Castillo-Albarran F et al. Clinical course and management of acute hepatitis A infection in adults. Ann Hepatol 2012;11:652-34.

3. Ida S, Tachikawa N, Nakajima A et al. Influence of human immunodeficiency virus type 1 infection on acute hepatitis A virus infection. Clin Infect Dis 2002; 34: 379-85.

4. Costa-Mattioli M, Allavena C, Poirier AS, Billaudel S, Raffi F, Ferre V. Prolonged hepatitis A infection in an HIV-1- seropositive patient. J Med Virol 2002; 68: 7-11.

5. Van Damme P, Van HK. A review of the long-term protection after hepatitis A and B vaccination. Travel Med Infect Dis 2007;5:79-84.

6. Rendi-Wagner, Korinek $M$, Winkler B, Kundi $M$, Kollaritsch $H$, Wiedermann U. Persistence of seroprotection 10 years after primary hepatitis $A$ vaccination in an unselected study population. Vaccine 2007;25:927-31.

7. Launay O, Grabar S, Gordien E et al. Immunological efficacy of a three-dose schedule of hepatitis A vaccine in HIV-infected adults: HEPAVAC study. J Acquired Immune Defic Synd 2008;49:272-5.

8. Crum-Cianflone NF, Wilkins $\mathrm{K}$, Lee et al. Long-term durability of immune responses after hepatitis A vaccination among HIV-infected adults. J Infect Dis 2011;203:1815-23.

9. Kourkounti S, Mavrianou N, Paparizos VA et al. Immune response to hepatitis A vaccination in HIVinfected men in Greece. Int J STD \& AIDS 2012;23:464-7.

10. Kourkounti S, Papaizos V, Leuow K, Kordosis T, Antoniou C. Hepatitis A vaccination and immunological parameters in HIV-infected patients. Viral Immunol 2013;26:357-63.

11. Mena G, Garcia-Basteiro AL, Llupia A et al. Factors associated with the immune response to hepatitis A vaccination in HIV-infected patients in the era of highly active antiretroviral therapy. Vaccine 2013;31:3668-74.

12. Tseng YT, Chang SY, Liu WC et al. Comparative effectiveness of two doses versus three doses of hepatitis $A$ vaccine in human immunodeficiency virus-infected and -uninfected men who have sex with men. Hepatology 2013; 57:1734-41.

13. Jimenez HR, Hallit RR, Debari VA, Slim J. Hepatitis A vaccine response in HIV-infected patients: are TWINRIX and HAVRIX interchangeable? Vaccine 2013;31:1328-33.

14. Jabłonowska E, Kuydowicz J. Durability of response to vaccination against viral hepatitis A in HIVinfected patients: a 5-year observation. Int J STD AIDS 2014;25:745-50.

15. Victor JC, Monto AS, Surdina TY et al. Hepatitis A vaccine versus immune globulin for postexposure prophylaxis. N Engl J Med 2007;357:1685-94.

16. Kohl I, Nemecek V, Summerová M, Chlíbek R, Nad-ová K, Mináriková O. Long-term protective effect of post-exposure Havrix administration during viral hepatitis Type A outbreaks. Eur J Epidemiol 2006;21:893-9. 


\section{HEPATITIS B}

1. Infection and disease: The hepatitis B virus (HBV) is transmitted through sexual intercourse, percutaneous and parenteral exposure to blood and infected body fluids, and vertically from mother to child. The severity of acute infection varies from asymptomatic to fulminant hepatitis. After primary infection, HBV persists in $90 \%$ of infants infected perinatally, $25-50 \%$ of children aged $1-5$ years and 1$5 \%$ of immunocompetent adults and older children. Chronic infection can lead to liver cirrhosis and hepatocellular carcinoma.

2. Epidemiology: Based on the prevalence of the infection, three geographical categories can be identified: low prevalence $(<2 \%)$, intermediate prevalence $(2-8 \%)$, and high prevalence $(>8 \%)$. Regions of low prevalence include Western, Northern and Central Europe, North America, and Australia. Worldwide, the risk of infection is increased in injecting drug users (IDUs), men who have sex with men (MSM), those with multiple sexual partners, household and other close contacts of HBV-infected persons, those receiving blood or blood products, patients and staff of haemodialysis centres, people sharing unsterile medical and dental equipment, people providing and receiving acupuncture and tattooing with unsterile devices, healthcare workers, staff and residents of residential accommodation for those with mental disabilities, and travellers to areas of high or intermediate HBV prevalence if engaging in exposure-prone activities (including undertaking relief aid work and/or participating in contact sports).

3. HBV in HIV-positive adults: Both the risk of HBV infection and that of chronicity are increased in HIV-seropositive persons [1]. Chronic HBV infection is found in $5-10 \%$ of HIV-positive persons worldwide and co-infected persons show increased rates of progression to cirrhosis and liver cancer and a higher mortality than persons with either infection alone [2].

4. Hepatitis B vaccine: The yeast-derived HBV vaccine is prepared with biosynthetic surface antigen made using recombinant technology. There is also a combined hepatitis $A /$ hepatitis $B$ vaccine. Newly developed pre-S/S HBV vaccines are under evaluation and may in the future play a role in improving vaccine response rates in special risk groups including HIV-positive patients [3, 4]. The vaccine is given by parenteral administration. In HIV-negative adults, the schedule of administration can be: Typical ( 3 doses at 0, 1, and 6 months); Accelerated (4 doses at 0, 1, 2, and 12 months); or Ultra-rapid (4 doses at 0, 7-10 days, 21 days, and 12 months). Approximately $80-90 \%$ of healthy young adults achieve HBV surface antibody (HBsAb) levels $>10 \mathrm{IU} / \mathrm{L}$ after a complete vaccine course. Antibody levels $>100 \mathrm{IU} / \mathrm{L}$ are regarded as ideal whereas a level $<10 \mathrm{IU} / \mathrm{L}$ is classified as non-response [5]. Factors that reduce responses to $\mathrm{HBV}$ vaccination include age $>40$ years, obesity, female gender, haemodialysis, smoking, and immunocompromise, including HIV infection.

HBsAb levels decline over time after successful vaccination. After 20 years, $18-37 \%$ of adults have HBsAb levels $>10 \mathrm{IU} / \mathrm{L}[6,7]$. There is some evidence that protective immunity is still present even though HBsAb levels have fallen $<10 \mathrm{IU} / \mathrm{L}$. Infection may occur, but it is mostly transient [7-10]. In a study from the Gambia, adolescents and young adults vaccinated in infancy showed a risk of HBV infection, but this did not usually result in a chronic infection [7]. Time since vaccination and a low peak HBsAb response were the strongest risk factors for HBV infection. There is limited evidence regarding the need for booster vaccine doses in healthy individuals. UK guidelines recommend that persons at ongoing risk receive a single booster 5 years after completion of the primary vaccine course.

General indications: In the UK HBV vaccination is offered to individuals who are at increased risk of infection or severe disease. The groups include IDUs, individuals who change sexual partners frequently (e.g., sexual workers), MSM, close contacts of people with HBV infection, families adopting children from countries with a high or intermediate HBV prevalence, foster carers, individuals receiving regular blood or blood products and their carers, patients with chronic renal failure, patients 
with chronic liver disease, Inmates of custodial institutions, Individuals in residential accommodation for those with learning difficulties, people travelling to or going to reside in areas of high or intermediate prevalence, and individuals at occupational risk.

5. HBV vaccine in HIV-positive adults: $H B V$ vaccination significantly reduces the risk of incident $H B V$ infection in HIV-positive persons, and also reduces the risk of a newly acquired infection becoming chronic [11]. HIV infection however affects responses to HBV vaccination, reducing HBsAb seroconversion rates, and HBsAb levels and longevity [12-16]. After standard vaccination, rates of HBsAb seroconversion ( $>10 \mathrm{IU} / \mathrm{L}$ ) range between $7 \%$ and $88 \%$, and correlate strongly with CD4 cell counts and viral load [12-21]. Strategies to improve responses have included revaccination of nonresponders once the viral load is suppressed on ART and the CD4 count is $>350-500$ cells $/ \mu \mathrm{L}$, and the use of larger and more frequent vaccine doses [19-23]. When using yeast-based HBV vaccines, highdose vaccination improves HBsAb responses in HIV-positive people. A systematic review and metaanalysis of five studies including a total of 883 patients compared HBsAb response with high-dose (40 $\mu \mathrm{g}$ ) vs. standard-dose (20 or $10 \mu \mathrm{g}$ depending on vaccine type) vaccination [22]. High-dose vaccination increased response rates with a pooled OR of $1.96(95 \% \mathrm{Cl} 1.47,2.61)$. With four studies that included only vaccine-naive patients the OR was $1.82(95 \% \mathrm{Cl} 1.35,2.47)$. No study heterogeneity was found. An open-label, multicentre, randomized trial of patients with CD4 counts $>200 \mathrm{cell} / \mu \mathrm{L}$ evaluated three HBV vaccination strategies: a. Three standard-dose $(20 \mu \mathrm{g})$ intramuscular administrations at 0,1 , and 6 months $(n=145)$; b. Four high-dose $(40 \mu \mathrm{g})$ intramuscular administrations at $0,1,2$, and 6 months $(n=148)$; and c. Four low-dose $(4 \mu \mathrm{g})$ intradermal administrations at $0,1,2$, and 6 months $(n=144)$ [20]. Response rates (HBsAb $\geq 10 \mathrm{IU} / \mathrm{L}$ ) 4 weeks after the last vaccine dose in patients who received at least 1 vaccine dose (missing $\mathrm{HBsAb}$ titre $=$ non-responder) was $65 \%(95 \% \mathrm{Cl} 56 \%-72 \%)$ in group a vs. $82 \%$ $(77 \%-88 \%)$ in group $b(p<0.001)$ and $77 \%(69 \%-84 \%)$ in group $c(p=0.02)$. A cohort study also found that HBAbs response rates were $83 \%$ and $91 \%$ after three and four double-doses, respectively and HBsAb levels were higher with the 4-dose schedule [24].

The ultra-rapid vaccination course ( 3 vaccine doses given over 3 weeks) is immunogenic and can improve completion rates in healthy adults. However, a randomised study comparing the ultra rapidvaccine course $(0,7$, and 21 days) with the typical course $(0,1$, and 6 months) in HIV-positive adults found that the former had reduced immunogenicity in patients with CD4 counts $<500$ cells $/ \mu \mathrm{L}$ [25]. The study used standard-dose vaccine; there are no data for using high-dose vaccine in an ultra-rapid schedule.

The relationship between $\mathrm{HBSAb}$ levels and protection has been investigated by comparing rates of HBV infection among vaccine recipients with initial HBsAb levels $<10 \mathrm{IU} / \mathrm{ml}$ or $\geq 10 \mathrm{IU} / \mathrm{L}$ [26]. Overall, 46/409 (11\%) vaccine recipients with HBsAb $<10 \mathrm{IU} / \mathrm{L}$ acquired HBV infection compared with 11/217 (5\%) vaccine recipients with $\mathrm{HBsAb} \geq 10 \mathrm{IU} / \mathrm{L}(\mathrm{HR} 0.51 ; 95 \% \mathrm{Cl} 0.3,1.0)$. Furthermore, in participants with initial HBsAb levels $<10 \mathrm{IU} / \mathrm{L}, 16 / 46$ (35\%) incident infections became chronic, whereas no chronic infections were detected in those with initial HBsAb levels $\geq 10 \mathrm{IU} / \mathrm{L}(\mathrm{p}=0.02)$. Based upon these data, it seems desirable to attempt to induce an HBsAb response in patients who fail to respond to the primary vaccine course, as determined by measuring HBsAb levels 4-8 weeks after the last vaccine dose. As longer time to revaccination predicts nonresponse to revaccination, the management of nonresponders should be timely [27]. Both standard-dose [27] and high-dose $[23,28]$ re-vaccination has been evaluated in HIV-positive non-responders. One study found that high-dose re-vaccination significantly increased HBsAb response rates (OR 4.2; $\mathrm{Cl}, 1.3-13.6 ; \mathrm{p}=0.018$ ) [28]. In two other studies, high-dose re-vaccination was effective in inducing HBsAb in $51 \%$ of 144 [23] and $67 \%$ of 30 [29] nonresponders respectively. Emerging data suggest that in addition to high-dose re-vaccination, using one [30] or four [31] standard doses of the adjuvanted vaccine Fendrix may improve response rates among people who do not make a HBsAb response to the primary vaccine course. In one cohort study, 18/22 (82\%) HIV-positive non-responders showed HBsAb levels $>100 \mathrm{IU} / \mathrm{L}$ following a 4-dose schedule, with an additional $3(14 \%)$ subjects achieving titres of $10-100 \mathrm{IU} / \mathrm{L}$ [31]. 
Duration of vaccine-induced protection is unknown in HIV-positive persons, but in general terms postvaccination HBsAb levels are lower and disappear more quickly than in HIV-negative persons. Among HIV-positive responders to HBV vaccination, the HBsAb level measured 4 weeks after the completion of the vaccination course is strongly predictive of the longevity of response [32,33]. In a cohort study of 155 HIV-positive vaccine recipients, the mean time to loss of detectable HBsAb was 2.0, 3.7 and 4.4 years for patients with HBsAb levels 10-100 IU/I, >100-1000 IU/I, and >1000 IU/I, respectively [33]. In addition, viral load suppression on ART during vaccination and at follow-up predicts longer persistence of $\mathrm{HBsAb}$ levels $>10 \mathrm{IU} / \mathrm{L}[33,33]$. These data indicate that it is desirable to boost the HBsAb response of vaccine recipients that show HBsAb levels $>10$ but $<100 \mathrm{IU} / \mathrm{L}$ after the primary vaccine course, with the aim improving the longevity of the response. Further boosting requirements for patients who make a response to vaccination are not well defined in immunocompromised patients. The available evidence indicates that while it may be practical to screen all immunised patients for HBsAb yearly, the frequency of HBsAb monitoring among successfully vaccinated patients could be reduced based upon the strength of the initial HBsAb response, and CD4 count, ART status, and viral load at vaccination and during follow-up. Consensus opinion is that booster doses are indicated in subjects whose $\mathrm{HBsAb}$ levels decline $<10 \mathrm{IU} / \mathrm{L}$ if at ongoing risk of exposure. Importantly, vaccinated patients should continue to undergo HBV surveillance as they remain at risk of infection [26].

"Occult" HBV infection and vaccination: Patients who test HBsAg negative, HBcAb positive and HBsAb negative (isolated $\mathrm{HBCAb}$ positivity) have traditionally posed a management challenge. These patients may belong to one of the following groups: (i) recent resolving HBV infection (HBV core IgM positive); (ii) occult HBV infection (low-level HBV DNA persistently or intermittently detectable in blood and detectable in the liver); (iii) HBsAg diagnostic escape mutants (HBV DNA levels usually high in blood in untreated patients); (iv) resolved HBV infection (strong HBcAb reactivity, possible HBeAb positivity, anamnestic HBsAb response $>10 \mathrm{IU} / \mathrm{L}$ observed 1-2 weeks after a single HBV vaccine dose); (v) falsepositive $H B c A b$ result and susceptibility to infection. While some experts recommend HBV DNA testing, HBV DNA detection in blood may be intermittent in those with occult HBV infection [34]. HBV vaccination can elicit an anamnestic $\mathrm{HBsAb}$ response as evidence of past infection and immunity. One study in HIV-negative patient showed anamnestic responses (HBsAb $\geq 10 \mathrm{IU} / \mathrm{L}$ ) in 20/21 subjects with isolated HBcAb after one vaccine dose [35] In contrast, studies in HIV-positive patients found an anamnestic response in $24-33 \%$ [36,37].

The HBV vaccine is safe and well tolerated in HIV-positive individuals. Injection site reactions are the most frequent side effects. HBV vaccination completion rates are closely dependent on the clinical setting providing HIV care [16], indicating that compliance should be audited regularly.

6. Post-exposure prophylaxis: After a recognised exposure to an HBsAg-positive contact, postexposure prophylaxis is guided by the vaccination history of the patient. Hepatitis-B-specific immunoglobulin ( $\mathrm{HBIg}$ ) can protect from infection or attenuate disease if given within 7 days of exposure. HBIg is given by intramuscular injection. A rapid ( 3 weekly injections over 3 months) vaccination course started within 7 days of exposure appears to be as effective as vaccination plus $\mathrm{HBlg}$ in healthy persons. There are no data on the efficacy of post-exposure prophylaxis by either strategy in HIV-positive persons.

\section{Recommendations for HIV-positive adults}

- We recommend that HIV-positive adults be screened for evidence of HBV infection or immunity, and that non-immune individuals (HBsAg negative, HBcAb negative, HBsAb negative) be offered HBV vaccination $[1 \mathrm{~A}]$ 
- We recommend that when using yeast-based vaccines, high-dose $(40 \mu \mathrm{g})$ vaccination be offered [1A]. In the UK, Engerix $B^{\circledR}$ should be given as a double-dose (total $40 \mu \mathrm{g}$ ) [1A]; with $\mathrm{HBvaxPRO}^{\circledast}$ the $40 \mu \mathrm{g}$ formulation should be used [1B]

- We recommend that when using the adjuvanted vaccine Fendrix ${ }^{\circledast}$ the standard $20 \mu \mathrm{g}$ formulation be given [1B]

- We recommend that, regardless of vaccine type, 4 vaccine doses are given at $0,1,2$, and 6 months [1B]

- We recommend that an ultra-rapid vaccination course (3 standard-dose administrations given over 3 weeks) be considered only in selected patients with CD4 counts $>500$ cells $/ \mu \mathrm{L}$ where there is an imperative need to ensure rapid completion of vaccination and/or where compliance with a full course is doubtful [1B]. We recommend against using highdose vaccination in an ultra-rapid schedule due to the lack of safety data [1D]

- We recommend that following completion of the primary vaccine course, HBsAb levels be measured 4-8 wks after the last vaccine dose [1A]

- We recommend that individuals that after the primary vaccine course have $\mathrm{HBsAb}$ levels $<10 \mathrm{IU} / \mathrm{L}$ receive 3 further vaccine doses at monthly intervals [1B]

$\circ$ These should be given at high dose $(40 \mu \mathrm{g})$ with Engerix $\mathrm{B}^{\circledR}$ or $\mathrm{HBvaxPRO}^{\circledR}$, and standard dose $(20 \mu \mathrm{g})$ with Fendrix ${ }^{\circledR}$

- We suggest that re-vaccination with Fendrix may be preferred in non-responders [2C]

- Retesting for HBsAb is indicated 4-8 weeks after the final vaccine dose [GPP]

- We suggest that depending on the level of risk, revaccination of non-responders may be delayed until the viral load is suppressed on ART and the CD4 count has increased $>350$ cells/ $\mu \mathrm{L}[2 \mathrm{~B}]$

- We recommend that individuals that after the primary vaccine course have HBsAb levels $\geq 10$ but $<100 \mathrm{IU} / \mathrm{L}$ receive one booster dose (see above for dosing) [1B]

0 Retesting for HBsAb is indicated 4-8 weeks after the final vaccine dose [GPP]

- We recommend that responders to HBV vaccination (HBsAb $>10 \mathrm{IU} / \mathrm{L}$ after completion of a full vaccine course) undergo regular HBAbs testing in order to guide subsequent boosting requirement [1B]

- We recommend that $\mathrm{HBsAb}$ screening intervals be guided by the initial HBsAb level (measured after completion of the primary vaccine course), risk of exposure, and CD4 cell count, ART use, and viral load at the time of vaccination and during follow-up [1B]. Longer intervals (i.e., 2-4 years] are indicated for subjects with initial HBsAb levels $>100 \mathrm{IU} / \mathrm{ml}$, CD4 counts $>350$ cells $/ \mu \mathrm{L}$, and viral load suppression on ART [1C]. Other subjects should undergo yearly $\mathrm{HBsAb}$ screening $[1 \mathrm{C}]$

- We recommend that subjects with an initial HBsAb response who show a decline of $H B s A b$ levels $<10 \mathrm{IU} / \mathrm{ml}$ are offer a booster dose (see above for dosing) [1C]

- We recommend individuals who have no evidence of protective vaccine-induced immunity have an annual HBsAg test or more frequent testing if there are known and ongoing risk factors for HBV acquisition [1B]

- We recommend patients with isolated HBcAb positivity be offered one HBV vaccine dose (see above for dosing), be tested for HBsAb 2 weeks later, and be offered completion of the vaccine course if the HBsAb level is $<10 \mathrm{IU} / \mathrm{L}[1 \mathrm{C}]$

- We recommend that compliance with HBV vaccination policy is audited regularly [1B]

- We recommend that following a high-risk exposure to an HBsAg-positive source, the HBV status of the HIV-positive contact be determined urgently if not known [1C]

- No prophylaxis is required in those with evidence of a current or past HBV infection

- Vaccinated patients with initial HBsAb $>10 \mathrm{IU} / \mathrm{L}$ should be offered one booster dose and if the CD4 count is $<200$ cells $/ \mu \mathrm{L}$ also receive $\mathrm{HBIg}[1 \mathrm{C}]$

- Non-responders to previous HBV vaccination (initial HBsAb $<10 \mathrm{IU} / \mathrm{L}$ ) should be offered a booster vaccine dose and also receive $\mathrm{HBIg}$ regardless of $\mathrm{CD} 4$ count $[1 \mathrm{C}]$ 
- Patients who have not been vaccinated or have an uncertain vaccination history should be offered a rapid vaccine course (0,1,2 months; see above for dosing) and also receive $\mathrm{HBlg}$ regardless of CD4 cell count [1C]

- When indicated, 2 doses of HBlg should be given 1 month apart

- Post-exposure prophylaxis should be given within 7 days of exposure [1D]. We suggest that prophylaxis beyond 7 days (up to 6 weeks after exposure) may be considered in selected cases; specialist advice should be sought [2D]

HBV vaccination decision flow-chart

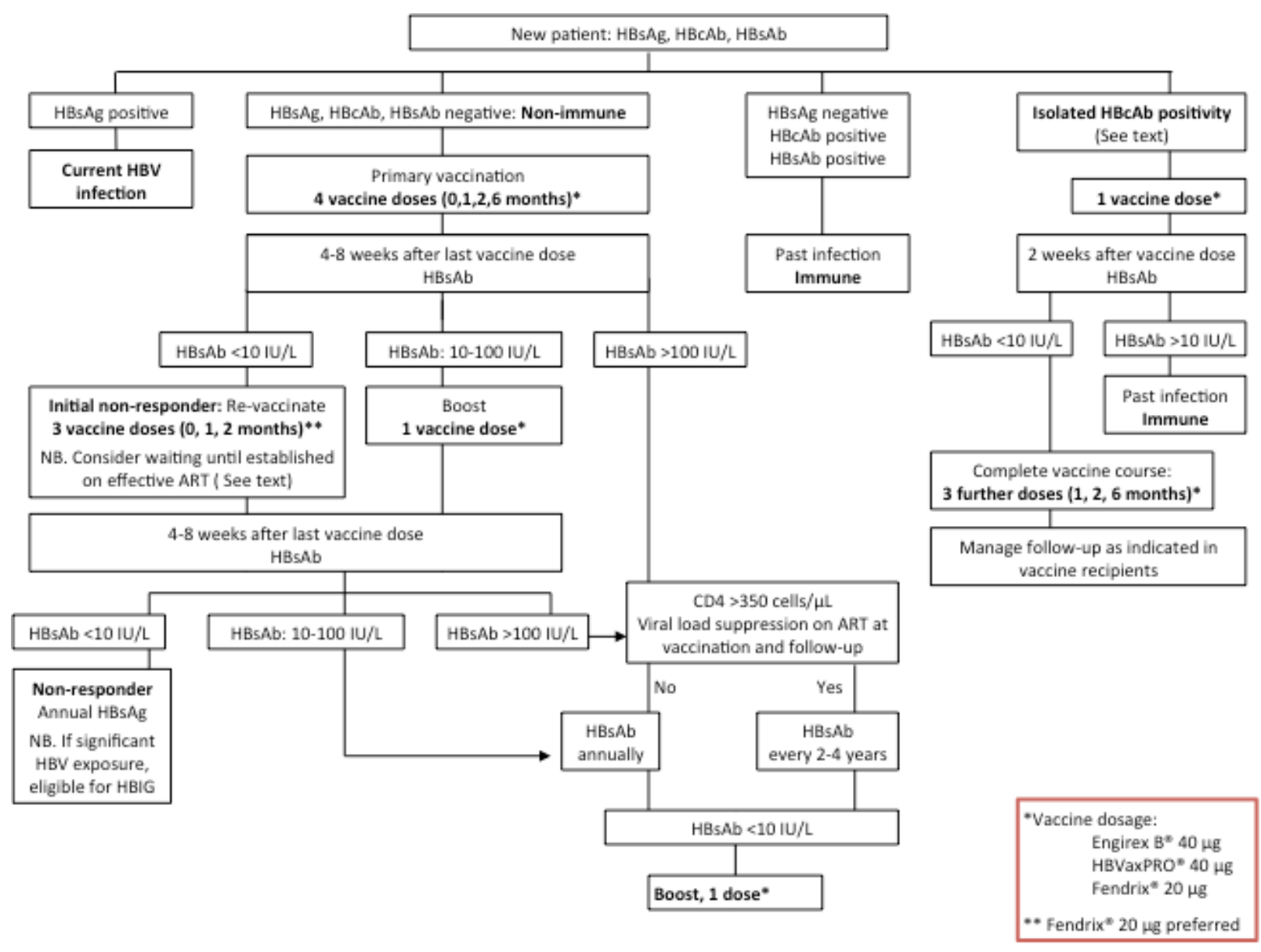

\section{References}

1. Colin JF, Cazals-Hatem D, Loriot MA et al. Influence of human immunodeficiency virus infection on chronic hepatitis B in homosexual men. Hepatol 1999; 29: 1306-1310.

2. Martín-Carbonero L, Poveda E. Hepatitis B virus and HIV infection. Semin Liver Dis 2012;32:114-9.

3. Shouval D. Hepatitis B vaccines. J Hepatol 2003;39 Suppl 1:S70-6.

4. Shouval $D$, Roggendorf $H$, Roggendorf $M$. Enhanced immune response to hepatitis $B$ vaccination through immunization with a Pre-S1/Pre-S2/S vaccine. Med Microbiol Immunol. 2015;204:57-68.

5. Jack AD, Hall AJ, Maine $N$ et al. What level of hepatitis $B$ antibody is protective? J Infect Dis 1999;179:489-92. 
6. Bagheri-Jamebozorgi $\mathrm{M}$, Keshavarz J, Nemati $\mathrm{M}$, et al. The persistence of anti-HBs antibody and anamnestic response 20 years after primary vaccination with recombinant hepatitis $B$ vaccine at infancy. Hum Vaccin Immunother 2014;10:3731-6.

7. Mendy M, Peterson I, Hossin S, et al. Observational study of vaccine efficacy 24 years after the start of hepatitis B vaccination in two Gambian villages: no need for a booster dose. PLoS One 2013;8:e58029.

8. Wainwright RB, Bulkow LR, Parkinson AJ, Zanis C, McMahon BJ. Protection provided by hepatitis B vaccine in a Yupik Eskimo population: results of a 10-year study. J Infect Dis 1997; 175: 674-677.

9. Yuen MF, Lim WL, Cheng CC, Lam SK, Lai CL. Twelve year follow-up of a prospective randomized trial of recombinant DNA yeast vaccine vs. plasma-derived vaccine without booster doses in children. Hepatology 1999; 29: 924-927.

10. European Consensus Group on Hepatitis B Immunity. Are booster immunisations needed for lifelong hepatitis B immunity? Lancet 2000; 355: 561-565.

11. Kellerman SE, Hanson DL, McNaghten AD, Fleming PL. Prevalence of chronic hepatitis $B$ and incidence of acute hepatitis $B$ infection in human immunodeficiency virus-infected subjects. J Infect Dis 2003;188:571-7.

12. Biggar RJ, Goedert JJ, Hoofnagle J. Accelerated loss of antibody to hepatitis B surface antigen among immunodeficient homosexual men infected with HIV. N Engl J Med 1987;316:630-1.

13. Collier AC, Corey L, Murphy VL, Handsfield HH. Antibody to human immunodeficiency virus (HIV) and suboptimal response to hepatitis B vaccination. Ann Intern Med 1988;109:101-5.

14. Tayal SC, Sankar KN. Impaired response to recombinant hepatitis B vaccine in asymptomatic HIVinfected individuals. AIDS 1994;8:558-9.

15. Veiga APR, Casseb J, Duarte AJS. Humoral response to hepatitis B vaccination and its relationship with T CD45RA (nai"ve) and CD45RO (memory) subsets in HIV-1-infected subjects. Vaccine 2006;24:7124-8.

16. Tedaldi EM, Baker RK, Moorman AC et al. Hepatitis A and B vaccination practices for ambulatory patients infected with HIV. Clin Infect Dis 2004;38:1478-84.

17. Rey $D$, Krantz V, Partisani $M$ et al. Increasing the number of hepatitis $B$ injections augments antiHBs response rate in HIV-infected patients. Effect on viral load. Vaccine 2000;18:1161-5.

18. Fonseca MO, Pang LW, de Paula Cavalheiro N, Barone AA, Heloisa Lopes M. Randomized trial of recombinant hepatitis $B$ vaccine in HIV-infected adult patients comparing a standard dose to a double dose. Vaccine 2005;23:2902-8.

19. Flynn PM, Cunningham CK, Rudy B, et al. Hepatitis B vaccination in HIV-infected youth: a randomized trial of three regimens. J Acquir Immune Defic Syndr 2011;56:325-32

20. Launay $O$, van der Vliet $D$, Rosenberg $A R$, et al. Safety and immunogenicity of 4 intramuscular double doses and 4 intradermal low doses vs standard hepatitis $B$ vaccine regimen in adults with HIV-1: a randomized controlled trial. JAMA 2011;305:1432-40.

21. Whitaker JA, Rouphael NG, Edupuganti S, Lai L, Mulligan MJ. Strategies to increase responsiveness to hepatitis B vaccination in adults with HIV-1. Lancet Infect Dis 2012;12:966-76

22. Ni JD, Xiong YZ, Wang XJ, Xiu LC. Does increased hepatitis B vaccination dose lead to a better immune response in HIV-infected patients than standard dose vaccination: a meta-analysis. Int J STD AIDS 2013 2013;24:117-22.

23. de Vries-Sluijs TE, Hansen BE, van Doornum GJ et al. A prospective open study of the efficacy of high-dose recombinant hepatitis $B$ rechallenge vaccination in HIV-infected patients. J Infect Dis 2008;197:292-4.

24. Potsch DV, Oliveira ML, Ginuíno C, et al. High rates of serological response to a modified hepatitis $B$ vaccination schedule in HIV-infected adults subjects. Vaccine 2010;28:1447-50.

25. de Vries-Sluijs TE, Hansen BE, van Doornum GJ, et al. A randomized controlled study of accelerated versus standard hepatitis $B$ vaccination in HIV-positive patients. J Infect Dis 2011;203:984-91.

26. Landrum ML, Hullsiek KH, Ganesan A, et al. Hepatitis B vaccination and risk of hepatitis B infection in HIV-infected individuals. AIDS 2010;24:545-55. 
27. Irungu $\mathrm{E}$, Mugo $\mathrm{N}$, Ngure $\mathrm{K}$, et al. Immune response to hepatitis $B$ virus vaccination among HIV-1 infected and uninfected adults in Kenya. J Infect Dis 2013;207:402-10.

28. Psevdos G, Kim JH, Groce V, Sharp V. Efficacy of double-dose hepatitis B rescue vaccination in HIVinfected patients. AIDS Patient Care STDS 2010;24:403-7.

29. Pettit NN, DePestel DD, Malani PN, et al. Factors associated with seroconversion after standard dose hepatitis B vaccination and high-dose revaccination among HIV-infected patients. HIV Clin Trials 2010;11:332-9.

30. Hoebe CJ, Vermeiren AP, Dukers-Muijrers NH. Revaccination with Fendrix ${ }^{\circledast}$ or HBVaxPro ${ }^{\circledR}$ results in better response rates than does revaccination with three doses of Engerix- $\mathrm{B}^{\circledR}$ in previous nonresponders. Vaccine 2012;30:6734-7.

31. de Silva TI, Green ST, Cole J, Stone BJ, Dockrell DH, Vedio AB. Successful use of Fendrix in HIVinfected non-responders to standard hepatitis B vaccines. J Infect 2014;68:397-9.

32. Powis JE, Raboud J, Ostrowski M, Loutfy MR, Kovacs C, Walmsley SL. The recombinant hepatitis B surface antigen vaccine in persons with HIV: is seroconversion sufficient for long-term protection? J Infect Dis 2012;205:1534-8.

33. Lopes VB, Hassing RJ, de Vries-Sluijs TE, et al. Long-term response rates of successful hepatitis $B$ vaccination in HIV-infected patients. Vaccine. 2013;31:1040-4.

34. Nebbia G, Garcia-Diaz A, Ayliffe U, et al. Predictors and kinetics of occult hepatitis B virus (HBV) infection in HIV-infected persons. J Med Virol 2007;79:1464-71.

35. Su FH, Bai CH, Chu FY, Lin YS, Su CT, Yeh CC. Significance and anamnestic response in isolated hepatitis $B$ core antibody-positive individuals 18 years after neonatal hepatitis $B$ virus vaccination in Taiwan. Vaccine 2012;30:4034-9.

36. Gandhi RT, Wurcel A, Lee $H$ et al. Response to hepatitis B vaccine in HIV-1-positive subjects who test positive for isolated antibody to hepatitis $B$ core antigen: implications for hepatitis $B$ vaccine strategies. J Infect Dis 2005;191:1435-41.

37. Chakvetadze C, Bani-Sadr F, Le Pendeven, $C$, et al. Serologic response to hepatitis B vaccination in HIV-Infected patients with isolated positivity for antibodies to hepatitis B core antigen. Clin Infect Dis 2010;50:1184-6. 


\section{HUMAN PAPILLOMA VIRUS}

1. Infection and disease: HPV establishes infection in the skin and mucous membranes. Transmission occurs through direct contact, when microtears allow the virus to invade basal epithelial cells. Most HPV infections are subclinical and resolve spontaneously. Persistence can lead to disease, including premalignant and malignant lesions [1]. Over 150 HPV types have been identified and are classified according to the oncogenic potential. HPV-6 and HPV-11 are non-oncogenic and responsible for about $90 \%$ of genital warts and most cases of recurrent respiratory papillomatosis. Oncogenic types cause cancers of the cervix, vulva, and vagina in women, penis in men, and anus and oropharynx in women and men [1]. Just over 60\% of HPV-associated cancers are caused by HPV-16 or HPV-18; HPV types 31, $33,45,52$, and 58 account for $10 \%$ of cases [1-4]. Co-infection with multiple HPV types is common [5].

2. Epidemiology: HPV is the most prevalent sexually transmitted infection in industrialised countries. Transmission between sexual partners is common, and appears to be more frequent from females to males than from males to females. Condoms reduce the risk of infection [6], although they are not fully protective ( $70 \%$ efficacy with consistent use). In women, HPV acquisition increases with age through the early 20s and then decreases, although acquisition continues in older women [7]. Men show a relatively constant incidence over a wide age range. HPV is a dominant cause of cancer worldwide. Cervical cancer remains a major health burden, particularly in less developed regions where screening and vaccination programmes are less established. Other HPV-related cancers are increasing in incidence among both men and women [1]. There is evidence indicating that HIV acquisition is significantly associated with HPV infection [8].

3. HPV in HIV-positive adults: Men and women with HIV infection show an increased risk and rate of HPV acquisition and persistence, frequent carriage of multiple HPV types, and an increased risk of HPV-related disease including rapidly progressive malignancies [9-38]. HPV carriage rates and overall disease risk increase at low CD4 cell counts. However, despite effective ART HIV-positive men and women remain disproportionately affected by HPV-related anogenital disease compared with HIVnegative people. Overall prevalence of HPV-16 and HPV-18 in HIV-positive women aged 13-45 years in the United States, Brazil, and South Africa is $32 \%$ and $20 \%$ respectively [39]. Anal HPV infection is highly prevalent in HIV-positive men who have sex with men (MSM). An Australian study of MSM aged 18-75 years showed a HPV-16 seroprevalence of 44\%, with a seroincidence of 1.3 per 100 person/years continuing in the mid 40s [19]. A meta-analysis of 34,189 HIV-positive and 114,260 HIVnegative individuals in North America reported that between 1996 and 2007 the incidence of anal cancer per 100,000 person/years was 131 in HIV-positive MSM, 46 in other HIV-positive men, 30 in HIV-positive women, 2 in HIV-negative men, and zero in the HIV-negative women surveyed in this study [21]. The analysis reported that incidence of anal cancer was higher in ART era likely reflecting improved survival and increased awareness and diagnosis.

4. HPV vaccine: Three virus-like particle (VLP) sub-unit vaccines based on the L1 capsid protein are currently in use for the prevention of HPV disease around the world [2,3]. They comprise a bivalent product (2vHPV; Cervarix, GlaxoSmithKline; HPV types 16 and 18) and a quadrivalent product (4vHPV; Gardasil 4, Merck; HPV types 6, 11, 16, 18), which were introduced in 2006 and 2007 respectively, and a nonavalent product (9vHPV; Gardasil 9, Merck; HPV types 6, 11, 16, 18, 31, 33, 45, 52, 58), which was licensed by the FDA in 2014. Both vaccine types are adjuvanted. VLPs are similar in shape and size to the HPV virion, but do not contain viral DNA, and are therefore non-infectious and non-oncogenic. The vaccines are given by parenteral administration. HPV vaccines are more immunogenic than natural infection, and highly efficacious in protecting susceptible women against cervical infection and pre-cancer related to HPV-16 and HPV-18. Protection is maintained for at least 10 years. Ongoing studies will determine whether effectiveness declines with time, and the requirement for boosters. The vaccines are also efficacious in preventing HPV-16 and HPV-18 infections at other anatomical sites in both sexes, including the precursors of vulvar, vaginal and anal cancer related to the vaccine types 
[2-4,40-42]. The 4VHPV and 9vHPV vaccines also reduce the incidence of genital warts associated with the vaccine types. Partial cross-protection against non-vaccine HPV types has been reported, but its effectiveness and duration is unknown. HPV vaccines are well tolerated and no safety concerns have emerged from clinical trials and post-license evaluations [43]. Non-inferiority of immune response and an acceptable safety profile have been demonstrated when the HPV vaccine is co-administered with other vaccines (assessed with meningococcal conjugate, hepatitis $A$, hepatitis $B$, combined hepatitis $A$ / $B$, tetanus, diphtheria, acellular pertussis, and inactivated poliovirus vaccines) [44].

General indications: In the UK, since 2008, HPV vaccination is routinely recommended for all girls aged $12-13$, along with a catch up programme for girls 13 to under 18 years of age. Two vaccine doses are given to those aged 9-14 years, and 3 doses to those aged 15-18 years. In November 2014, the Joint Committee on Vaccination and Immunisation (JCVI) issued an interim position statement recommending HPV vaccination with a 3 dose series (0, 1-2, and 6 months) for MSM aged up to 40 years attending sexual health services after considering evidence on the impact and cost-effectiveness of a targeted vaccination programme in this group [45]. The price of the vaccine and HIV status of MSM impacted on the cost effectiveness of this recommendation. Other males of any age and women $>18$ years of age are not currently covered by the UK national programme, although this is under review. Gardasil (4VHPV currently) is the preferred vaccine in the UK due to the additional protection against genital warts. In February 2015, the US Advisory Committee on Immunization Practices (ACIP) recommended 9vHPV as one of three HPV vaccines that can be used for routine vaccination of females, whereas $4 \mathrm{VHPV}$ or $9 \mathrm{VHPV}$ are recommended for males. ACIP recommends vaccination for women up to 26 years, males up to 21 years, MSM up to 26 years, and immunocompromised persons (including those with HIV infection) up to 26 years [2].

Cost-effectiveness considerations: HPV vaccination has been shown to be cost-effective in preadolescent females. As HPV vaccines protect against HPV types not already acquired, costeffectiveness declines with increasing likelihood of previous exposure. For women, studies differ in their conclusions about the age cut-off at which the cost-effectiveness ratio becomes unfavourable, ranging from 15 to 26 years within available data. The cost-effectiveness of vaccinating young males is generally lower than with young females, firstly because the burden of disease is lower in men than in women, and secondly because men derive benefits from female-only vaccination programmes via herd immunity, particularly if vaccine coverage is high $[2-4,41,42,46]$. Population-based studies in countries with high female vaccine coverage confirm a beneficial impact of herd immunity in heterosexual males; the benefit however is not extended to MSM. One US-based study addressed the cost-effectiveness of vaccinating MSM through 26 years of age, and concluded that vaccination is likely to be a cost-effective intervention for the prevention of genital warts and anal cancer in this group [46]. Outcomes were most sensitive to variations in anal cancer incidence, duration of vaccine protection, and HIV prevalence in MSM. A more recent unpublished analysis reviewed by the JCVI analysed the cost-effectiveness of vaccinating MSM up to age of 40 years [45]. In this model, costeffectiveness was higher for 4VHPV due to the added protection against genital warts. Under the criteria used by JCVI, vaccinating HIV-positive MSM aged 16 to 25 years was cost-effective at the list price of the vaccine. Vaccinating HIV-positive MSM aged 16 to 40 years was also incrementally costeffective under the base case assumptions. Extending vaccination to all MSM aged 16 to 40 years was not incrementally cost-effective when using the list price of the vaccines. However, vaccination of all MSM aged 16 to 40 years was cost-effective under the criteria used by JCVI at a threshold vaccine price below the list price. The JCVI highlighted that key operational and delivery issues remain to be addressed for the programme to be considered. In US-based models assuming that 9vHPV would cost $\$ 13$ more per dose than 4VHPV, introduction of 9vHPV was cost-effective when compared with 4vHPV for both sexes [2]. Because the additional five types in 9VHPV account for a higher proportion of HPVassociated cancers in females compared with males and cause cervical pre-cancers, the additional protection from 9vHPV is expected to benefit mostly females. 
Vaccine safety: For eligible individuals, HPV vaccination is indicated regardless of a previous history of abnormal smear test results, pre-cancer lesions likely to be HPV-associated, or anogenital warts, although the benefit of vaccination decreases with increasing likelihood of a previous exposure to the vaccine types. There are no data to support laboratory testing to exclude a prior HPV exposure before vaccination. Whilst the vaccines are not expected to have therapeutic effects, vaccination of individuals pre-exposed to the vaccine types is safe, may boost immunity, and may prevent reinfection $[47,48]$. For those with incomplete vaccination, completion of the course is indicated with the appropriate vaccine type, although there are no strict contraindications to changing the vaccine mid-course [2]. HPV vaccines are contraindicated for persons with a history of immediate hypersensitivity to any vaccine component. 4VHPV and 9vHPV are contraindicated for persons with a history of immediate hypersensitivity to yeast [2]. HPV vaccines are not recommended for use in pregnant women, as pregnant women were not included in the vaccine clinical trials. Whilst pregnancy testing is not indicated before vaccination, if a woman is found to be pregnant after initiating the vaccination series, the remainder of the 3-dose series should be delayed until after pregnancy. If a vaccine dose has been administered during pregnancy, no intervention is needed. A new pregnancy registry has been established for 9vHPV and no safety signal has been identified to date. Pregnancy registries for 2VHPV and 4VHPV have been closed [2].

5. HPV vaccine in HIV-positive adults: In studies that have most commonly employed 4vHPV, vaccination has been shown to be safe and immunogenic in HIV-positive children [49,50]; females aged 16-23 years [51], 18-25 years [52], or 13-45 years [39]; males aged 22-61 years [53]; and males and females aged 13-27 years $[54,55]$. Overall seroconversion rates are high in all groups, and both seroconversion rates and antibody titres are higher than with natural infection, and highest in those receiving ART and showing high CD4 cell counts and a suppressed viral load. A study of men and women aged 13-27 years compared responses to 4VHPV in $46 \mathrm{HIV}$-negative individuals and $46 \mathrm{HIV}$ positive patients with CD4 counts $>200$ cells $/ \mu \mathrm{L}$ (mean 715 cells $/ \mu \mathrm{L}$ ) and a stably suppressed viral load [54]. Seroconversion rates one month after the administration of the third vaccine dose were $91 \%$ (HIV-negative) and $85 \%$ (HIV-positive) respectively ( $p=0.52)$, and there was no significant difference in antibody titres. In a study of males aged 22-61 years, the proportion exhibiting seroconversion was $95 \%$ or greater for each of the four HPV types included in 4VHPV [53]. Anti-HPV 16 antibody concentrations were lower than those historically reported in HIV-negative women but similar to those reported in HIV-negative MSM, and were higher in subjects receiving ART. The median CD4 count at the time of vaccination was 517 (IQR 423-680) in the study population, and $92 \%$ of subjects had a viral load $<10,000$ copies/mL; there was no impact of nadir CD4 count on immune responses. In a study of HIV-positive women aged 13-45 years, seroconversion proportions one month after the administration of the third dose of 4VHPV for HPV types $6,11,16$, and 18 were $96 \%, 98 \%, 99 \%$, and $91 \%$, respectively, at CD4 count $>350$ cells $/ \mu \mathrm{L} ; 100 \%, 98 \%, 98 \%$, and $85 \%$, respectively, at CD4 count 201-350 cells $/ \mu \mathrm{L}$, and $84 \%, 92 \%, 93 \%$, and $75 \%$, respectively, at CD4 count $\leq 200$ cells/ $\mu \mathrm{L}$ [53]. Women with viral load $>10,000$ copies $/ \mathrm{mL}$ had lower rates of seroconversion. In one study of HIV-positive adults, 4vHPV was reported to induce similar antibody responses in males and females [39]. Following vaccination, local reactions like pain, swelling and redness occur in $9 \%$ of HIV-negative and $33 \%$ of HIVpositive subjects [43], but are usually of short duration. Systemic adverse reactions may include headache (2\% of HIV-negative and $14 \%$ of HIV-positive subjects [43]), and occasionally fever, nausea, dizziness, fatigue, and myalgia, but these are also short-lived. No adverse impact on CD4 cell counts and viral load have been observed in HIV-positive patients.

Studies are ongoing to demonstrate the clinical efficacy of HPV vaccines in HIV-positive individuals. Meanwhile, factors that inform the cost-benefit evaluation include a) a high rate of HPV carriage, limiting vaccine efficacy; b) uncertainties about the duration of vaccine-induced protection; c) the consideration that seropositivity for all vaccine types is uncommon, indicating that at least partial protection can be achieved; d) evidence that HPV acquisition continues in adults; e) the high burden of disease in spite of effective ART; f) the safety of HPV vaccines, including safety in those with 
established HPV infection and disease; g) the demonstrated ability of HPV vaccines to boost natural immunity, which may reduce the risk of re-infection; $h$ ) a high level of willingness to be vaccinated among surveyed groups [45]. While younger HIV-positive people are likely to benefit the most from vaccination, older men and women may continue to derive at least partial benefit from vaccination.

\section{Recommendations for HIV-positive adults}

- We recommend that previously unvaccinated HIV-positive men and women aged up to 26 years be offered HPV vaccination, regardless of CD4 count, ART use, and viral load [1B]

- We recommend that previously unvaccinated HIV-positive MSM aged up to 40 years be offered HPV vaccination, regardless of CD4 count, ART use, and viral load [1B]

- We suggest that previously unvaccinated HIV-positive women aged up to 40 years be offered HPV vaccination, regardless of CD4 count, ART use, and viral load [2D]

- We suggest that in ART-naïve patients with CD4 counts $<200$ cells/ $\mu \mathrm{L}$ vaccination may be deferred until the patient is established on ART [2B]

- We recommend that 3 doses of the quadrivalent $4 \mathrm{vHPV}$ vaccine be administered at $0,1-2$, and 6 months [1B]. We recommend maintaining the 3 -dose regimen in HIV-positive patients [1A]. If the vaccine schedule is interrupted, the vaccination series should be completed rather than restarted

- We recommend that all eligible HIV-positive adults who have received $<3$ vaccine doses before the age of 18 years complete a 3 -dose vaccination course with 4vHPV [1C]

- We recommend that 9vHPV be used in both men and women once it becomes available in place of $4 \mathrm{VHPV}[1 \mathrm{C}]$

\section{References}

1. Wakeham K, Kavanagh K. The burden of HPV-associated anogenital cancers. Curr Oncol Rep 2014;16:402.

2. Petrosky E, Bocchini JA Jr, Hariri S, et al. Use of 9-valent human papillomavirus (HPV) vaccine: updated HPV vaccination recommendations of the advisory committee on immunization practices. MMWR Morb Mortal Wkly Rep 2015;64:300-4.

3. Pils S, Joura EA. From the monovalent to the ninevalent HPV vaccine. Clin Microbiol Infect 2015 May 13.

4. Bosch FX, Broker TR, Forman D, et al. Comprehensive control of human papillomavirus infections and related diseases. Vaccine 2013;31 Suppl 6:G1-31.

5. King EM, Gilson R, Beddows $\mathrm{S}$, et al. Human papillomavirus DNA in men who have sex with men: type-specific prevalence, risk factors and implications for vaccination strategies. $\mathrm{Br} \mathrm{J}$ Cancer 2015;112:1585-93.

6. Lam JU, Rebolj M, Dugué PA, Bonde J, von Euler-Chelpin M, Lynge E. Condom use in prevention of Human Papillomavirus infections and cervical neoplasia: systematic review of longitudinal studies. J Med Screen 2014;21:38-50.

7. Grainge MJ, Seth R, Guo L, et al. Cervical human papillomavirus screening among older women. Emerg Infect Dis 2005;11:1680-5.

8. Lissouba $\mathrm{P}$, Van de Perre $\mathrm{P}$, Auvert $\mathrm{B}$. Association of genital human papillomavirus infection with HIV acquisition: a systematic review and meta-analysis. Sex Transm Infect 2013;89:350-6.

9. Conley LJ, Ellerbrock TV, Bush TJ, Chiasson MA, Sawo D, Wright TC. HIV-1 infection and risk of vulvovaginal and perianal condylomata acuminata and intraepithelial neoplasia: a prospective cohort study. Lancet 2002;359:108-13.

10. Grulich $A E$, van Leeuwen $M T$, Falster MO, Vajdic CM. Incidence of cancers in people with HIV/AIDS compared with immunosuppressed transplant recipients: a meta-analysis. Lancet 2007;370:59-67.

11. D'Souza G, Wiley DJ, Li X, et al. Incidence and epidemiology of anal cancer in the Multicenter AIDS Cohort Study. J Acquir Immune Defic Syndr 2008; 48:491-9. 
12. Patel $P$, Hanson DL, Sullivan PS, et al. Incidence of types of cancer among HIV-infected persons compared with the general population in the United States, 1992-2003. Ann Intern Med 2008; 148:728-36.

13. de Pokomandy A, Rouleau D, Ghattas G, et al. Prevalence, clearance, and incidence of anal human papillomavirus infection in HIV-infected men. J Infect Dis 2009;199:965-73.

14. Hessol NA, Holly EA, Efird JT, et al. Anal intraepithelial neoplasia in a multisite study of HIVinfected and high-risk HIV-uninfected women. AIDS 2009; 23:59-70.

15. Palefsky J. Human papillomavirus-related disease in people with HIV. Curr Opin HIV AIDS 2009;4:52-6.

16. Kreuter A, Wieland U. Human papillomavirus diseases in HIV-infected men who have sex with men. Curr Opin Infect Dis 2009;22:109-14.

17. Kojic EM, Cu-Uvin S, Conley L, et al. Human papillomavirus infection and cytologic abnormalities of the anus and cervix among HIV-infected women in the study to understand the natural history of HIV/AIDS in the era of effective therapy (the SUN study). Sex Transm Dis 2011; 38:253-9.

18. Low AJ, Clayton T, Konate I, et al. Genital warts and infection with human immunodeficiency virus in high-risk women in Burkina Faso: a longitudinal study. BMC Infect Dis 2011;11:20.

19. Poynten IM, Jin F, Templeton DJ, et al. Prevalence, incidence, and risk factors for human papillomavirus 16 seropositivity in Australian homosexual men. Sex Transm Dis 2012;39:726-32.

20. Kahn JA, Burk RD, Squires KE, et al. Prevalence and risk factors for HPV in HIV-positive young women receiving their first HPV vaccination. J Acquir Immune Defic Syndr 2012;61:390-9.

21. Silverberg MJ, Lau B, Justice AC, et al. Risk of anal cancer in HIV-infected and HIV-uninfected individuals in North America. Clin Infect Dis 2012;54:1026-34.

22. Machalek DA, Poynten $M$, Jin $F$, et al. Anal human papillomavirus infection and associated neoplastic lesions in men who have sex with men: a systematic review and meta-analysis. Lancet Oncol 2012;13:487-500.

23. Abraham AG, Strickler HD, Jing $Y$, et al. Invasive cervical cancer risk among HIV-infected women: a North American multi-cohort collaboration prospective study. J Acquir Immune Defic Syndr 2013; 62:405-13.

24. Nicol AF, Grinsztejn B, Friedman RK, et al. Seroprevalence of HPV vaccine types $6,11,16$ and 18 in HIV-infected and uninfected women from Brazil. J Clin Virol 2013;57:147-51.

25. Dartell M, Rasch V, Munk C, Kahesa C, Mwaiselage J, Iftner T, Kjaer SK. Risk factors for high-risk human papillomavirus detection among HIV-negative and HIV-positive women from Tanzania. Sex Transm Dis 2013;40:737-43.

26. Wiley DJ, Li X, Hsu H, et al. Factors affecting the prevalence of strongly and weakly carcinogenic and lower-risk human papillomaviruses in anal specimens in a cohort of men who have sex with men (MSM). PLoS One 2013;8:e79492.

27. Mooij SH, Boot HJ, Speksnijder AG, et al. Oral human papillomavirus infection in HIV-negative and HIV-infected MSM. AIDS 2013;27:2117-28.

28. Videla S, Darwich L, Cañadas MP, et al. Natural history of human papillomavirus infections involving anal, penile, and oral sites among HIV-positive men. Sex Transm Dis 2013;40:3-10.

29. Konopnicki D, Manigart $Y$, Gilles $C$, et al. High-risk human papillomavirus infection in HIV-positive African women living in Europe. J Int AIDS Soc 2013;16:18023.

30. Heard I, Cubie HA, Mesher D, Sasieni P, MACH-1 Study Group. Characteristics of HPV infection over time in European women who are HIV-1 positive. BJOG 2013;120:41-9.

31. Hernandez AL, Efird JT, Holly EA, Berry JM, Jay N, Palefsky JM. Incidence of and risk factors for type-specific anal human papillomavirus infection among HIV-positive MSM. AIDS 2014;28:1341-9.

32. Tong WW, Hillman RJ, Kelleher AD, Grulich AE, Carr A. Anal intraepithelial neoplasia and squamous cell carcinoma in HIV-infected adults. HIV Med 2014;15:65-76.

33. Olesen TB, Munk C, Christensen J, Andersen KK, Kjaer SK. Human papillomavirus prevalence among men in sub-Saharan Africa: a systematic review and meta-analysis. Sex Transm Infect 2014;90:455-62. 
34. Schim van der Loeff MF, Mooij SH, Richel O, de Vries HJ, Prins JM. HPV and anal cancer in HIVinfected individuals: a review. Curr HIV/AIDS Rep 2014;11:250-62.

35. Stier EA, Sebring MC, Mendez AE, Ba FS, Trimble DD, Chiao EY. Prevalence of anal human papillomavirus infection and anal HPV-related disorders in women: a systematic review. Am J Obstet Gynecol 2015 Mar 19.

36. Ananworanich J, Prasitsuebsai W, Kerr SJ, et al. Cervical cytological abnormalities and HPV infection in perinatally HIV-infected adolescents J Virus Erad 2015;1:30-7.

37. Supindham T, Chariyalertsak S, Utaipat $U$, et al. High prevalence and genotype diversity of anal HPV infection among MSM in Northern Thailand. PLoS One 2015;10:e0124499.

38. Welling CA, Mooij SH, van der Sande MA, et al. Association of HIV infection with anal and penile low-risk human papillomavirus infections among men who have sex with men in Amsterdam. Sex Transm Dis 2015;42:297-304.

39. Kojic EM, Kang M, Cespedes MS, et al. Immunogenicity and safety of a quadrivalent human papillomavirus vaccine in HIV-1-infected women. Clin Infect Dis 2014;59:127-35.

40. Palefsky JM, Giuliano AR, Goldstone S, et al. HPV vaccine against anal HPV infection and anal intraepithelial neoplasia. N Engl J Med 2011;365:1576-85.

41. Dochez C, Bogers JJ, Verhelst R, Rees H. HPV vaccines to prevent cervical cancer and genital warts: an update. Vaccine 2014;32:1595-601.

42. Herrero R, González P, Markowitz LE. Present status of human papillomavirus vaccine development and implementation. Lancet Oncol 2015;16:e206-e216.

43. Macartney K, Chiu C, Georgousakis M, Brotherton JML. Safety of human papillomavirus vaccines: a review. Drug Saf 2013;36:393-412.

44. Noronha AS, Markowitz LE, Dunne EF. Systematic review of human papillomavirus vaccine coadministration. Vaccine 2014;32:2670-4.

45. Joint Committee on Vaccination and Immunisation (JCVI). Interim position statement on HPV vaccination of men who have sex with men (MSM) https://www.gov.uk/government/uploads/ system/uploads/attachment_data/file/373531/JCVI_interim_statement_HPV_vacc.pdf

46. Kim J. Targeted human papillomavirus vaccination of men who have sex with men in the USA - a cost-effectiveness modelling analysis. Lancet Infect Dis 2010;10:845-52.

47. Swedish KA, Factor SH, Goldstone SE. Prevention of recurrent high-grade anal neoplasia with quadrivalent human papillomavirus vaccination of men who have sex with men: a nonconcurrent cohort study. Clin Infect Dis 2012;54:891-8.

48. Miltz A, Price H, Shahmanesh M, Copas A, Gilson R. Systematic review and meta-analysis of L1VLP-based human papillomavirus vaccine efficacy against anogenital pre-cancer in women with evidence of prior HPV exposure. PLoS One 2014;9:e90348.

49. Levin $M J$, Moscicki $A B$, Song $L Y$, et al. Safety and immunogenicity of a quadrivalent human papillomavirus (types $6,11,16$, and 18 ) vaccine in HIV-infected children 7 to 12 years old. J Acquir Immune Defic Syndr 2010;55:197-204.

50. Weinberg A, Song LY, Saah A, et al. Humoral, mucosal, and cell-mediated immunity against vaccine and nonvaccine genotypes after administration of quadrivalent human papillomavirus vaccine to HIV-infected children. J Infect Dis 2012;206:1309-18.

51. Kahn JA, Xu J, Kapogiannis BG, Rudy B, et al. Immunogenicity and safety of the human papillomavirus 6, 11, 16, 18 vaccine in HIV-infected young women. Clin Infect Dis 2013;57:735-44.

52. Denny L, Hendricks B, Gordon C, et al. Safety and immunogenicity of the HPV-16/18 ASO4adjuvanted vaccine in HIV-positive women in South Africa: A partially-blind randomised placebocontrolled study. Vaccine 2013;31:5745-53.

53. Wilkin T, Lee JY, Lensing SY, et al. Safety and immunogenicity of the quadrivalent human papillomavirus vaccine in HIV-1-infected men. J Infect Dis 2010;202:1246-53.

54. Giacomet V, Penagini F, Trabattoni D, et al. Safety and immunogenicity of a quadrivalent human papillomavirus vaccine in HIV-infected and HIV-negative adolescents and young adults. Vaccine 2014;32:5657-61. 
55. Rainone V, Giacomet V, Penagini $F$, et al. Human papilloma virus vaccination induces strong human papilloma virus specific cell-mediated immune responses in HIV-infected adolescents and young adults. AIDS 2015;29:739-43.

56. Toft L, Storgaard $M$, Müller $M$, et al. Comparison of the immunogenicity and reactogenicity of Cervarix and Gardasil human papillomavirus vaccines in HIV-infected adults: a randomized, double-blind clinical trial. J Infect Dis 2014;209:1165-73. 


\section{INFLUENZA}

1. Infection and disease: There are three types of influenza viruses - A, B and C. Influenza A and influenza B account for most cases of the disease. Influenza is highly infectious. Transmission occurs through respiratory droplets and aerosols. Severity varies from asymptomatic to fatal infections. Influenza can exacerbate underlying medical conditions and lead to serious complications. The greatest morbidity and risk for complications, hospitalization, and death are seen in very young children, those aged $\geq 65$ years, pregnant women, and patients with underlying conditions including the immunocompromised [1,2]. In 2012, the World Health Organisation (WHO) identified pregnant women as the highest priority group for influenza vaccination [3].

2. Epidemiology: Influenza A viruses undergo changes in the principal surface antigens, haemagglutinin $(\mathrm{H})$ and neuraminidase $(\mathrm{N})$. Minor changes ('antigenic drift') occur progressively from season to season. Major changes ('antigenic shift') result periodically in the emergence of new subtypes that can cause epidemics or pandemics. Influenza B viruses are also subject to antigenic drift but with less frequent changes. Three influenza A pandemics occurred in the last century $(1918,1957$, 1968). The most recent pandemic occurred in 2009 with a novel strain of influenza A/H1N1; a disproportionately high mortality was observed among children, young adults, and pregnant women [4]. Outbreaks of influenza A occur most years. Influenza B causes less extensive outbreaks, usually between outbreaks of influenza $A$. The influenza season is October-May in the northern hemisphere and April-September in the southern hemisphere. In the tropics, influenza may occur all year round.

3. Influenza in HIV-positive adults: HIV infection is associated with increased severity of influenza and greater risk of complications, resulting in excess hospitalisation and mortality during influenza seasons [5-14]. Effective ART reduces the rates of hospitalisations and mortality, although the risk of severe outcomes remains comparable to that of other high-risk groups for which annual influenza vaccination is recommended $[15,16]$. In the recent $2009 \mathrm{~A} / \mathrm{H} 1 \mathrm{~N} 1$ pandemic, HIV-positive adults with advanced immunosuppression or comorbid conditions were found to be at an increased risk of influenza-related complications [17].

4. Influenza vaccine: Influenza vaccines are prepared twice yearly using virus strains considered most likely to be circulating in the forthcoming winter (for Northern and Southern Hemisphere), as recommended by WHO according to global epidemiological surveillance. There are two types of influenza vaccines available in the UK - inactivated and live-attenuated vaccines. Inactivated vaccines are usually multivalent. Trivalent inactivated vaccines (TIVs) typically contain two influenza A strains and one influenza B strain. Quadrivalent preparations contain one additional influenza B virus. Monovalent vaccines are prepared in response to specific epidemiological circumstances such as emergence of a shifted strain. Inactivated vaccines are most commonly made from virus grown in hen eggs. In adults, they are usually given as a single dose by intramuscular injection (or deep subcutaneous injection in those with bleeding disorders), or less commonly by intradermal injection. A live attenuated influenza vaccine for administration by nasal spray is approved for use in the UK in healthy children aged 2 to 18 years. Studies are currently assessing numerous vaccine candidates including inactivated egg-grown and cell-culture derived subunit or whole virus vaccines, adjuvanted vaccines, and live attenuated vaccines. A high-dose (4-times higher antigen content) TIV is licensed in the US for those aged $\geq 65$ years (Fluzone high-dose) [18].

In healthy adults, TIVs provide around $60 \%$ protection against virologically-proven influenza infection [19]. Development of protective antibodies occurs about 2 weeks after vaccination and protection lasts for about 1 year. Although responses to vaccination are often reduced in the elderly and those with underlying conditions, vaccination can still protect against severe disease, complications such as bronchopneumonia, hospital admission, and mortality [20-23]. Inactivated influenza vaccines are safe and well tolerated and are recommended for use in pregnant and breastfeeding women [24]. 
General indications: In the UK, annual influenza vaccination is recommended for all children aged 2-4 years, those aged $\geq 65$ years, adults and children aged over 6 months in clinical risk groups, pregnant women, and health care workers in direct contact with patients. Clinical risk groups include patients with:

- Chronic respiratory, heart, renal, liver, or neurological disease

- Diabetes

- Immunocompromise (including HIV infection)

- Asplenia or splenic dysfunction

- Morbid obesity

5. Influenza vaccine in HIV-positive adults: With inactivated influenza vaccines, antibody responses have been found to be lower in HIV-positive patients compared with HIV-negative controls, and to be correlated with CD4 cell counts and viral load [25-37]. Whilst ART improves responses, the degree of immune restoration remains unclear, with some studies indicating a persistent defect relative to HIVnegative subjects [37-44]. In one recent study, HIV infection worsened age-associated defects in antibody responses to influenza vaccine among women aged above 55 years [44]. One other study comparing HIV-positive and HIV-negative individuals suggested merely quantitative differences in the vaccine responses, thus offering a rationale for boosting strategies in the HIV-positive population [43]. In HIV-positive adults however, administering higher/more frequent doses of standard nonadjuvanted vaccine preparations has not been consistently associated with improved immunogenicity, whilst enhanced responses have been observed with novel adjuvanted preparations [40,45-55]. Data on the clinical efficacy of influenza vaccination in HIV-positive adults are limited. A previous systematic review and meta-analysis concluded that a reasonable estimate could not be derived from available data [56]. A more recent systematic review and meta-analysis set out to assess the efficacy and effectiveness of influenza vaccination in respect to the prevention of all clinical outcomes, including influenza, all-cause hospitalization, pneumonia, and mortality [37]. Three randomized-controlled trials and three cohort studies were identified, including a total of 1562 HIV-positive individuals. In adults (but not in children), TIV prevented laboratory-confirmed influenza with a pooled efficacy of $85 \%$ (95\% confidence interval 22-97\%; evidence quality: moderate); no significant effects on other clinical outcomes were demonstrable (evidence quality: moderate to low; high risk of bias detected in the cohort studies), indicating the need for further studies. A recent randomized-controlled trial of TIV in HIV-positive pregnant women demonstrated a vaccine efficacy of $58 \%(95 \% \mathrm{Cl} 0.2-82 \%)$ [42].

Inactivated influenza vaccines are safe and well tolerated in HIV-positive individuals [26-55]. Injection site reactions are the most frequent side effects. Systemic side effects are uncommon, and include allergic reactions most likely due to hypersensitivity to residual egg protein. The vaccines also appear to be safe when administered to HIV-positive pregnant women [42,57].

6. Antiviral therapy for pre-and post-exposure prophylaxis: Antiviral therapy with either oral oseltamivir or inhaled zanamivir can be used for the pre- and post-exposure prophylaxis of influenza [58]. The efficacy in HIV-positive persons is unknown.

\section{Recommendations for HIV-positive adults}

- We recommend that HIV-positive adults be offered annual influenza vaccination with a parenteral non-replicating vaccine, and this includes HIV-positive pregnant women [1A]

- We recommend the vaccine be given between Sept and early November [1B]. We suggest that depending on the epidemiological circumstances, there is still a potential benefit of vaccination until March [2D]

- We suggest that a quadrivalent vaccine may be preferred where available [1D] 
- We recommend a single vaccine dose be given [1B]. There is insufficient evidence to recommend higher/more frequent doses in order to increase immunogenicity when using the inactivated influenza vaccines currently available in the UK. This area will be kept under review

- We recommend that HIV services, in partnership with primary care, devise strategies to ensure prioritized patients receive annual vaccination, such as patient recall and notification [1C]

- We recommend against the use of replicating live attenuated influenza vaccines in HIV-positive adults [1D]

- We recommend that close contacts of HIV-positive persons be offered annual influenza vaccination, which should be preferably with inactivated rather than live attenuated vaccines where the HIV-positive person is profoundly immunocompromised [1D]

- We recommend that in identified circumstances of exposure, antiviral prophylaxis be considered for patients who are either unvaccinated or unlikely to benefit from vaccination (CD4 counts $<200$ cells/ $\mu \mathrm{L}$ or poor match between vaccine and circulating influenza strain) if at risk of complications, particularly if profoundly immunocompromised [1D]. Expert advice should be sought

\section{References}

1. Kunisaki KM and Janoff EN. Influenza in immunosuppressed populations: a review of infection frequency, morbidity, mortality, and vaccine responses. Lancet Infect Dis 2009;9:493-504.

2. Memoli MJ, Athota R, Reed $S$, et al. The natural history of influenza infection in the severely immunocompromised vs nonimmunocompromised hosts. Clin Infect Dis 2014;58:214-24.

3. World Health Organization. Vaccines against influenza WHO position paper - November 2012. Wkly Epidemiol Rec 2012;87:461-76.

4. Simonsen L, Spreeuwenberg P, Lustig R, et al. Global mortality estimates for the 2009 Influenza Pandemic from the GLaMOR project: a modeling study. PLoS Med 2013;10:e1001558.33.

5. Safrin S, Rush JD and Mills J. Influenza in patients with human immunodeficiency virus infection. Chest 1990;98:33-7.

6. Fine $A D$, Bridges $C B$, De Guzman $A M$, et al. Influenza $A$ among patients with Human Immunodeficiency Virus: an outbreak of infection at a residential facility in New York City. Clin Infect Dis 2001;32:1784-91.

7. Lin JC, Nichol KL. Excess mortality due to pneumonia or influenza during influenza seasons among persons with acquired immunodeficiency syndrome. Arch Intern Med 2001;161 441-6.

8. Boschini $A$, Longo $B$, Caselli $F$, et al. An outbreak of influenza in a residential drug-rehabilitation community. J Med Virol 2006;78:1218-22.

9. Ope MO, Katz MA, Aura B, et al. Risk factors for hospitalized seasonal influenza in rural western Kenya. PloS One 2011;6:e20111.

10. Mor SM, Aminawung JA, Demaria A, Jr. and Naumova EN. Pneumonia and influenza hospitalization in HIV-positive seniors. Epidemiol Infect 2011;139:1317-25.

11. Cohen C, Moyes J, Tempia S, et al. Severe influenza-associated respiratory infection in high HIV prevalence setting, South Africa, 2009-2011. Emerg Infect Dis 2013;19:1766-74.

12. Tempia S, Walaza S, Viboud C, Cohen AL, Madhi SA, et al. Deaths Associated with Respiratory syncytial and influenza viruses among persons $>/=5$ years of age in HIV-prevalent area, South Africa, 1998-2009. Emerg Infect Dis 2015;21:600-8.

13. Cohen C, Moyes J, Tempia S, Groome M, Walaza S, et al. Mortality amongst patients with influenza-associated severe acute respiratory illness, South Africa, 2009-2013. PLoS One 2015;10:e0118884.

14. Sheth AN, Althoff KN, Brooks JT. Influenza susceptibility, severity, and shedding in HIV-infected adults: a review of the literature. Clin Infect Dis 2011;52:219-27.

15. Neuzil KM, Coffey CS, Mitchel EF, Griffin MR. Cardiopulmonary hospitalizations during influenza season in adults and adolescents with advanced HIV infection. J Acquir Immune Defic Syndr 2003;34:304-7. 
16. Cohen C, Simonsen L, Sample J, et al. Influenza-related mortality among adults aged 25-54 years with AIDS in South Africa and the United States of America. Clin Infect Dis 2012;55:996-1003.

17. Sheth AN, Patel P, Peters PJ. Influenza and HIV: lessons from the 2009 H1N1 influenza pandemic. Curr HIV/AIDS Rep 2011;8:181-91.

18. CDC. Advisory Committee on Immunization Practices (ACIP) recommended immunization schedule for adults aged 19 years or older - United States, 2014. MMWR. 2014;63:110-112.

19. Demicheli V, Jefferson T, Al-Ansary LA, Ferroni E, Rivetti A, Di Pietrantonj C. Vaccines for preventing influenza in healthy adults. Cochrane Database Syst Rev 2014;3:CD001269.

20. Mangtani P, Cumberland P, Hodgson CR, Roberts JA, Cutts FT, Hall AJ. A cohort study of the effectiveness of influenza vaccine in older people, performed using the United Kingdom general practice research database. J Infect Dis 2004;190:1-10.

21. Baxter R, Ray GT, Fireman BH. Effect of influenza vaccination on hospitalizations in persons aged 50 years and older. Vaccine 2010; 28:7267-72.

22. Puig-Barbera J, Diez-Domingo J, Arnedo-Pena A, et al. Effectiveness of the 2010-2011 seasonal influenza vaccine in preventing confirmed influenza hospitalizations in adults: a case-case comparison, case-control study. Vaccine 2012;30:5714-20.

23. Kwong JC, Campitelli MA, Gubbay JB, et al. Vaccine effectiveness against laboratory-confirmed influenza hospitalizations among elderly adults during the 2010-2011 season. Clin Infect Dis 2013;57:820-7.

24. Naleway AL, Irving SA, Henninger ML, et al. Safety of influenza vaccination during pregnancy: a review of subsequent maternal obstetric events and findings from two recent cohort studies. Vaccine 2014;32:3122-7.

25. Nelson KE, Clements ML, Miotti P, Cohn S, Polk BF. The influence of human immunodeficiency virus (HIV) infection on antibody responses to influenza vaccines. Ann Intern Med 1988;109:383-8.

26. Kroon FP, van Dissel JT, de Jong JC, van Furth R. Antibody response to influenza, tetanus and pneumococcal vaccines in HIV-seropositive individuals in relation to the number of CD4+ lymphocytes. AIDS 1994;8:469-76.

27. Iorio AM, Alatri A, Francisci D, et al. Immunogenicity of influenza vaccine (1993-94 winter season) in HIV-seropositive and -seronegative ex-intravenous drug users. Vaccine 1997;15:97-102.

28. Fowke KR, D'Amico R, Chernoff DN, et al. Immunologic and virologic evaluation after influenza vaccination of HIV-1-infected patients. AIDS 1997;11:1013-21.

29. Fuller JD, Craven DE, Steger KA, Cox N, Heeren TC, Chernoff D. Influenza vaccination of human immunodeficiency virus (HIV)-infected adults: impact on plasma levels of HIV type 1 RNA and determinants of antibody response. Clin Infec Dis 1999;28:541-7.

30. Amendola A, Boschini A, Colzani D, et al. Influenza vaccination of HIV-1-positive and HIV-1negative former intravenous drug users. J Med Virol 2001;65:644-8.

31. Yamanaka $H$, Teruya $K$, Tanaka $M$, et al. Efficacy and immunologic responses to influenza vaccine in HIV-1-infected patients. J Acquir Immune Defic Syndr 2005;39:167-73.

32. Tebas $P$, Frank I, Lewis M, et al. Poor immunogenicity of the H1N1 2009 vaccine in well controlled HIV-infected individuals. AIDS 2010;24:2187-92.

33. Crum-Cianflone NF, Eberly LE, Duplessis C, et al. Immunogenicity of a monovalent 2009 influenza A (H1N1) vaccine in an immunocompromised population: a prospective study comparing HIVinfected adults with HIV-uninfected adults. Clin Infect Dis 2011;52:138-46.

34. Yanagisawa N, Maeda K, Ajisawa A, et al. Reduced immune response to influenza A (H1N1) 2009 monovalent vaccine in HIV-infected Japanese subjects. Vaccine 2011;29:5694-8.

35. Tiu CT, Lin YS, Pagala M, et al. Antibody response to inactivated influenza A (H1N1) 2009 monovalent vaccine in patients with and without HIV. J Acquir Immune Defic Syndr 2011;58:e99102.

36. Parmigiani A, Alcaide ML, Freguja R, et al. Impaired antibody response to influenza vaccine in HIVinfected and uninfected aging women is associated with immune activation and inflammation. PloS One 2013;8:e79816. 
37. Remschmidt C, Wichmann O, Harder T. Influenza vaccination in HIV-infected individuals: systematic review and assessment of quality of evidence related to vaccine efficacy, effectiveness and safety. Vaccine 2014;32:5585-92.

38. Kroon FP, Rimmelzwaan GF, Roos MT, et al. Restored humoral immune response to influenza vaccination in HIV-infected adults treated with highly active antiretroviral therapy. AIDS 1998;12:F217-23.

39. Launay O, Desaint C, Durier C, et al. Safety and immunogenicity of a monovalent 2009 influenza A/H1N1v vaccine adjuvanted with AS03A or unadjuvanted in HIV-infected adults: a randomized, controlled trial. J Infect Dis 2011;204:124-34.

40. Durier C, Desaint C, Lucht F, et al. Long-term immunogenicity of two doses of 2009 A/H1N1v vaccine with and without ASO3(A) adjuvant in HIV-1-infected adults. AIDS 2013;27:87-93.

41. Nunes $M C$, Cutland $C L$, Dighero $B$, et al. Kinetics of hemagglutination-inhibition antibodies following maternal influenza vaccination in HIV-infected and HIV-uninfected women-infant dyads. J Infect Dis 2015 Jun 16. pii:jiv339

42. Madhi SA, Cutland $C L$, Kuwanda $L$, et al. Influenza vaccination of pregnant women and protection of their infants. N Engl J Med 2014;371:918-31.

43. Weinberg A, Muresan P, Richardson KM, et al. Determinants of vaccine immunogenicity in HIVinfected pregnant women: analysis of $B$ and $T$ cell responses to pandemic H1N1 monovalent vaccine. PLoS One 2015;10:e0122431.

44. George VK, Pallikkuth S, Parmigiani A, Alcaide M, Fischl M, Arheart KL, Pahwa S. HIV infection worsens age-associated defects in antibody responses to influenza vaccine. J Infect Dis 2015;211:1959-68.

45. Iorio AM, Francisci D, Camilloni B, et al. Antibody responses and HIV-1 viral load in HIV-1seropositive subjects immunised with either the MF59-adjuvanted influenza vaccine or a conventional non-adjuvanted subunit vaccine during highly active antiretroviral therapy. Vaccine 2003;21:3629-37.

46. Bickel $\mathrm{M}$, von Hentig $\mathrm{N}$, Wieters I, et al. Immune response after two doses of the novel split virion, adjuvanted pandemic H1N1 influenza A vaccine in HIV-1-infected patients. Clin Infect Dis 2011;52:122-7.

47. Cooper C, Thorne A, Klein M, et al. Immunogenicity is not improved by increased antigen dose or booster dosing of seasonal influenza vaccine in a randomized trial of HIV infected adults. PloS One 2011; 6:e17758.

48. Hatakeyama S, Iwatsuki-Horimoto K, Okamoto $\mathrm{K}$, et al. Unadjuvanted pandemic H1N1 influenza vaccine in HIV-1-infected adults. Vaccine 2011; 29:9224-8.

49. Ho J, Moir S, Wang W, et al. Enhancing effects of adjuvanted 2009 pandemic H1N1 influenza A vaccine on memory B-cell responses in HIV-infected individuals. AIDS 2011;25:295-302.

50. Nielsen $A B$, Nielsen HS, Nielsen L, Thybo $S$ and Kronborg G. Immune response after one or two doses of pandemic influenza A (H1N1) monovalent, AS03-adjuvanted vaccine in HIV infected adults. Vaccine 2012;30:7067-71.

51. Santini-Oliveira M, Camacho LA, Souza TM, et al. H1N1pdm09 adjuvanted vaccination in HIVinfected adults: a randomized trial of two single versus two double doses. PloS One 2012;7:e39310.

52. El Sahly HM, Davis C, Kotloff K, et al. Higher antigen content improves the immune response to 2009 H1N1 influenza vaccine in HIV-infected adults: a randomized clinical trial. J Infect Dis 2012;205:703-12.

53. Cooper C, Klein M, Walmsley $S$, et al. High-level immunogenicity is achieved vaccine with adjuvanted pandemic $\mathrm{H} 1 \mathrm{~N} 1$ (2009) and improved with booster dosing in a randomized trial of HIVinfected adults. HIV Clin Trials 2012;13:23-32.

54. Lagler H, Grabmeier-Pfistershammer K, Touzeau-Romer V, et al. Immunogenicity and tolerability after two doses of non-adjuvanted, whole-virion pandemic influenza A (H1N1) vaccine in HIVinfected individuals. PloS One 2012;7:e36773. 
55. McKittrick N, Frank I, Jacobson JM, et al. Improved immunogenicity with high-dose seasonal influenza vaccine in HIV-infected persons: a single-center, parallel, randomized trial. Ann Intern Med 2013;158:19-26.

56. Anema A, Mills E, Montaner J, Brownstein JS, Cooper C. Efficacy of influenza vaccination in HIVpositive patients: a systematic review and meta-analysis. HIV Med 2008; 9:57-61.

57. Abzug MJ, Nachman SA, Muresan P, et al. Safety and immunogenicity of 2009 pH1N1 vaccination in HIV-infected pregnant women. Clin Infect Dis 2013;56:1488-97.

58. Jefferson $T$, Jones $M A$, Doshi $P$, et al. Neuraminidase inhibitors for preventing and treating influenza in healthy adults and children. Cochrane Database Syst Rev 2014;4:CD008965. 


\section{JAPANESE ENCEPHALITIS}

1. Infection and disease: Japanese encephalitis virus (JEV) is a mosquito-borne flavivirus [1]. Approximately 1:250 infections become clinically apparent. Severity ranges from a flu-like illness to life-threatening encephalitis. The case-fatality ratio of patients with encephalitis is $20-30 \%$, and survivors have a $30 \%$ risk of permanent sequelae. Infection during the first or second trimesters of pregnancy can cause miscarriage. No antiviral therapy is available.

3. Epidemiology: JEV is a leading cause of encephalitis in Asia, mainly affecting the South-East and Western Pacific regions [1]. Infections occur predominantly in rice growing and pig farming rural areas, and occasionally in urban areas. The highest transmission rates are during and just after wet seasons, but seasonal patterns vary both within individual countries and from year to year.

2. JEV in HIV-positive adults: It is not known whether the natural history of Japanese encephalitis is modified by HIV infection.

4. JEV vaccine: Several JEV vaccines are available globally, including inactivated mouse brain-derived vaccines (no longer recommended), inactivated Vero cell-derived vaccines, live attenuated vaccines, and live recombinant (chimeric) vaccines [1,2]. The internationally licensed IXIARO vaccine is Vero cellderived and available in the UK. The IXIARO vaccine is safe and immunogenic in healthy subjects $[1,2]$. The vaccine is given by parenteral administration. The IXIARO vaccine is given to adults in two doses 24-28 days apart. Following completion of the primary course, a booster is recommended after 12-24 months for those at continued risk. Responses are long-lived, and emerging data suggest that further booster doses may be scheduled 10 years following the first booster [3]. A randomised clinical trial evaluated short-term antibody responses to an accelerated course of 2 vaccine doses 1 week apart (and co-administered with rabies vaccine) in healthy persons aged 18-65 years [4]. Short-term immunogenicity with the accelerated course was non-inferior to that measured with the standard schedule.

General indications: In the UK, the IXIARO vaccine is offered to travellers to South and South-East Asia and the Far East if staying for a month or longer in endemic areas during the transmission season, especially if travel will include rural areas. Other travellers with shorter exposure periods are immunised if the risk is considered sufficient. The vaccine is also recommended for those who are going to reside in an area where JEV is endemic or epidemic, and for those at risk of occupational exposure (e.g., laboratory workers).

5. JEV vaccine HIV-positive adults: No studies have been published on the safety, immunogenicity, and clinical efficacy of JEV vaccination in HIV-positive adults. Studies in children show that inactivated vaccines are safe and immunogenic [1]. Immune responses are reduced relative to HIV-negative children, although improved by ART [5-7]. There is insufficient evidence for modifying dosing or boosting requirements relative to standard recommendations.

\section{Recommendations for HIV-positive adults}

- We recommend that HIV-positive adults who are at risk of JEV exposure (e.g., through travel or occupation) be offered an inactivated Vero cell-derived JEV vaccine (typically IXIARIO), with 2 doses given 24-28 days apart [1C]

- We recommend against the use of an abbreviated vaccination schedule (typically 2 doses 1 week apart), unless there is an urgent need to complete primary vaccination prior to a risk of exposure [1C] 
- We recommend that following completion of the primary course, a booster vaccine dose is offered 12-24 months later for those at continued risk, with a further booster planned after 10 years $[1 \mathrm{C}]$

\section{References}

1. World Health Organisation. Japanese encephalitis vaccines: WHO position paper - February 2015. Wkly Epidemiol Rec 2015;90:69-87.

2. Wang SY, Cheng XH, Li JX, Li XY, Zhu FC, Liu P. Comparing the immunogenicity and safety of 3 Japanese encephalitis vaccines in Asia-Pacific area: A systematic review and meta-analysis. Hum Vaccin Immunother 2015;11:1418-25.

3. Paulke-Korinek M, Kollaritsch H, Kundi M, Zwazl I, Seidl-Friedrich C, Jelinek T. Persistence of antibodies six years after booster vaccination with inactivated vaccine against Japanese encephalitis. Vaccine 2015 May 30.

4. Jelinek T, Burchard GD, Dieckmann S, et al. Short-term immunogenicity and safety of an accelerated pre-exposure prophylaxis regimen with Japanese encephalitis vaccine in combination with a rabies vaccine: a phase iii, multicenter, observer-blind study. J Travel Med 2015 May 22.

5. Rojanasuphot S, Shaffer N, Chotpitayasunondh T, et al. Response to JE vaccine among HIV-infected children, Bangkok, Thailand. Southeast Asian J Trop Med Public Health 1998;29:443-50

6. Puthanakit T, Aurpibul L, Yoksan S, Sirisanthana T, Sirisanthana V. Japanese encephalitis vaccination in HIV-infected children with immune recovery after highly active antiretroviral therapy. Vaccine 2007;25:8257-61.

7. Puthanakit T, Aurpibul L, Yoksan S, Sirisanthana T, Sirisanthana V. A 3-year follow-up of antibody response in HIV-infected children with immune recovery vaccinated with inactivated Japanese encephalitis vaccine. Vaccine 2010;28:5900-2.

8. Chokephaibulkit K, Plipat N, Yoksan S, et al. A comparative study of the serological response to Japanese encephalitis vaccine in HIV-infected and uninfected Thai children. Vaccine 2010;28:3563-6. 


\section{MEASLES, MUMPS AND RUBELLA}

1. Infection and disease: Measles and mumps are paramyxoviruses, whereas rubella is a togavirus. Measles, mumps and rubella are transmitted by the respiratory route. Measles is highly communicable and carries a high risk of complications including hepatitis $(60 \%)$, diarrhoea (8\%), otitis media (7\%), pneumonia (1-6\%) and encephalitis (0.1\%), leading to death in 2:1000 cases in developed countries. Up to $30 \%$ of mumps infections are asymptomatic and symptomatic infections are typically in the form of parotitis; neurological complications, usually mild aseptic meningitis, occur in up to $15 \%$ of symptomatic cases but permanent neurological sequelae are rare, including deafness 1 : 20,000 cases). Other complications of mumps are orchitis (20-50\% of post-pubertal males) and pancreatitis (2-5\%); the mortality rate is $1-3: 10,000$ cases. Rubella is usually a mild illness; in up to $70 \%$ of adult women it is complicated by arthralgia or arthritis. Pregnant women are at increased risk of fatal pneumonitis and miscarriage after measles and of foetal damage after rubella infection.

2. Epidemiology: Measles, mumps and rubella remain common diseases in many countries of the world. Patients are at risk of exposure while travelling abroad, or within the UK [1-3]. There has been a substantial increase in measles cases reported in the UK in recent years due to a reduction in vaccine coverage in children, with ongoing risk of community-wide transmission. This reflects poor herd immunity and the high secondary attack rate of measles in a susceptible population.

3. Measles, Mumps and Rubella in HIV-positive adults: There is no evidence to suggest that mumps and rubella are more severe in the HIV setting. However, measles can be life-threatening in people with advanced HIV infection [4-6]. There may be no rash, and complications such as pneumonitis and encephalitis may present several months after the initial infection. A history of measles immunization is not a reliable predictor of measles IgG seropositive status and seropositivity does not guarantee protection $[7,8]$.

4. MMR vaccine: The MMR vaccine contains replicating live attenuated viruses. The vaccine is given by parenteral administration. In adults, two doses are required to confer protection against measles, with the second dose given at any time but at least one month after the first. MMR is highly immunogenic and clinically efficacious in preventing measles, mumps and rubella in children [9]. Measles IgG develop in $90 \%$ of healthy subjects after one dose of MMR, and $99 \%$ after two doses. Side effects include:

- Fever and rash (5-15\% of vaccine recipients), usually starting 7-12 days after vaccination and lasting 1-2 days

- Arthralgia and/or arthritis (up to $25 \%$ of women), usually mild and transient

- Transient lymphadenopathy

- Parotitis and deafness (rare)

- Clinically apparent thrombocytopenia (<1 per 30,000 doses)

- Neurological complications, including aseptic meningitis, encephalitis and encephalopathy $(<1: 1,000,000$ doses $)$

- Allergic reaction; severe anaphylaxis is rare $(<1: 1,000,000$ doses $)$

With the exception of allergic reactions, side effects are less frequent following the first dose and occur primarily among the small proportion of persons who did not respond to the first dose. The MMR vaccine is contraindicated in immunocompromised patients and in pregnancy, and pregnancy should be avoided for one month after vaccination. The vaccine is not contraindicated in breastfeeding women. MMR vaccine recipients do not act as a potential source of infection to their contacts.

5. MMR vaccine in HIV-positive adults: Vaccine responses are reduced in HIV-positive patients [7, 1012], although improved by effective ART [13-18]. Revaccination of previously immunised individuals following immune reconstitution on ART provides a strategy for improving seroconversion rates and 
magnitude and longevity of vaccine-induce responses. While the MMR vaccine is also contraindicated in persons who are severely immunocompromised, including HIV-positive patients with CD4 counts $<200$ cells $/ \mu \mathrm{L}$, it is in general safe in HIV-positive patients with less profound immunocompromise [1318]. Prior to 1993, it was advocated for both asymptomatic and symptomatic patients. A change in policy was prompted by a case of fatal measles-vaccine-associated pneumonitis in a severely immunocompromised man, presenting almost one year after vaccination [19]. Vaccine-associated pneumonitis and encephalitis have also been described in severely immunocompromised patients. Serious illnesses have not been reported in HIV-positive individuals in association with mumps or rubella vaccine administration.

6. Post-exposure prophylaxis: Following a contact with a case of measles, passive immune prophylaxis with intramuscular Human Normal Immunoglobulin (HNIG) is indicated in selected groups, including immunocompromised patients. In most cases, an urgent (within 3 days of contact) measles IgG test is requested to decide upon the need for prophylaxis. A prophylactic dose of HNIG is not likely to benefit measles IgG-positive contacts, although patients with profound deficits of cellular immunity (typically those with primary immunodeficiency) may still benefit. HNIG is given as soon as possible after the contact, ideally within three days, and no later than six days $[20,21]$. In selected cases, intravenous immunoglobulin (IVIG) may be considered up to 18 days after exposure, in which case it may attenuate rather than prevent the infection. There is no evidence to support the use of HNIG following exposure to mumps or rubella. Because of the rapid induction of the measles antibody, contacts of measles may be protected by MMR vaccination administered within three days of exposure. This is not the case for the mumps and rubella components. There are no data regarding the use of postexposure MMR vaccination following measles exposure in individuals with HIV or other immunocompromised patients.

\section{Recommendations for HIV-positive adults}

- We recommend that HIV-positive adults be screened for measles IgG regardless of a history of childhood vaccination [1B]

- We recommend that measles seronegative patients with CD4 counts $>200$ cells $/ \mu \mathrm{L}$ who are clinically stable are offered 2 doses of the MMR vaccine at an interval of at least 1 month [1B]

- We suggest that based on the likelihood of exposure, vaccination may be postponed in patients with CD4 counts $>200$ cells/ $\mu \mathrm{L}$ that are not yet established on ART [2C]

- We recommend that in selected circumstances when measles seronegative patients are at a significant risk of exposure but cannot receive the MMR vaccine due to a low CD4 count, patients be offered pre-exposure prophylaxis with HNIG [1C]. Any protection afforded will be short-lived ( $\sim 3$ weeks)

- We recommend that after a recognised exposure to measles, HIV-positive adults be screened for measles IgG within 3 days of exposure and regardless of a history of previous vaccination (although prophylaxis should not be delayed while waiting for the results) [1C]. We recommend that a risk assessment be undertaken about the need for and mode of post-exposure prophylaxis, along the following guidelines:

- Measles seronegative, CD4 count $>200$ cells $/ \mu \mathrm{L}$, preferably with stable viral load suppression on ART: MMR vaccine within 3 days of contact [1D] or HNIG within 6 days of contact [1C]

- Other measles seronegative: HNIG within 6 days of contact [1C] or IVIG up to 18 days after contact [1D]

- CD4 count $<200$ cells/ $\mu$ L (regardless of measles IgG serostatus): HNIG within 6 days of contact [1C] or in selected high-risk cases IVIG up to 18 days after contact [1D] 
- We recommend that HIV-positive women of child-bearing age are screened for rubella IgG if their rubella IgG status is unknown, and that rubella seronegative women be offered MMR vaccination provided their CD4 count is $>200$ cells $/ \mu \mathrm{L}$ and they are not pregnant [1C]

- We suggest that either one MMR vaccine dose followed 4 weeks later by repeat rubella serology and revaccination if required, or 2 vaccine doses 1 month apart may be considered acceptable options for rubella seronegative women who are measles seropositive [2C]. Women who are also Measles seroneagtive should receive 2 vaccine doses 1 month apart [1B]

\section{References}

1. Jansen VA, Stollenwerk N, Jensen HJ, Ramsay ME, Edmunds WJ, Rhodes CJ. Measles outbreaks in a population with declining vaccine uptake. Science 2003; 301:804.

2. Vivancos R, Keenan A, Farmer S, et al. An ongoing large outbreak of measles in Merseyside, England, January to June 2012. Euro Surveill 2012;17:pii=20226.

3. European Centre for Disease Prevention and Control. Measles and rubella monitoring, February 2014 - Reporting on January-December 2013 surveillance data and epidemic intelligence data to the end of February 2014. Stockholm: ECDC; 2014.

4. Kaplan LJ, Daum RS, Smaron M, McCarthy CA. Severe measles in immunocompromised patients. JAMA 1992;267:1237-41.

5. Mustafa MM, Weitman SD, Winick NJ, Bellini WJ, Timmons CF, Siegel JD. Subacute measles encephalitis in the young immunocompromised host: report of 2 cases diagnosed by polymerase chain reaction and treated with ribavirin and review of the literature. Clin Infect Dis 1993;16:65460

6. Moss WJ, Fisher C, Scott S, et al. HIV type 1 Infection Is a risk factor for mortality in hospitalized Zambian children with measles. Clin Infect Dis. 2008;46:523-7.

7. Belaunzarán-Zamudio PF, García-León ML, Wong-Chew RM, et al. Early loss of measles antibodies after MMR vaccine among HIV-infected adults receiving HAART. Vaccine 2009;27:7059-64.

8. Palumbo P, Hoyt L, Demasio K, Oleske J, Connor E. Population-based study of measles and measles immunization in human immunodeficiency virus-infected children. Pediatr Infect Dis J 1992;11:1008-14.

9. Demicheli V, Rivetti A, Debalini MG, Di Pietrantonj C. Vaccines for measles, mumps and rubella in children. Cochrane Database Syst Rev 2012;2:CD004407.

10. Sprauer MA, Markowitz LE, Nicholson JK, et al. Response of human immunodeficiency virusinfected adults to measles-rubella vaccination. J Acquir Immune Defic Syndr 1993; 6: 1013-1016.

11. Wallace MR, Hooper DG, Graves SJ, Malone JL. Measles seroprevalence and vaccine response in HIV-infected adults. Vaccine 1994; 12: 1222-1224.

12. Stermole BM, Grandits GA, Roediger MP, et al. Long-term safety and serologic response to measles, mumps, and rubella vaccination in HIV-1 infected adults. Vaccine 2011;29:2874-80

13. Berkelhamer S, Borock E, Elsen C, Englund J, Johnson D. Effect of highly active antiretroviral therapy on the serological response to additional measles vaccinations in humanimmunodeficiency virus-infected children. Clin Infect Dis 2001;32:1090-94.

14. Farquhar C, Wamalwa D, Selig S, et al. Immune responses to measles and tetanus vaccines among Kenyan human immunodeficiency virus type 1 (HIV-1)-infected children pre- and post-highly active antiretroviral therapy and revaccination. Pediatr Infect Dis J 2009;28:295-9.

15. Aurpibul L, Puthanakit T, Sirisanthana T, Sirisanthana V. Persistence of measles, mumps, and rubella protective antibodies 3 years after revaccination in HIV-infected children receiving antiretroviral therapy. Clin Infect Dis 2010;50:1415-8.

16. Scott $P$, Moss WJ, Gilani Z, Low N. Measles vaccination in HIV-infected children: systematic review and meta-analysis of safety and immunogenicity. J Infect Dis 2011;204 (Suppl 1):S164-78. 
17. Abzug MJ, Qin $M$, Levin MJ, et al. Immunogenicity, immunologic memory, and safety following measles re-vaccination in HIV-infected children receiving highly active antiretroviral therapy. J Infect Dis 2012;206:512-22.

18. Mclean HQ, Fiebelkorn AP, Temte JL, Wallace GS. Prevention of measles, rubella, congenital rubella syndrome, and mumps, 2013: summary recommendations of the Advisory Committee on Immunization Practices (ACIP). MMWR Morb. Mortal. Wkly Rep 2013;62(RR04):1-34.

19. Centers for Disease Control and Prevention. Measles pneumonitis following Measles-MumpsRubella vaccination of a patient with HIV infection, 1993. Morbid Mortal Wkly Rep 1996;45:603-6.

20. Ramsay M, Manikkavasagan G, Brown K, Craig L. Post exposure prophylaxis for measles: Health Protection Agency. Revised guidance May 2009. Available from: https://www.gov.uk/government/uploads/system/uploads/attachment_data/file/327787/Post_e xposure_prophylaxis_for_measles_May_2009.pdf_(Access date 07/07/2015).

21. Young MK, et al. Post-exposure passive immunisation for preventing measles. Cochrane Database Syst Rev 2014;4:CD010056. 


\section{MENINGOCOCCUS}

1. Infection and disease: Neisseria meningitidis is a gram-negative bacterium. There are at least 12 capsular groups including the clinically important A, B, C, Y, and W135. Around 5-11\% of adults carry the bacterium in the nasopharynx in the absence of symptoms. Transmission occurs via the respiratory route during close contact and is often associated with overcrowded conditions. $N$. meningitidis is a common cause of meningitis and septicaemia in children and young adults, with a high risk of mortality or permanent sequelae. The case fatality rate is less than $10 \%$ overall. Less common manifestations include myocarditis, endocarditis, pericarditis, arthritis, conjunctivitis, urethritis, pharyngitis, and cervicitis. It is not fully understood why the disease develops in some individuals but not in others. Patients with anatomic or functional asplenia and those with complement deficiencies are at an increased risk of disease.

2. Epidemiology: Following the widespread use of group $C$ conjugate vaccines, group $B$ is now the major cause of bacterial meningitis and septicaemia in young children in Europe, and accounts for most cases of invasive meningococcal disease (IMD) in the UK. In June 2015 Public Health England declared a national incident related to the rapid and accelerating increase in cases of IMD caused by group W [1]. In the US, groups C, B, and $Y$ account for $35 \%, 32 \%$, and $26 \%$ of isolates, respectively. Groups A and W135 are common epidemic strains in sub-Saharan Africa and the Middle East, respectively. Proof of vaccination within the past three years is required for visitors arriving in Saudi Arabia for the Hajj and Umrah pilgrimages. Outbreaks of meningococcal infection have been observed in university campuses, and have also been reported among men who have sex with men (MSM) in Europe and North America. In 2012, the incidence rate of IMD among MSM aged 18-64 years in New York City was 12.6 per 100,000 persons, compared with 0.16 per 100,000 persons among other males of the same age [2].

3. Meningococcus in HIV-positive adults: Recent data indicate that HIV-positive patients remain at increased risk of IMD in the ART era [3-5]. In an observational study from New York City, Miller et al. identified 263 (mostly unvaccinated) patients with IMD of whom 40 were HIV-positive [4]. HIV-positive cases differed from HIV-negative patients with IMD in being more often male, non-white, smokers, and presenting with meningococcal septicaemia rather than meningitis. The relative risk for IMD amongst HIV patients was overall 10.0 (95\% Cl 7.2-14.1), and increased in those with CD4 count $<200$ cells $/ \mu \mathrm{L}$ and viral load $>400$ copies $/ \mathrm{mL}$. Similar results were obtained from an observational study in South Africa, which indicated also that patients with HIV had double the risk of death [5]. HIV infection alone is not currently an indication for meningococcal vaccination [6].

4. Meningococcus vaccine: Different types of meningococcal vaccine are currently available including a polysaccharide vaccine (no longer recommended for routine use), conjugate vaccines, and multicomponent vaccines. The conjugated vaccines MenC and MenACWY are directed against group $C$ and groups $A, C W$, and $Y$, respectively. The multicomponent MenB vaccines are directed against group B. The choice of vaccine is related to age, epidemiological circumstances, and previous vaccination history. The vaccines are given by parenteral administration. Meningococcal vaccines are highly immunogenic and effective; they induce serogroup-specific protection. Fever and injection site reactions are the most common adverse events reported. More serious complications are very rare.

General indications: Indications for meningococcal vaccination are evolving rapidly in the UK. MenC is part of the infant vaccination programme and is also indicated for adults aged less than 25 years who have never received the vaccine, received the last MenC vaccine dose before 10 years of age, or have an uncertain vaccination history. In March 2015, the 4 CMenB vaccine was included in the UK infant vaccination programme, but no routine use has yet been indicated for those over 11 years of age. In June 2015, MenACWY was recommended for adolescents and university entrants. MenC, MenACWY, and/or MenB are also indicated for patients at risk of disease, mainly comprising those with asplenia, 
splenic dysfunction or complement disorders (including those on complement inhibitor treatment). MenACWY is indicated for travellers that are at recognised risk based on itinerary, duration of stay and planned activities. In North America, targeted vaccination of MSM has been recommended in some states. Vaccination is also used during outbreaks of meningococcal infection with vaccine serogroups to reduce the number of secondary cases.

5. Meningococcus vaccine in HIV-positive adults: Several reports of adequate serological responses to meningococcus vaccination are available, generally showing better responses in those with less advanced disease, and no major adverse reactions [7-11]. The immunogenicity and safety of MenACWY in HIV-positive children and young adults (aged 2-24) has been reported from the P1065 study in the USA [8-10]; one study in Brazilian children reported on the immunogenicity and safety of the MenC vaccine [11]. In the P1065 study, response rates to a single vaccine dose varied from $55-86 \%$ across the different serogroups, with higher response rates in younger children and those with higher CD4 cell counts and lower viral load. Response rates increased with a second dose of vaccine. In the Brazilian study, the response rate to a single dose of MenC vaccine was $72 \%$, increasing to $81 \%$ when non-responders received a second dose. In both of these studies adverse events were rare and compatible with studies in HIV-negative subjects.

6. Post-exposure prophylaxis: Close contacts of confirmed cases of meningococcal infection are offered antibiotic prophylaxis (e.g., ciprofloxacin) and appropriate vaccination.

\section{Recommendations for HIV-positive adults}

- We recommend that HIV-positive adults follow the general indications for meningococcal vaccination and be offered vaccination where indicated [1B]. The categories and recommended vaccine currently comprise:

- Those aged $<25$ years of age who have not been previously vaccinated, have uncertain vaccination history, or received the last MenC vaccine below the age of 10 years - MenC [1B] and MenACWY [1B], and possibly MenB [1C], according to national guidance

- Have functional or anatomic asplenia or persistent complement component deficiency MenC, MenB, and/or MenACWY, according to vaccination history [1B]

- Are at risk of exposure through travel - MenACWY [1B]

- Are at risk of exposure through an outbreak - MenC [1B], MenB [1C], or MenACWY [1B], according to the epidemiological scenario, and including MSM who may be exposed to outbreaks due to residence, travel, or social interactions

- We recommend that HIV-positive patients are offered 2 vaccine doses at the interval of 2 months in order to increase immunogenicity [1C]

- We recommend that patients receiving MenACWY are offered a booster dose every 5 years if at ongoing risk through travel or due to underlying conditions [2C]

- This guidance should be interpreted in the context of national epidemiological data and applied according to the evolving national vaccination programme [GPP]

- We recommend that HIV-positive adults who are close contacts of meningococcal disease be offered antibiotic prophylaxis and appropriate vaccination [1C]

\section{References}

1. Public Health England. MenACWY vaccine introduction. June 2015. https://www.gov.uk/government/publications/menacwy-vaccine-introduction [accessed 06/07/2015]

2. CDC. Notes from the field: serogroup $C$ invasive meningococcal disease among men who have sex with men - New York City, 2010-2012. MMWR Morb Mortal Wkly Rep 2013;61:1048. 
3. Simon MS, Weiss D, Gulick RM. Invasive meningococcal disease in men who have sex with men. Ann Intern Med 2013;159:300.

4. Miller L, Arakaki L, Ramautar A, et al. Elevated risk for invasive meningococcal disease among persons with HIV. Ann Intern Med 2014;160:30-7.

5. Cohen C, Singh E, Wu HM, et al. Increased incidence of meningococcal disease in HIV-infected individuals associated with higher case-fatality ratios in South Africa. AIDS 2010;24:1351-60.

6. Cohn AC, MacNeil JR, Clark TA, et al. Prevention and control of meningococcal disease: recommendations of the Advisory Committee on Immunization Practices (ACIP). MMWR Recomm Rep 2013;62(RR-2):1.

7. Rubin LG, Levin MJ, Ljungman P, et al. 2013 IDSA clinical practice guideline for vaccination of the immunocompromised hosts. Clin Infect Dis 2014;58:e44.

8. Siberry GK, Williams PL, Lujan-Zilbermann J, et al. Phase $\mathrm{I} / \mathrm{II}$, open-label trial of safety and immunogenicity of meningococcal (groups $A, C, Y$, and $W-135$ ) polysaccharide diphtheria toxoid conjugate vaccine in human immunodeficiency virus-infected adolescents. Pediatr Infect Dis J 2010;29:391-6.

9. Lujan-Zilbermann J, Warshaw MG, Williams PL, et al. Immunogenicity and safety of 1 vs 2 doses of quadrivalent meningococcal conjugate vaccine in youth infected with human immunodeficiency virus. J Pediatr 2012;161:676-81.

10. Siberry GK, Warshaw MG, Williams PL, et al. Safety and immunogenicity of quadrivalent meningococcal conjugate vaccine in 2- to 10-year-old human immunodeficiency virus-infected children. Pediatr Infect Dis J 2012;31:47-52.

11. Bertolini DV, Costa LS, van der Heijden IM, Sato HK, Marques HH. Immunogenicity of a meningococcal serogroup $C$ conjugate vaccine in HIV-infected children, adolescents, and young adults. Vaccine 2012;30:5482-6. 


\section{PERTUSSIS (WHOOPING COUGH)}

1. Infection and disease: Whooping cough is a highly contagious disease of the respiratory tract usually caused by the bacterium Bordetella pertussis. A similar illness can be caused by $B$. parapertussis but this is not preventable with available vaccines. The infection is transmitted through direct close contact with a case, and vaccination provides the most effective prevention strategy. Protection afforded by vaccination or from past infection is not life-long [1]. Disease severity ranges from mild to life-threatening, and infants and young children are most at risk of complications. Older children and adults who have previously had disease or been vaccinated may still become infected but usually have mild disease.

2. Epidemiology: In the UK the introduction of routine vaccination against pertussis in 1957 resulted in a marked reduction in pertussis notifications and deaths, and pertussis control has been good since the 1990s during a sustained period of high coverage [2]. Pertussis activity increased considerably from late 2011 leading to a national outbreak being declared in April 2012. Most cases were in previously vaccinated adolescents and young adults but the highest incidence of morbidity and mortality occurred in unvaccinated infants. Public health action has identified two target groups: those who are vulnerable to suffering severe disease (young infants) and those who are at risk of transmitting the infection to vulnerable individuals [1]. In October 2012 a temporary programme was introduced to offer pertussis vaccination to pregnant women, ideally between 28-32 weeks of pregnancy, with the aim of protecting infants through intrauterine transfer of maternal antibodies. In June 2014 the Joint Committee on Vaccination and Immunisation (JCVI) advised that this temporary programme should continue for at least a further five years as pertussis continues to circulate at heightened levels.

3. Pertussis in HIV-positive adults: Pertussis has been diagnosed in HIV-positive children and adults, and should be considered as a cause of respiratory disease in persons with HIV [3-7]. However, pertussis is not generally considered an opportunistic infection amongst immunocompromised individuals [1] and current evidence does not suggest that pertussis is common among persons with HIV or that they are more likely to be a reservoir for B. pertussis in the community.

4. Pertussis vaccine: Pertussis vaccines licensed in the UK are inactivated acellular vaccines made from highly purified components of $B$. pertussis, and are only available as part of combined products:

1) diphtheria/tetanus/acellular pertussis/inactivated polio vaccine/

Haemophilus influenzae type b (DTaP/IPV/Hib) - for primary immunisation in children

2) diphtheria/tetanus/acellular pertussis/inactivated polio vaccine/ (DTaP/

IPV or dTaP/IPV) - for pre-school boosters

3) diphtheria/tetanus/acellular pertussis/inactivated polio vaccine (dTaP/

IPV) - for adults requiring vaccination, including pregnant women

The vaccines are given by parenteral administration. Pertussis vaccines are safe and immunogenic in immunocompetent adults. Vaccination does not induce lifelong immunity, and the possible need for boosters in adolescence is under review. Vaccination is generally well tolerated [7]. Injection site reactions are common and may occur more frequently following subsequent doses.

General indications: Pertussis vaccination in not available for individuals aged $\geq 10$ years, except in pregnancy or as part of outbreak control. For adults, including pregnant women, a vaccine containing low dose diphtheria and tetanus is preferred. Since 2014, Boostrix ${ }^{\circledast}-$ IPV (dTaP/IPV) is the vaccine offered for the prenatal programme. Repevax ${ }^{\circledR}$ (dTaP/IPV) may be a suitable alternative, whereas Infanrix ${ }^{\circledR}-I P V$ is used only in exceptional circumstances when neither Boostrix ${ }^{\circledR}$ IPV nor Repevax ${ }^{\circledR}$ (dTaP/IPV) is available. Pregnant women are offered a single vaccine dose not earlier than 28 weeks and ideally between week 28 and week 32 of pregnancy. The vaccine will act as a reinforcing dose and 
is offered in every pregnancy regardless of prior vaccination status. Vaccination after week 38 is unlikely to provide passive protection to the infant but would potentially protect the mother from pertussis infection and thereby reduce the risk of exposure to her infant.

5. Pertussis vaccine in HIV-positive adults: After vaccination, antibody titres are lower in HIV-positive children compared to HIV-negative children, and correlate with the CD4 cell count [6]. No data on the efficacy of the pertussis vaccine in HIV-positive adults are available. There is no evidence of increased risk of side effects or adverse reactions to vaccination in individuals with HIV infection.

6. Post-exposure prophylaxis: Antibiotic prophylaxis (usually with macrolides) - to be started within 21 days of onset of cough in the index patient - is indicated for all asymptomatic household contacts of a suspected, epidemiologically linked, or confirmed pertussis case. Secondary attack rates are high, even when household contacts are current with vaccinations. Antibiotic prophylaxis may also be indicated for contacts who are at high risk of severe disease or are likely to come in contact with a person at high risk (e.g., pregnant women in the third trimester). Vaccination may also be considered for those who have been offered antibiotic prophylaxis.

\section{Recommendations for HIV-positive adults}

- We recommended that HIV-positive adults who meet general indications for pertussis vaccination and including HIV-positive pregnant women be offered one dose of the dTaP/IPV vaccine regardless of CD4 count, ART use, and viral load [1C]

- We recommended that HIV-positive adults who are in contact with case of pertussis are considered for antibiotic prophylaxis and vaccination in line with standard recommendations [1C]

\section{References}

1. Health Protection Agency Guidelines for the public health management of pertussis. https://www.gov.uk/government/uploads/system/uploads/attachment_data/file/323098/HPA_G uidelines_for_the_Public_Health_Management_of_Pertussis_2012_PB65.01-_Oct_2012.pdf [accessed 07/06/2015]

2. Amirhalingam G, Gupta S, Campbell H. Pertussis immunisation and control in England and Wales, 1957 to 2012: a historical review. Euro Surveill 2013;18:20587.

3. Ng VL, York M, Hadley WK. Unexpected isolation of Bordetella pertussis from patients with acquired immunodeficiency syndrome. J Clin Microbiol 1989;27: 337-8.

4. Doebbeling BN, Feilmeier ML, Herwaldt LA. Pertussis in an adult man infected with the human immunodeficiency virus. J Infect Dis 1990;161:1296-8.

5. Cohn SE, Knorr KL, Gilligan PH, Smiley ML, Weber DJ. Pertussis is rare in human immunodeficiency virus disease. Am Rev Respir Dis 1993;147:411-3.

6. Colebunders R, Vael C, Blot K, Van Meerbeeck J, Van den Ende J, Leven M. Bordetella pertussis as a cause of chronic respiratory infection in an AIDS patient. Eur J Clin Microbiol Infect Dis 1994; 13:313-5.

7. De Martino M, Podda A, Galli L et al. A cellular pertussis vaccine in children with perinatal human immunodeficiency virus-type 1 infection. Vaccine 1997;15: 1235-8.

8. Halperin SA, Smith B, Russell $\mathrm{M}$ et al. An adult formulation of a 5-component acellular pertussis vaccine combined with diphtheria and tetanus toxoids is safe and immunogenic in adolescents and adults. Vaccine 2000; 18: 1312-9. 


\section{PNEUMOCOCCUS}

1. Infection and disease: Streptococcus pneumoniae, or pneumococcus, is a Gram-positive bacterium. There are over 90 serotypes and although all can cause infections, a few serotypes account for most cases of disease [1]. Infection is acquired through direct person-to-person contact via respiratory droplets and by autoinoculation in persons carrying the bacteria in their upper respiratory tract. Pneumococci may be isolated from the nasopharynx of healthy persons in the absence of disease. The rate of asymptomatic carriage varies with age, environmental factors, and the presence of other infections of the respiratory tract. HIV-positive adults and children tend to have higher carriage rates. The mechanisms that control the healthy carrier state vs. invasive disease are poorly understood. Pneumococci can cause: (i) upper respiratory tract infections (e.g. otitis media and sinusitis) (ii) pneumonia and other lower respiratory tract infections, and (iii) invasive pneumococcal disease (IPD), including bacteraemia and meningitis; the latter is frequently complicated by neurological sequelae. Pneumococcal case fatality is high, up to $15 \%$ in pneumonia and $30 \%$ in meningitis.

2. Epidemiology: Pneumococcal disease occurs throughout the world, although geographically there is wide variation in the incidence of IPD. The greatest burden of disease is in developing countries. In the UK infections are more common during the winter and in early spring. The pneumococcus is the most frequent bacterial co-infection associated with influenza. Rates of antibiotic resistance are increasing in many parts of the world and susceptibility to penicillin, cephalosporin and macrolides can no longer be assumed. Penicillin resistance is present in $5 \%$ of UK isolates with a similar proportion of macrolide resistant isolates. This has little impact on management of respiratory infections, but penicillin cannot be used to manage meningitis when resistance is present. Pneumococcal infection is a major contributor to mortality among young children in developing countries. Pneumococcal disease is also common in children in developed countries, but in these settings mortality is seen predominantly in those aged $\geq 65$ years and adults with underlying conditions [2], including:

- alcoholism

- cancer (particularly haematological malignancy)

- chronic cardiovascular disease

- chronic pulmonary disease (e.g. chronic obstructive pulmonary disease or emphysema, but not asthma)

- chronic liver disease (cirrhosis)

- chronic renal disease

- diabetes mellitus

- absent or non-functioning spleen (e.g. sickle cell disease)

- hypogammaglobulinaemia

- malnutrition

- immunocompromise, including HIV infection

3. Pneumococcus in HIV-positive adults: Pneumococcus infection is a significant cause of pneumonia and IPD in HIV-positive persons [3,4]. Disease can occur early in the course of HIV infection and may recur. Paediatric serotypes are frequently involved and close contact with children is a recognized risk factor for infection. Risk factors for severe disease include low CD4 cell counts, African race, injecting drug use, smoking, a previous AIDS-defining diagnosis, previous pneumonia, chronic illness (i.e. lung, heart, liver, or kidney disease), and alcoholism [5-8]. The annual attack rate of pneumococcal bacteraemia was as high as $1 \%$ among persons with AIDS [9]. The incidence of IPD has declined with effective ART $[10,11]$ but HIV-positive adults remain at an approximately 40 times higher risk of disease compared with age-matched HIV-negative adults. Major risk factors for IPD are similar to those reported in HIV-negative individuals and include associated co-morbidity, prior hospitalization with alcoholism, and current smoking as prominent [12]. Compared with HIV-negative adults, HIVpositive persons show an increased risk of mortality after controlling for age and severity of 
presentation, and the risk is related to the CD4 cell count. With an increasing proportion of associated co-morbidities in ageing HIV-positive populations (e.g. cirrhosis, chronic pulmonary disease) casefatality has tended to increase in recent years.

Universal vaccination with pneumococcal conjugate vaccine (PCV) was introduced into the UK paediatric vaccine schedule in 2006; PCV-7 initially including serotypes 4, 6B, 9V, 14, 18C, 19F \& 23F; in 2011 PCV-13 added the serotypes 1, 3, 5, 6A, 7F, 19A. These vaccines have had a dramatic impact on the epidemiology of pneumococcal disease. Not only have they been highly effective at presenting disease from the vaccine serotypes in the vaccinated children, but also there has been a reduction in disease caused by vaccine serotypes in all age groups as a consequence of herd protection. This has however been offset by an increase in disease caused by non-PCV serotypes. In the US, a net reduction in IPD in HIV-positive adults of around $25 \%$ was attributed to paediatric PCV use with only about $8 \%$ of IPD disease caused by PCV-7 serotypes five years after introduction [13]. The pattern has been similar in the UK with PCV-7 serotypes dramatically reducing as a cause of disease [8]. Recent UK surveillance among adults with IPD has also shown a fall in the 6 additional serotypes included in PCV13. At the present time, the proportion of IPD cases caused by PCV-13 serotypes in HIV-positive adults is unclear, although it is likely to be falling. The burden of non-bacteraemic pneumococcal pneumonia is believed to be 5-10 times greater than the IPD burden. The contribution of PCV-13 serotypes to this syndrome is less clear due to difficulties of measurement, but is also likely to be falling as a result of reduced community transmission.

4. Pneumococcal vaccine: Two different vaccines have been developed: the pneumococcal polysaccharide vaccine (PPV) and the pneumococcal protein-conjugated vaccine (PCV). Both vaccine types have a license in the UK for use in adults and are given by parenteral administration.

- PPV-23 is composed of purified preparations of pneumococcal capsular polysaccharide from 23 different serotypes, which has traditionally accounted for around $90 \%$ of cases of IPD. PPV- 23 has been available in the UK for much of the last 30 years. It is given as a single dose by subcutaneous or intramuscular injection.

- PCV vaccines were specifically designed for use in infant populations where pure polysaccharide vaccines fail to induce protective immune responses. Immunogenicity is improved by attaching the pneumococcal polysaccharide to a "carrier" protein. Two preparations are available: a 13valent preparation (PCV-13) and a 10-valent preparation (PCV-10). PCV-13 has been evaluated in adult populations. No adult studies have been reported with PCV-10.

No serious safety concerns have been identified with either PPV-23 or the PCVs. Injection site reactions occur in $30-50 \%$ of PPV-23 vaccine recipients but usually resolve within 48 hours. Local reactions are reported more frequently following a second dose of PPV-23 than after the first dose, especially if fewer than three years have elapsed since the first injection. Systemic reactions with fever and myalgia occur uncommonly $(<1 \%)$ and more serious adverse events are very rare. Reactions to the PCVs may be more common than with PPV-23 but the serious adverse event profile is similar. Contraindications to vaccination include:

- $\quad$ PPV-23: Vaccination given within the previous three years

- $\quad$ PCV: Previous serious adverse reaction to PCV

5. Vaccine efficacy: The efficacy of pneumococcal vaccines has been the subject of significant debate. In the case of PPV there have been a limited number of randomised controlled trials (RCT) and large number of observational studies with significant variation in reports of efficacy, particularly in those reported from outside the US. In the case of PCV, there is a much smaller literature, although this includes two RCTs with consistent results. 


\section{PPV-23}

Immunogenicity: More than $80 \%$ of healthy young adults who receive PPV-23 develop antibodies against the serotypes contained in the vaccine, usually within 2-3 weeks. In older adults and persons with underlying conditions, responses are often reduced or absent. HIV-positive adults produce significantly lower peak levels and durability of response compared to HIV-negative adults. The functional quality of antibodies produced in HIV-positive adults in response to PPV is also significantly impaired in comparison to HIV-negative adults. ART use has not been shown to convincingly improve response to PPV-23 [14-19]. The degree of immunodeficiency as measured by CD4 cell count may also affect immunogenicity $[15,20]$. HIV-positive patients with CD4 counts $<500$ cells/ $\mu \mathrm{L}$ have shown lower responses than patients with higher CD4 cell counts [21], although this effect is not consistent across reports [22-24]. Routine boosting is not recommended in immunocompetent individuals previously vaccinated with the PPV-23 vaccine. However revaccination after 5-10 years of the first dose is part of general guidance for the use of PPV-23 in specific risk groups. Repeat doses of PPV in HIV-positive adults however produce attenuated antibody responses [25]. Recent studies in thalassaemic patients have suggested a dose dependent attenuation in pneumococcal memory responses with repeat doses of PPV [26]. Importantly, the relationship between antibody levels and protection from IPD is not certain in adult populations.

Clinical efficacy: Overall, PPV-23 is estimated to be approximately $60 \%$ effective in preventing IPD in otherwise healthy older adults, but is less or ineffective in those groups that also have the greatest risk of disease. PPV-23 efficacy against non-bacteraemic pneumonia has not been demonstrated unequivocally. Several meta-analyses have shown that vaccination reduced bacteraemic pneumococcal pneumonia in low-risk adults, but did not show efficacy against non-bacteraemic pneumonia and in high-risk groups [27-30]. Studies on the clinical efficacy of pneumococcal vaccination in HIV-positive adults have reported inconsistent findings. Most have been conducted in persons not receiving ART or receiving suboptimal mono and dual therapy. In the only randomized controlled trial, the vaccine showed no efficacy in reducing the risk of pneumococcal disease among Ugandan HIV-positive persons not taking ART [31]. Surprisingly, there was a borderline increase in pneumonia of any cause in vaccine recipients (HR 1.89, 95\% Cl 1.1-3.2). Follow-up reports showed a persistent excess of 'all-cause' pneumonia in vaccine recipients - although a small survival advantage was also observed in this extremely high mortality study [32].

Ten observational studies of varying size and quality have been reported evaluating PPV- 23 in routine use against a pneumococcal disease end-point, six from the USA [5,6,33-36], two from Spain [37,38], one from Brazil [39], and one from Taiwan [15]. Six studies reported varying effectiveness (20-79\%) against IPD; two studies reported $20-35 \%$ effectiveness against pneumonia. Within these studies effectiveness was associated with higher CD4 cell counts (>200 or $>500$ cells $/ \mu \mathrm{L}$ ) $[5,33,36]$, non African-American race [6], and viral load $<100,000$ copies/mL [36]. In the six studies able to evaluate ART use, five confirmed this as independently protective against pneumococcal disease $(50-77 \%$ effective) with only one study showing no independent protective effect [36]. None of the studies were able to demonstrate an impact of ART use on PPV-23 efficacy. The underlying confounding associated with vaccine receipt and risk of pneumococcal disease remains problematic when interpreting these observational studies. There are no studies reporting clinical end-point efficacy with repeat PPV-23 use in HIV-positive adults.

\section{PCV}

PCV is a highly effective paediatric vaccine, which is now in use in most developed countries following a series of successful RCTs. As noted above the introduction of these vaccines has led to dramatic changes in pneumococcal disease epidemiology through herd protection effects. A large-scale trial of PCV-13 in approximately 85,000 over 65 year-old HIV-negative Dutch residents was recently completed [40]. In this study a single dose of PCV-13 reduced vaccine serotype IPD by $75 \%$. 
Immunogenicity: Serological studies of PCV confirm its immunogenicity in HIV-positive adults. However responses are reduced when compared to HIV-negative adults $[41,42]$ and demonstrable superiority of PCV response over PPV response may be limited to certain serotypes [43-49]. Durability of serological response appears to be enhanced by ART usage $[50,51]$ and repeat dosing elicits a better response than with repeat doses of PPV [52].

Clinical efficacy: The vaccine is effective in HIV-positive children, reducing the risk of vaccine serotype IPD by $60-65 \%$ and the risk of clinical lower respiratory tract disease by $15 \%$ [53]. A randomised placebo-controlled trial of PCV-7 in HIV-positive Malawian adults who had recovered from IPD, reduced vaccine serotype IPD by $74 \%$ [54]. In this study efficacy was unequivocally demonstrated at CD4 counts $<200$ cells/ $\mu \mathrm{L}$. The study was not powered to assess the interaction with ART or duration of response. Most participants received vaccine prior to commencing ART and efficacy was not measurable 12 months after vaccination. The study used a two-dose schedule with vaccinations given one month apart. Serological assessments suggest that the second dose of vaccine may provide little if any benefit over a single dose.

\section{$P C V+P P V$}

Only serological studies are available to inform this approach to vaccination. Serological responses to PCV serotypes are increased by boosting with either PCV or PPV in the majority of published studies $[42,43,45,47,48]$. There are no studies to support the effectiveness of this approach to prevent disease end-points.

5. Pneumococcal vaccine in HIV-positive adults: The most robust evidence for the use of pneumococcal vaccines in HIV-positive adults relates to PCV use. The conjugated vaccines are immunogenic and have proven to be clinically effective in RCTs including one undertaken in HIVpositive adults with low CD4 counts. A strong recommendation based on these data would be justified for vaccine to be given at all CD4 counts with or without ART, and with or without co-morbidities that would increase pneumococcal disease risk. However, with the routine use of PCV in the infant vaccine programme, the burden of pneumococcal disease attributable to PCV-13 serotypes is now falling. With a large herd protection, the clinical effectiveness of this approach may become increasingly limited as disease burden falls. There is a clear research need to determine the burden of IPD and non bactaeramic pneumonia caused by PCV-13, PPV-23, and non-vaccine serotypes among HIV-positive populations in the UK, in order to inform vaccination practices.

\section{Recommendations for HIV-positive adults}

- We recommend that HIV-positive adults receive a single dose of PCV-13 irrespective of CD4 cell count, ART use, and viral load [1B]. This recommendation will be reviewed in light of the evolving epidemiology of PCV-13 type pneumococcal disease in the UK.

- PCV-13 should be given at least 3 months after any use of PPV-23

- We suggest that HIV-positive adults that meet the indications for PPV-23 vaccination within the national programme (typically aged $>65$ years or with co-morbidity other than HIV) follow general guidance and receive a single dose of PPV-23 [2C]

- PPV-23 should be given at least 3 months after any PCV-13

- We recommend against repeat PPV-23 or repeat PCV-13 dosing [1C]

\section{References}

1. Hausdorff WP, Bryant J, Paradiso PR, Siber GR. Which pneumococcal serogroups cause the most invasive disease: implications for conjugate vaccine formulation and use, part I. Clin Infect Dis 2000;30:100-21. 
2. van Hoek AJ, Andrews N, Waight PA, Stowe J, Gates P, George R, Miller E. The effect of underlying clinical conditions on the risk of developing invasive pneumococcal disease in England. J Infect 2012;65:17-24.

3. Miller RF, Foley NM, Kessel D, Jeffrey AA. Community acquired lobar pneumonia in patients with HIV infection and AIDS. Thorax 1994;49:367-8.

4. Rimland D, Navin TR, Lennox JL, et al. Prospective study of etiologic agents of community-acquired pneumonia in patients with HIV infection. AIDS 2002;16:85-95.

5. Dworkin MS, Ward JW, Hanson DL, Jones JL, Kaplan JE. Pneumococcal disease among human immunodeficiency virus-infected persons: incidence, risk factors, and impact of vaccination. Clin Infect Dis 2001;32:794-800.

6. Breiman RF, Keller DW, Phelan MA, et al. Evaluation of effectiveness of the 23-valent pneumococcal capsular polysaccharide vaccine for HIV-infected patients. Arch Intern Med 2000;160:2633-8.

7. Gilks CF, Ojoo SA, Ojoo JC, et al. Invasive pneumococcal disease in a cohort of predominantly HIV1 infected female sex-workers in Nairobi, Kenya. Lancet 1996;347:718-23.

8. Yin $Z$, Rice $B D$, Waight $P$, et al. Invasive pneumococcal disease among HIV-positive individuals, 2000-2009. AIDS 2012;26:87-94.

9. Redd SC, Rutherford GW, Sande MA, Lifson AR, Hadley WK, Facklam RR, Spika JS. The role of human immunodeficiency virus infection in pneumococcal bacteremia in San Francisco residents. $J$ Infect Dis 1990;162:1012-7.

10. Heffernan RT, Barrett NL, Gallagher KM, et al. Declining incidence of invasive Streptococcus pneumoniae infections among persons with AIDS in an era of highly active antiretroviral therapy, 1995-2000. J Infect Dis 2005;191:2038-45.

11. Grau I, Pallares R, Tubau F, et al. Epidemiologic changes in bacteremic pneumococcal disease in patients with human immunodeficiency virus in the era of highly active antiretroviral therapy. Arch Intern Med 2005;165:1533-40.

12. Grau I, Ardanuy C, Linares J, Podzamczer D, Schulze MH, Pallares R. Trends in mortality and antibiotic resistance among HIV-infected patients with invasive pneumococcal disease. HIV Med 2009;10:488-95.

13. Cohen AL, Harrison LH, Farley MM, et al. Prevention of invasive pneumococcal disease among HIVinfected adults in the era of childhood pneumococcal immunization. AIDS 2010;24:2253-62.

14. Rodriguez-Barradas MC, Alexandraki I, Nazir T, Foltzer M, Musher DM, Brown S, Thornby J. Response of human immunodeficiency virus-infected patients receiving highly active antiretroviral therapy to vaccination with 23 -valent pneumococcal polysaccharide vaccine. Clin Infect Dis 2003;37:438-47.

15. Hung CC, Chen MY, Hsieh SM, Hsiao CF, Sheng WH, Chang SC. Clinical experience of the 23-valent capsular polysaccharide pneumococcal vaccination in HIV-1-infected patients receiving highly active antiretroviral therapy: a prospective observational study. Vaccine 2004;22:2006-12.

16. Subramaniam KS, Segal R, Lyles RH, Rodriguez-Barradas MC, Pirofski LA. Qualitative change in antibody responses of human immunodeficiency virus-infected individuals to pneumococcal capsular polysaccharide vaccination associated with highly active antiretroviral therapy. J Infect Dis 2003;187:758-68.

17. Iyer AS, Leggat DJ, Ohtola JA, et al. Response to pneumococcal polysaccharide vaccination in HIVpositive individuals on long term highly active antiretroviral therapy. J AIDS Clin Res 2015;6:421.

18. Leggat DJ, Iyer AS, Ohtola JA, et al. Response to pneumococcal polysaccharide vaccination in newly diagnosed HIV-positive individuals. J AIDS Clin Res 2015;6:419.

19. Rodriguez-Barradas MC, Serpa JA, Munjal I, Mendoza D, Rueda AM, Mushtaq M, Pirofski LA. Quantitative and qualitative antibody responses to immunization with the pneumococcal polysaccharide vaccine in HIV-Infected patients after initiation of antiretroviral treatment: results from a randomized clinical trial. J Infect Dis 2015;211:1703-11. 
20. Loeliger AE, Rijkers GT, Aerts P, Been-Tiktak A, Hoepelman Al, van Dijk H, Borleffs JC. Deficient antipneumococcal polysaccharide responses in HIV-seropositive patients. FEMS Immunol Med Microbiol 1995;12:33-41.

21. Rodriguez-Barradas MC, Musher DM, Lahart C, et al. Antibody to capsular polysaccharides of Streptococcus pneumoniae after vaccination of human immunodeficiency virus-infected subjects with 23-valent pneumococcal vaccine. J Infect Dis 1992;165:553-6.

22. Vandenbruaene $M$, Colebunders R, Mascart-Lemone F, et al. Equal IgG antibody response to pneumococcal vaccination in all stages of human immunodeficiency virus disease. J Infect Dis 1995;172:551-3.

23. French N, Gilks CF, Mujugira A, Fasching C, O'Brien J, Janoff EN. Pneumococcal vaccination in HIV1-infected adults in Uganda: humoral response and two vaccine failures. AIDS 1998;12:1683-9.

24. Amendola A, Tanzi E, Zappa A, Colzani D, Boschini A, Musher DM, Zanetti AR. Safety and immunogenicity of 23-valent pneumococcal polysaccharide vaccine in HIV-1 infected former drug users. Vaccine 2002;20:3720-4.

25. Tasker SA, Wallace MR, Rubins JB, Paxton WB, O'Brien J, Janoff EN. Reimmunization with 23-valent pneumococcal vaccine for patients infected with human immunodeficiency virus type 1: clinical, immunologic, and virologic responses. Clin Infect Dis 2002;34: 813-21.

26. Papadatou I, Piperi C, Alexandraki K, Kattamis A, Theodoridou M, Spoulou V. Antigen-Specific BCell Response to 13-valent pneumococcal conjugate vaccine in asplenic individuals with betathalassemia previously immunized with 23-valent pneumococcal polysaccharide vaccine. Clin Infect Dis 2014;59:862-5.

27. Huss A, Scott $P$, Stuck AE, Trotter C, Egger M. Efficacy of pneumococcal vaccination in adults: a meta-analysis. CMAJ 2009;180:48-58.

28. Cornu C, Yzebe D, Leophonte P, Gaillat J, Boissel JP, Cucherat M. Efficacy of pneumococcal polysaccharide vaccine in immunocompetent adults: a meta-analysis of randomized trials. Vaccine 2001;19:4780-90.

29. Moore RA, Wiffen PJ, Lipsky BA. Are the pneumococcal polysaccharide vaccines effective? Metaanalysis of the prospective trials. BMC Fam Pract 2000;1:1.

30. Fine MJ, Smith MA, Carson CA, et al. Efficacy of pneumococcal vaccination in adults. A metaanalysis of randomized controlled trials. Arch Intern Med 1994;154:2666-77.

31. French N, Nakiyingi J, Carpenter LM, et al. 23-valent pneumococcal polysaccharide vaccine in HIV1-infected Ugandan adults: double-blind, randomised and placebo controlled trial. Lancet 2000;355:2106-11.

32. Watera C, Nakiyingi J, Miiro G, Muwonge R, Whitworth JA, Gilks CF, French N. 23-Valent pneumococcal polysaccharide vaccine in HIV-infected Ugandan adults: 6-year follow-up of a clinical trial cohort. AIDS 2004;18:1210-3.

33. Gebo KA, Moore RD, Keruly JC, Chaisson RE. Risk factors for pneumococcal disease in human immunodeficiency virus-infected patients. J Infect Dis 1996;173:857-62.

34. Guerrero M, Kruger S, Saitoh A, Sorvillo F, Cheng KJ, French C, Beall G. Pneumonia in HIV-infected patients: a case-control survey of factors involved in risk and prevention. AIDS 1999;13:1971-5.

35. Rodriguez-Barradas MC, Goulet J, Brown S, Get al. Impact of pneumococcal vaccination on the incidence of pneumonia by HIV infection status among patients enrolled in the Veterans Aging Cohort 5-Site Study. Clin Infect Dis 2008;46:1093-1100.

36. Teshale EH, Hanson D, Flannery B, Phares C, Wolfe M, Schuchat A, Sullivan P. Effectiveness of 23valent polysaccharide pneumococcal vaccine on pneumonia in HIV-infected adults in the United States, 1998--2003. Vaccine 2008;26:5830-4.

37. Lopez-Palomo C, Martin-Zamorano M, Benitez E, Fernandez-Gutierrez C, Guerrero F, RodriguezIglesias M, Giron-Gonzalez JA. Pneumonia in HIV-infected patients in the HAART era: incidence, risk, and impact of the pneumococcal vaccination. J Med Virol 2004;72:517-24.

38. Penaranda M, Falco V, Payeras A, et al. Effectiveness of polysaccharide pneumococcal vaccine in HIV-infected patients: a case-control study. Clin Infect Dis 2007;45:e82-7. 
39. Veras MA, Enanoria WT, Castilho EA, Reingold AL. Effectiveness of the polysaccharide pneumococcal vaccine among HIV-infected persons in Brazil: a case control study. BMC Infect Dis 2007;7:119.

40. Bonten M, Bolkenbaas M, Huijts S, Webber C, Gault S, Gruber W, Grobbee D. Community acquired pneumonia immunisation trial in adults (CAPITA). Pneumonia 2004;3:1.

41. Gordon SB, Kayhty $H$, Molyneux ME, et al. Pneumococcal conjugate vaccine is immunogenic in lung fluid of HIV-infected and immunocompetent adults. J Allergy Clin Immunol 2007;120:208-10.

42. Chen $M$, Ssali $F$, Mulungi $M$, et al. Induction of opsonophagocytic killing activity with pneumococcal conjugate vaccine in human immunodeficiency virus-infected Ugandan adults. Vaccine 2008;26:4962-8.

43. Feikin DR, Elie $C M$, Goetz $M B$, et al. Randomized trial of the quantitative and functional antibody responses to a 7-valent pneumococcal conjugate vaccine and/or 23-valent polysaccharide vaccine among HIV-infected adults. Vaccine 2001;20:545-53.

44. Kroon FP, van Dissel JT, Ravensbergen E, Nibbering PH, van Furth R. Enhanced antibody response to pneumococcal polysaccharide vaccine after prior immunization with conjugate pneumococcal vaccine in HIV-infected adults. Vaccine 2000;19:886-94.

45. Lesprit P, Pedrono G, Molina JM, et al. Immunological efficacy of a prime-boost pneumococcal vaccination in HIV-infected adults. AIDS 2007;21:2425-34.

46. Crum-Cianflone NF, Huppler Hullsiek K, Roediger M, et al. A randomized clinical trial comparing revaccination with pneumococcal conjugate vaccine to polysaccharide vaccine among HIVinfected adults. J Infect Dis 2010;202:1114-25.

47. Penaranda M, Payeras A, Cambra A, Mila J, Riera M. Conjugate and polysaccharide pneumococcal vaccines do not improve initial response of the polysaccharide vaccine in HIV-infected adults. AIDS 2010;24:1226-8.

48. Ho YL, Brandao AP, de Cunto Brandileone MC, Lopes MH. Immunogenicity and safety of pneumococcal conjugate polysaccharide and free polysaccharide vaccines alone or combined in HIV-infected adults in Brazil. Vaccine 2013;31:4047-53.

49. Lu CL, Hung CC, Chuang YC, et al. Serologic response to primary vaccination with 7-valent pneumococcal conjugate vaccine is better than with 23-valent pneumococcal polysaccharide vaccine in HIV-infected patients in the era of combination antiretroviral therapy. Hum Vaccin Immunother 2013;9:398-404.

50. Sogaard OS, Schonheyder HC, Bukh AR, Harboe ZB, Rasmussen TA, Ostergaard L, Lohse N. Pneumococcal conjugate vaccination in persons with HIV: the effect of highly active antiretroviral therapy. AIDS 2010;24:1315-22.

51. Slayter KL, Singer J, Lee TC, Kayhty H, Schlech WF. Immunization against pneumococcal disease in HIV-infected patients: conjugate versus polysaccharide vaccine before or after reconstitution of the immune system (CTN-147). Int J STD AIDS 2013;24:227-31.

52. Lu CL, Chang SY, Chuang YC, et al. Revaccination with 7-valent pneumococcal conjugate vaccine elicits better serologic response than 23-valent pneumococcal polysaccharide vaccine in HIVinfected adult patients who have undergone primary vaccination with 23-valent pneumococcal polysaccharide vaccine in the era of combination antiretroviral therapy. Vaccine 2014;32:1031-5.

53. Klugman KP, Madhi SA, Huebner RE, Kohberger R, Mbelle N, Pierce N. A trial of a 9-valent pneumococcal conjugate vaccine in children with and those without HIV infection. N Engl J Med 2003;349:1341-8.

54. French N, Gordon SB, Mwalukomo T, et al. A trial of a 7-valent pneumococcal conjugate vaccine in HIV-infected adults. N Engl J Med 2010;362:812-22. 


\section{POLIOMYELITIS}

1. Infection and disease: Poliomyelitis is caused by poliovirus serotypes 1,2 and 3. Polioviruses are neuroinvasive enteroviruses that are spread by the faecal-oral and respiratory routes. Most infections are sub-clinical, but a minority give rise to neurological manifestations including aseptic meningitis, encephalomyelitis, and the poliomyelitis syndrome, characterized by the acute onset of flaccid paralysis. The live attenuated oral poliovirus vaccine (OPV) is shed asymptomatically in the stool of vaccine recipients for several days; shedding may be prolonged in immunocompromised persons, which may allow reversion to virulence and give rise to vaccine-associated paralytic polio (VAPP) in vaccine recipients or their contacts.

2. Epidemiology: Poliomyelitis continues to occur in only a few countries and is now exceedingly rare in the UK. The last indigenous case of wild-type infection was in 1984, with the last imported case in 1993. Travellers going to certain parts of Africa and Asia may be at risk for polio.

3. Poliomyelitis in HIV-positive people: No specific data are available on wild-type poliomyelitis in HIV-positive persons. HIV-positive children - including those who are mildly to moderately symptomatic - retain the ability to clear enteroviruses, including vaccine-related poliovirus, and do not appear to be at increased risk of prolonged OPV shedding relative to HIV-negative children [1,2].

4. Polio vaccine: Replicating live attenuated OPV is no longer available in the UK, having been replaced in 2004 with the trivalent (serotypes 1-3) enhanced inactivated poliovirus vaccine (IPV) in all routine vaccine schedules. The vaccine is given to adults in combination with tetanus and diphtheria toxoid (Td/IPV). The vaccine is given by parenteral administration. IPV is highly immunogenic. Antibodies to all three poliovirus serotypes develop in $>90 \%$ of healthy recipients after 2 doses and in $>99 \%$ after 3 doses. The duration of immunity conferred by IPV is not known. A total of five vaccine doses at the appropriate intervals (as per the UK childhood vaccination schedule) are considered to give lasting immunity, with reinforcing doses recommended every 10 years for those at risk. The vaccine is well tolerated. Injection site reactions are common but usually self-limited and may occur more frequently following subsequent doses. Fever and other systemic reactions are uncommon. Severe systemic reactions are rare.

General indications: The aim of the UK national vaccination programme is to ensure that all individuals receive at least 5 vaccine doses. Td/IPV is recommended for vaccination of those aged $\geq 10$ years. Adults who are either unvaccinated or have an uncertain vaccination history are advised to receive primary immunization with three vaccine doses at either monthly intervals or at 0, 1-2 months, and 612 months [3]. Two further doses are scheduled 5 and 10 years after the last dose. Adults who have received partial vaccination are advised to receive the remaining doses, regardless of the interval since the last dose and type of vaccine previously received. It is also recommended that travellers to areas that pose a risk of exposure should ensure they are fully vaccinated.

5. Polio vaccine in HIV-positive adults: Both OPV and IPV can elicit neutralizing antibody responses in HIV-positive children and adults, and in patients with CD4 counts $<300$ cells/ $\mu \mathrm{L}$ [4-9]. The seroprevalence of poliovirus-neutralizing antibodies varies among HIV-positive adults. HIV-positive patients born and resident in the UK since 1962 have generally received a complete 5-dose vaccine course as part of routine childhood immunization. High prevalence rates, comparable to those in normal controls, have been reported in some cohorts. However, in a seroepidemiological study of Italian drug users, those with HIV infection were more likely to lack protection, with $34 \%$ seronegative for poliovirus type 3 and $11 \%$ lacking neutralizing antibodies to all three virus types [10]. OPV is contraindicated in patients with HIV and their contacts. IPV can be administered safely to immunocompromised adults. 
6. Post-exposure prophylaxis: Following inadvertent administration of OPV, exposure to a close contact given OPV, or exposure to wild-type poliovirus, immunocompromised patients can receive post-exposure prophylaxis with intramuscular human normal immunoglobulin (HNIG). A serum should be collected for baseline serology testing, but prophylaxis should not be delayed pending the results. HNIG is not indicated if the patient is known to be antibody-positive to all three poliovirus types. Stool samples are collected one week apart for analysis. If poliovirus is detected, administration of HNIG is repeated at 3-weekly intervals until two consecutive stool samples test negative. Intravenous immunoglobulin may be considered if intramuscular injections are contraindicated.

\section{Recommendations for HIV-positive adults}

- We recommend that HIV-positive adults that require vaccination against diphtheria, tetanus, or polio be given the Td/IPV vaccine in accordance with general indications, and regardless of CD4 cell count, ART use, and viral load [1B]

- We recommend that individuals who are either unvaccinated or have an uncertain vaccination history receive 3 vaccine doses at monthly interval (or at $0,1-2$, and 6-12 months) followed by 2 reinforcing doses after 5 and 10 years, whereas partially vaccinated individuals should complete the 5 -dose vaccine course [1B]

- We recommend that fully vaccinated individuals ( 5 doses) receive a booster dose every 10 years if at risk of exposure, typically through travel [1C]

- We recommend that individuals who may be occupationally exposed to poliovirus (e.g. laboratory workers) be tested for specific antibodies 3 months after vaccination to confirm protective immunity and revaccinated if required [1C]

- We recommend that HIV-positive patients who are exposed to OPV or wild-type polio are considered for post-exposure prophylaxis with HNIG, based on considerations of vaccination history, CD4 cell counts, viral load, ART status, and poliovirus serology [1C]

\section{References}

1. Troy SB, Musingwini G, Halpern MS, et al. Vaccine poliovirus shedding and immune response to oral polio vaccine in HIV-infected and -uninfected Zimbabwean infants. J Infect Dis 2013;208:672-8.

2. Khetsuriani $\mathrm{N}$, Helfand $\mathrm{R}$, Pallansch $\mathrm{M}$, et al. Limited duration of vaccine poliovirus and other enterovirus excretion among human immunodeficiency virus infected children in Kenya. BMC Infect Dis 2009;9:136.

3. Centers for Disease Control (CDC). Poliomyielitis. http://www.cdc.gov/vaccines/pubs/pinkbook/downloads/polio.pdf (accessed June 2015)

4. Vardinon N, Handsher R, Burke M, Zacut V, Yust I. Poliovirus vaccination responses in HIV-infected patients: correlation with T4 cell counts. J Infect Dis 1990;162:238-41.

5. Barbi $M$, Bardare $M$, Luraschi $C$ et al. Antibody response to inactivated polio vaccine (E-IPV) in children born to HIV-positive mothers. Eur J Epidemiol 1992;8:211-6.

6. Barbi M, Biffi MR, Binda S et al. Immunization in children with HIV seropositivity at birth: antibody response to polio vaccine and tetanus toxoid. AIDS 1992;6:1465-9.

7. Mathisen GE, Allen AD. Inactivated polio vaccine hyperimmunization in adults with HIV disease: a placebo-controlled study. AIDS 1992; 6:737-51.

8. Kroon FP, van Dissel JT, Labadie J, van Loon AM, van Furth R. et al. Antibody response to diphtheria, tetanus, and poliomyelitis vaccines in relation to the number of CD4 + T Imphocytes in adults infected with human immunodeficiency virus. Clin Infect Dis 1995;21:1197-203.

9. Gnanashanmugam D, Troy SB, Musingwini G, et al. Immunologic response to oral polio vaccine in human immunodeficiency virus-infected and uninfected Zimbabwean children. Pediatr Infect Dis J 2012;31:176-80.

10. Pregliasco F, Minolfi V, Boschin A, Andreassi A, Profeta ML. A seroepidemiologic survey of immunity against poliomyelitis in a group of HIV-positive and HIV-negative drug addicts. Eur J Epidemiol 1995; 11:693-5. 


\section{RABIES}

1. Infection and disease: Rabies is caused by viruses of the lyssavirus genus, including the classic rabies virus genotype 1 and other related viruses [e.g. European Bat lyssaviruses (EBLV) and Australian bat lyssavirus (ABLV)]. Rabies is transmitted by contact with a rabid animal, generally as the result of a bite or scratch [1-3]. Transmission may also occur when infectious material, such as saliva or aerosolized secretions from an infected animal, comes into contact with mucous membranes or abraded skin, or on rare occasions through inhalation of virus-containing aerosol. Virus may be present in the saliva of patients with rabies, but person-to-person spread of the disease has not been documented, with the exception of a few cases of transplant-associated transmission from donors unsuspected of having rabies [4]. Rabies classically presents as an acute encephalomyelitis and less commonly with an ascending flaccid paralysis. In both forms, coma and death follow almost invariably although a few cases of survival have been described [5].

2. Epidemiology: Human rabies is common in most developing countries, where it occurs in both urban and rural areas [1-3]. In the majority of industrialised countries human rabies is rare, mainly because of oral vaccination of wildlife and mandatory vaccination of domestic animals. No case of indigenous human rabies from terrestrial animals has been reported in the UK since 1902. An indigenous case of EBLV infection occurred in 2002 in a bat handler who was bitten by a bat and did not receive pre-or post-exposure rabies prophylaxis. Animal rabies is widespread in every continent except Antarctica. In Asia, Africa, and parts of Latin America both stray and domestic dogs remain the principal vector and transmitter of rabies to humans. Canine rabies is endemic throughout most of these regions, and $90 \%$ of human cases with a defined source are caused by exposure to dogs, usually in the form of bites. Rabies reservoir species include wild mammals such as racoons, skunks, foxes, and insectivorous bats in North America; vampire bats and mongooses in Central America; jackals, hyenas and mongooses in Africa; wolves, foxes, and insectivorous bats in Europe; and fruit bats in Australia. In some parts of the world, other domestic and wild mammals such as cats and monkeys may transmit infection. In the UK, EBLVs have been detected in Daubenton's bats [6]. Public Health England (PHE) provides indications of rabies risk by country [7]. Prevention through vaccination prior to exposure is available but underused, and disease prevention mostly relies on rabies post-exposure prophylaxis (rabies-PEP) [8]. The number of people requiring rabies-PEP has increased in recent years in the UK, and is almost 900 per year in England and Wales, of which $10 \%$ in people potentially exposed to bats in the UK and $90 \%$ potentially exposed overseas.

3. Rabies in HIV-positive adults: It is not known if the natural history of rabies is modified by HIV infection.

4. Rabies vaccine: Human rabies vaccines are inactivated. Vaccines commonly available in Europe, North America, Australia, and New Zealand are cell culture-based and include the human diploid cell vaccine (HDCV), the purified chick embryo cell vaccine (PCECV), and the purified Vero cell rabies vaccine (PVRV) [9]. HDCV and PCECV are available in the UK. Vaccines of nerve tissue origin are still in use in some developing countries, but are reactogenic and some are of low immunogenicity; these are not generally recommended, although they are still preferable to no vaccine. Rabies vaccines are administered intramuscularly (or subcutaneously if bleeding disorders); the standard schedule is with three vaccine doses given at 0,7 , and 28 (or 21) days. Intradermal administration of smaller vaccine doses is used in some developing countries, but is generally not recommended. In pre-exposure rabies prophylaxis, cell culture-based vaccines administered through the intramuscular route induce a satisfactory antibody response in approximately $95 \%$ of healthy recipients, with rare failures; responses are usually maintained for at least 10 years. Although associated with mild and transient reactions, cell culture-derived rabies vaccines are considered safe [10]. Injection site reactions occur in $30-74 \%$ of vaccine recipients, whereas mild systemic reactions are reported in 5-40\%. 
Serology testing: A rabies-neutralizing antibody level $\geq 0.5 \mathrm{IU} / \mathrm{ml}$, as per World Health Organization (WHO) guidelines, is considered the minimal adequate response indicating unequivocal seroconversion [11]. There are strict indications for serological testing in order to guide vaccine use, and those eligible in the UK include vaccine candidates who have had a severe reaction to a previous vaccine dose, people with regular and continuous exposure to rabies, and those in whom vaccine immunogenicity may be reduced including HIV-positive individuals. Rabies serology is available at selected UK laboratories and advice can be obtained through the PHE Rabies clerk on +44 (0) 208327 6204 or through the Animal and Plant Health Agency (APHA) Rabies Help Line (+44 (0) 1932357345 or (0) 1932 341111).

General indications for pre-exposure rabies prophylaxis in healthy individuals: Pre-exposure rabies vaccination is offered in the UK to the following categories:

- At continuous risk of exposure - Laboratory workers (3 vaccine doses, serology testing after the primary course and every 6 months thereafter, booster vaccine dose if antibody titre falls below $0.5 \mathrm{IU} / \mathrm{ml})$

- At frequent risk of exposure - Bat handlers, persons who regularly handle imported animals, animal control and wildlife workers, veterinary staff or zoologists who travel regularly in rabies enzootic areas, health workers in rabies enzootic areas who will be at risk of direct exposure to body fluids or tissue from a patient with confirmed or probable rabies ( 3 vaccine doses, booster vaccine dose at 1 year, then a booster vaccine dose every 3-5 years, or based on serology results where available)

- At occasional risk of exposure - Travellers to rabies enzootic areas, especially if post-exposure medical care and rabies biologics at the destination are lacking or in short supply, or they are undertaking higher risk activities such as cycling or running, or they are living or staying for more than one month ( 3 vaccine doses, booster dose considered at 10 years post-primary course if the risk recurs; serology not generally offered). It should be noted that an Australian study called into question such selection criteria, based on a case series indicating that most injuries occurred within 30 days of arrival in a rabies-endemic region, most were injured whilst participating in common tourist activities, more than a third did not initiate contact with animals, and the most common injury sites were hands and fingers - high risk sites for rabies transmission due to rich nerve supply [12].

5. Post-exposure prophylaxis: Management consists of wound treatment and risk assessment for appropriate rabies-PEP, taking into account the circumstances of the exposure, including the local incidence of rabies in the species involved and the immune status of the person. Detailed guidance has been published by PHE [9]. Contact details for specialist advice in England, Wales, Scotland, and Northern Ireland are listed in the Green Book [www.gov.uk/government/uploads/system/uploads/attachment_data/file/85762/Green-Book-

Chapter-27-v3_0.pdf]. For head and neck bites, treatment should ideally be started within 12 hours of reporting; for other exposures treatment should be started ideally within 24 hours. Because the incubation period for rabies can be prolonged, treatment should be considered whatever the interval from exposure. Rabies-PEP initiated at an early stage is nearly $100 \%$ effective in preventing rabies, but delayed or incomplete treatment results in human deaths, often associated with severe lesions on or near the head or hand.

Rabies vaccine is the mainstay of rabies-PEP, and the aim is to achieve an antibody titre of $\geq 0.5 \mathrm{IU} / \mathrm{mL}$, as per WHO guidelines [11], as quickly as possible. Individuals with no prior vaccination or with an incomplete or uncertain vaccination history are offered five vaccine doses at $0,1,3,7,14$, and 30 days. Individuals that have received a full primary course of a cell culture-based vaccine are offered two vaccine doses at 0 and 3-7 days. Human rabies immunoglobulin (HRIG) is employed in selected cases, and is usually given within 7 days post-initiation of rabies vaccination in individuals who were not fully vaccinated pre-exposure. The entire HRIG dose $(20 \mathrm{lU} / \mathrm{kg})$ is infiltrated, if anatomically possible, in and 
around the site of exposure, with any remaining solution administered intramuscularly at a site different from that used for the vaccine. Reactions with HRIG include local pain and low-grade fever, but no serious adverse reactions have been reported. In developing countries, equine rabies immunoglobulin (ERIG) is sometimes used, which has a higher incidence of adverse effects and may vary in quality.

In the US and Australia the full vaccine course for rabies-PEP consists of four vaccine doses (at 0, 3, 7, and 14 days), with a fifth dose offered (day 28) only in the case of immune impairment (through disease or treatment) [12].

6. Rabies vaccine in HIV-positive adults: There are limited data on the immunogenicity and clinical efficacy of rabies vaccines for pre- or post-exposure prophylaxis in HIV-positive patients. Available evidence indicates that vaccine immunogenicity is influenced by the CD4 cell count and viral load, with low or absent antibody responses reported in some patients with CD4 counts $<200-250$ cells $/ \mu \mathrm{L}$ [1317] or even with CD4 counts $>500$ cells/ $\mu \mathrm{L}$ [9]. Effective ART has been shown to restore antibody responses to vaccination [18]. Approximately $88 \%$ of subjects with CD4 counts $>450$ cells $/ \mu \mathrm{L}$ while receiving stably suppressive ART ( 6 months) develop a protective antibody response to three doses of a cell culture-based vaccine [19]. The duration of responses is reduced relative to HIV-negative persons, and is affected by ART discontinuation $[18,19]$. Higher (double) and more frequent vaccine doses, and combined intradermal and subcutaneous vaccine administration have been proposed as management options for HIV-positive patients who fail to mount an acceptable antibody response, but data are limited [12]. Whether the intradermal route may be more effective at producing an immune response in HIV-positive patients than intramuscular vaccine remains unclear [20]. Current opinion is that caution is needed in assessing HIV-positive patients after a potential rabies exposure even when immunocompromise is thought to be mild [12]. In the few studies reported, rabies cell culture-based vaccines were well tolerated in HIV-positive persons [12-17], including when vaccines were used at double the standard dose [12].

\section{Recommendations for HIV-positive adults}

\section{Pre-exposure prophylaxis for travellers}

- We recommend that HIV-positive adults who are at risk of rabies exposure through travel be counselled about pre-exposure prophylaxis and offered vaccination with a cell culture-derived vaccine as indicated [1B]

- We recommend 3 vaccine doses be given intramuscularly on days 0,7 , and 28 . Advancing the third dose to day 21 is not recommended because it may curtail the immune response [1B]

- We recommend that patients be counselled about the risk of poor vaccine immunogenicity, which is reduced although not abolished in patients with CD4 cell counts $>500$ cells $/ \mu \mathrm{L}$ who are receiving stably suppressive ART [1B]

- We recommend that patients at increased risk of vaccine failure (based upon CD4 count, ART use, and viral load) undergo rabies serology testing 2-4 weeks after the last vaccine dose, and if the antibody response is $<0.5 \mathrm{IU} / \mathrm{mL}$ be offered a booster vaccine dose, followed by repeat serology testing $[1 \mathrm{C}]$. We suggest that the booster may be given at double the standard dose to increase immunogenicity [2C]

- We recommend that if the risk of travel-related exposure recurs, a first booster be offered 1 year after completion of the primary vaccine course, and subsequent boosters be given every 3-5 years or based on the results of serology testing where indicated [1C]

- We recommend travellers be advised that vaccination does not eliminate the need for wound management and post-exposure vaccination [GPP]

Pre-exposure prophylaxis for those at continuous or frequent exposure in the occupational setting 
- We recommend that HIV-positive adults with CD4 counts $>200$ cells $/ \mu \mathrm{L}$ and stable viral load suppression on ART be offered pre-exposure rabies vaccination with 3 doses of a cell culturederived vaccine given intramuscularly at 0,7 , and 28 days [1C]. We recommend that such patients undergo rabies serology testing 2-4 weeks after the last vaccine dose, and if the antibody response is $<0.5 \mathrm{IU} / \mathrm{mL}$ be offered a booster vaccine dose, followed by repeat serology testing [1B]. We suggest that the booster may be given at double the standard dose to increase immunogenicity [2C]. Exposure must be avoided in those who fail to mount an acceptable antibody response after the booster dose [GPP]

- We recommend that in patients at continuous risk of exposure who have an initial response to vaccination, subsequent booster doses are guided by serology testing performed every 6 months as per national guidance [1C]

- We recommend that in patients at frequent risk exposure who have an initial response to vaccination, subsequent booster doses be guided by serology testing performed at regular intervals $[1 \mathrm{C}]$. We recommend that in such patients the frequency of serology testing may vary between 1 and 3 years, and be guided by the CD4 cell count, ART use, and viral load at the time of vaccination and during follow-up [1C]

- We recommend that patients with CD4 counts $<200$ cells $/ \mu \mathrm{L}$ avoid continuous or frequent exposure to rabies [1C]

\section{Post-exposure prophylaxis}

- We recommend that each case be assessed individually following expert advice, because responses to rabies vaccination may be reduced even in patients with mild immunodeficiency [1B]

- We recommend that the following patients are regarded as non-immune and offered 5 doses of a cell culture-derived vaccine given intramuscularly at $0,1,3,7,14$, and 30 days, together with HRIG [1C]:

- Previously unvaccinated

- Previously given partial vaccination ( $<3$ doses)

- Previously given complete vaccination ( 3 doses) not followed by serological evidence of an adequate antibody response

- Uncertain vaccination history

- CD4 count $<500$ cells $/ \mu \mathrm{L}$ and not receiving stably suppressive ART

- We suggest that patients who previously received a complete vaccine course (3 doses) followed by serological evidence of an adequate antibody response, and with a CD4 count $>500$ cells $/ \mu \mathrm{L}$ and stable viral load suppression ( $>6$ months) on ART at the time of vaccination and during subsequent follow-up may be managed with 2 intramuscular vaccine doses given at 0 and 3-7 days and without HRIG [2D]

- We recommend that all patients undergo serology testing 2 weeks after the last vaccine dose to determine responses to vaccination and that non-responders are offered double-dose and/or more frequent vaccine doses accordingly [1C], and are considered for combined intradermal and subcutaneous double-dose vaccine administration [1D]

\section{References}

1. World Health Organization. Rabies. Available at http://www.who.int/rabies/en/ (accessed 06/07/2015)

2. Crowcroft NS, Thampi N. The prevention and management of rabies. BMJ 2015;350:g7827.

3. Fooks AR, Banyard AC, Horton DL, Johnson N, McElhinney LM, Jackson AC. Current status of rabies and prospects for elimination. Lancet 2014;384:1389-99.

4. Srinivasan A, Burton EC, Kuehnert MJ, et al. Transmission of rabies virus from an organ donor to 4 transplant recipients. N Engl J Med 2005;352:1103-11.

5. de Souza A, Madhusudana SN. Survival from rabies encephalitis. J Neurol Sci 2014;339:8-14. 
6. Fooks AR, Brookes SM, Healy D et al. Detection of antibodies to EBLV-2 in Daubenton's bats in the UK. Vet Rec 2004;154:245-6.

7. Public Health England. Rabies risks by country. https://www.gov.uk/government/publications/rabies-risks-by-country (accessed 06/07/2015).

8. Dodet B, Durrheim DN, Rees H. Rabies: underused vaccines, unnecessary deaths. Vaccine 2014;32:2017-9.

9. Public Health England. Rabies post-exposure prophylaxis: management guidelines. https://www.gov.uk/government/publications/rabies-post-exposure-prophylaxis-managementguidelines (accessed 06/07/2015)

10. Dobardzic A, Izurieta H, Woo EJ, et al. Safety review of the purified chick embryo cell rabies vaccine: data from the Vaccine Adverse Event Reporting System (VAERS), 1997-2005. Vaccine 2007; 25:4244-51.

11. World Health Organisation. Rabies vaccines: WHO position paper. Weekly epidemiological record. 2010;85: 309-20 http://www.who.int/wer/2010/wer8532.pdf (accessed 06/07/2015).

12. Conroy N, Vlack S, Williams JM, Patten JJ, Horvath RL, Lambert SB. Using serology to assist with complicated post-exposure prophylaxis for rabies and Australian Bat Lyssavirus. PLoS Negl Trop Dis 2013;7: e2066.10.

13. Thisyakorn U, Pancharoen $\mathrm{C}$, Ruxrungtham $\mathrm{K}$ et al. Safety and immunogenicity of preexposure rabies vaccination in children infected with human immunodeficiency virus type 1 . Clin Infect Dis 2000;30:218.

14. Thisyakorn U, Pancharoen C, Wilde H. Immunologic and virologic evaluation of HIV-1-infected children after rabies vaccination. Vaccine 2001;8:1534-7.

15. Tantawichien T, Jaijaroensup W, Khawplod $P$, Sitprija V. Failure of multiple-site intradermal postexposure rabies vaccination in patients with human immunodeficiency virus with low CD4 T lymphocyte counts. Clin Infect Dis 2001;33:E122-4.

16. Jaijaroensup W, Tantawichien T, Khawplod P, Tepsumethanon S, Wilde H. Postexposure rabies vaccination in patients infected with human immunodeficiency virus. Clin Infect Dis 1999;28:913-4.

17. Pancharoen $C$, Thisyakorn $U$, Tantawichien $T$, et al. Failure of pre- and postexposure rabies vaccinations in a child infected with HIV. Scand J Infect Dis 2001;33:390-1.

18. Gelinck LB, Jol-van der Zijde CM, et al. Restoration of the antibody response upon rabies vaccination in HIV-infected patients treated with HAART. AIDS 2009;23:2451-8.

19. Azzoni L, Foulkes AS, Firnhaber C, et al. Antiretroviral therapy interruptions result in loss of protective humoral immunity to neoantigens in HIV-infected individuals. AIDS 2012;26:1355-62.

20. Sirikwin S, Likanonsakul S, Waradejwinyoo $S$, et al. Antibody response to an eight-site intradermal rabies vaccination in patients infected with Human Immunodeficiency Virus. Vaccine 2009;27:4350-4. 


\section{SMALLPOX}

1. Infection and disease: Variola virus, a member of the orthopoxviridae family, causes smallpox. The infection is spread through droplets and aerosol and the most common mode of transmission is through face-to-face contact with an infectious individual [1]. The fatality rate is $\sim 25 \%$ overall, and severe complications such as blindness can occur. Following a worldwide vaccination campaign, smallpox was declared eradicated from the world in 1980 and routine vaccination was stopped. The last naturally occurring case in the world was in Somalia in 1977. Vaccine programmes were later restarted in several countries (e.g., in the military or health care workers) in response to a hypothetical threat from bioterrorism [1-3]. In the UK, people who were vaccinated against smallpox prior to national programmes being discontinued (i.e., most people born before 1971) will have some level of protection [4,5]; the vaccine is currently available for selected individuals who may come in contact with orthopox viruses through their occupation (e.g., laboratory workers). Some governments have stockpiled smallpox vaccines for deployment in case of intentional or accidental release $[2,3]$.

2. Smallpox vaccine: Replicating smallpox vaccines such as ACAM2000 are prepared with live vaccinia virus, which is closely related to the smallpox virus, and administered percutaneously via scarification in the skin of the upper arm [2,3]. Virus replication at the injection site produces a major cutaneous reaction or "take", which indicates a successful immune response. Primary vaccination is administered in a single dose; a booster dose is recommended after three years. People who have received two doses are likely to be protected for at least 10 years. A non-replicating vaccine based on Modified Vaccinia Ankara (Imvanex) was approved in 2013 for use in adults, including HIV-positive patients [6]. The approval was granted under 'exceptional circumstances' due to lack of clinical data. Imvanex is derived from a vaccinia virus strain that was attenuated through multiple passages in tissue culture and lost the ability to replicate in mammalian cells. The primary course for previously unvaccinated individuals consists of two doses given by subcutaneous administration at least one month apart. Two doses are also recommended for previously vaccinated patients who are immunocompromised. There are inadequate data to determine the need for and appropriate timing of further booster doses. Imvanex does not produce a visible cutaneous reaction following administration. In healthy persons, smallpox vaccines are highly effective in inducing protective immunity $[2,3,6]$. The protective efficacy of Imvanex against smallpox has not been studied [6].

3. Vaccine safety: Replicating smallpox vaccines have been associated with side effects ranging from frequent benign events to rare but life-threatening complications. Among vaccine recipients, 36\% become sufficiently ill to miss work, school, or recreational activities or to have trouble sleeping [2]. In a smallpox vaccination campaign conducted in health care workers in Arkansas in 2003, there was a $2 \%$ adverse event rate and a $0.5 \%$ hospitalization rate [7]. Myopericarditis is a recognised complication [8]. It is reported to occur in 5.7 of 1000 primary vaccine recipients; most cases are mild and selflimited with few documented reports of dilated cardiomyopathy [3]. Other serious adverse events include encephalitis, encephalomyelitis, encephalopathy, progressive vaccinia, generalized vaccinia, severe vaccinial skin infections, erythema multiforme major (including Stevens-Johnson syndrome), and eczema vaccinatum (severe and destructive infection of skin affected by eczema or other chronic skin disorder caused by spread of vaccinia virus). Permanent sequelae or death, ocular complications, blindness, and foetal death have occurred following either primary vaccination or revaccination with replicating smallpox vaccines [3]. Inadvertent transfer from the site of inoculation causes swelling, tenderness and rash at the site of transfer, and may result in vaccinia keratitis and subsequent corneal scarring. Progressive vaccinia is characterized by a slow and uncontrolled growth of vaccinia virus at the site of inoculation, frequently complicated by viraemia and generalized infection involving skin and multiple organs, with a $40-80 \%$ risk of mortality; it usually occurs in the presence of immunodeficiency. Death is most often the result of encephalitis or progressive vaccinia. 
A vaccinated person can transmit the vaccine virus directly through contact with the injection site and indirectly through objects that come in contact with the area around the vaccination site, including clothes, bedding, bandages and furniture. Infectivity lasts until the vaccination wound has healed and the scab has fallen off, usually within 14-21 days.

Contraindications to replicating smallpox vaccines include:

- Pregnancy and breast-feeding. The overall risk associated with maternal smallpox vaccination appears low. Foetal vaccinia is a rare consequence but is associated with a high rate of foetal loss [9]

- Current or past eczema and atopic dermatitis, or a current significant skin condition

- Heart disease, or $\geq 3$ known major cardiac risk factors

- Immunodeficiency caused by disease or treatment (including HIV infection)

- The vaccines are generally not recommended for those $>65$ years of age

Imvanex appears to be safe and well tolerated and does not increase the risk for development of myopericarditis $[3,10]$. The most common adverse reactions observed in clinical trials were injection site reactions and mild to moderate systemic reactions that resolved without intervention within seven days following vaccination. Imvanex is preferable for individuals at increased risk of adverse events with replicating smallpox vaccines in circumstances when the risk for smallpox is minimal and a delay in the onset of immunity (relative to using the replicating vaccine) would not increase this risk to an unacceptable level [3]. As a precautionary measure, use is avoided during pregnancy and breastfeeding unless it is considered that the possible benefit in terms of preventing smallpox would outweigh the potential risk.

4. Smallpox vaccine in HIV-positive adults: Although the safety of the replicating vaccine ACAM2000 has not been studied in persons with HIV infection, HIV-positive persons with low CD4 cell counts are at risk of progressive vaccinia when vaccinated with replicating smallpox vaccines [11-13]. In a study of 10 military recruits with a mean CD4 count of 483 cells/ $\mu \mathrm{L}$ (range 286-751) the replicating vaccine was well tolerated and immunogenic [13]; however, there is one case report of progressive vaccinia in a HIV-positive military recruit who received smallpox vaccination in 1984 with a CD4 count $<25$ cells $/ \mu \mathrm{L}$ [12]. The non-replicating vaccine Imvanex was well tolerated and highly immunogenic in $91 \mathrm{HIV}$ positive patients with CD4 counts $\geq 350$ cells $/ \mu \mathrm{L}$ and viral load $<400$ copies $/ \mathrm{mL}$, with no vaccine-related serious adverse events and an overall safety profile comparable to that of uninfected subjects [14]. LC16m8, a replicating smallpox vaccine licensed in Japan, shows reduced virulence in animal studies and has been proposed as a potential option for immunocompromised patients [15]. This remains controversial however as clinical data are lacking [16]. In 2014, the World Health Organisation specifically indicated that Imvanex should be considered for use, where approved, in individuals for whom replicating smallpox vaccines are contraindicated due to immunocompromise [17].

In the past, high doses of intravenous vaccinia immunoglobulin (VIGIV) derived from immunized individuals appeared to be effective in halting a proportion of cases of progressive vaccinia. The experience with VIGIV for the treatment of progressive vaccinia in persons with AIDS is limited to one reported case [12]. Antiviral drugs such as cidofovir (or others in advanced stages of development such as liposomal cidofovir, tecovirimat or brincidofovir) are recommended for the treatment of complications [3], although clinical data are scarce.

5. Post-exposure prophylaxis: Persons exposed to smallpox are at high risk for developing smallpox and transmitting the virus to others. Vaccination with replicating smallpox vaccines given within three days of exposure prevents disease or reduces its severity; partial protection is observed if postexposure prophylaxis is started after 4-7 days of exposure. There are no absolute contraindications to the use of replicating smallpox vaccines in this setting [3]. Whilst persons with atopic dermatitis (eczema), HIV infection with CD4 counts of 50-199 cells/ $\mu \mathrm{L}$, other immunocompromised states, and 
persons with vaccine or vaccine-component allergies are at higher risk for adverse events, replicating vaccines still are recommended in these groups as the risk of severe smallpox is considered higher than the risk of vaccine-related adverse events [3]. Although persons vaccinated with Imvanex have a lower risk for serious adverse events, protection is less certain also considering the requirement for two doses given at least one month apart. Persons with severe immunodeficiency, including HIVpositive patients with CD4 cell counts $<50$ cells/ $\mu \mathrm{L}$, are not expected to benefit from vaccination and can be managed with appropriate antivirals, or Imvanex when antivirals are not immediately available [3].

\section{Recommendations for HIV-positive adults}

- We recommend that all vaccine candidates are informed that smallpox vaccines might pose a serious risk to people with HIV infection, and that HIV testing is offered prior to vaccination to those who wish to be tested [1B]

- We recommend that for vaccine candidates that are HIV-positive, an assessment is made of the risk of contracting smallpox vs. the risk of vaccine-related side effects, using the CD4 cell count as a guide to inform vaccine use [1B]

- We recommend that in cases where vaccination is indicated but there is no urgency to induce a rapid immune response (e.g., most occupational settings) HIV-positive adults regardless of CD4 cells counts receive the non-replicating smallpox vaccine Imvanex, with 2 doses given subcutaneously at least 1 month apart [1B]

- We recommended that in selected scenarios where there is urgency to induce a rapid immune response, patients with CD4 counts $\geq 200$ cells $/ \mu \mathrm{L}$ may be offered a replicating smallpox vaccine followed by close monitoring for adverse events [1C]

- We recommend that following exposure, patients with CD4 counts $>50$ cells $/ \mu \mathrm{L}$ are offered vaccination with a replicating smallpox vaccine given preferably within 3 days and up to 10 days after the exposure $[1 \mathrm{C}]$. We suggest that in similar circumstances patients with CD4 counts $<50$ cells/ $\mu \mathrm{L}$ are unlikely to respond to vaccination and should be managed by appropriate antiviral therapy, although there is no absolute contraindication to Imvanex vaccination [2C]. Expert opinion should be sought

- We recommended that vaccine recipients who experience vaccine complications should receive VIGIV and/or appropriate antiviral therapy according to availability [1C]. Expert opinion should be sought

- We recommend that HIV-positive persons avoid close contact with recipients of replicating smallpox vaccines as they may spread the vaccine virus through direct or indirect contact with the vaccine reaction site $[1 \mathrm{C}]$

\section{References}

1. Adalja AA, Toner E, Inglesby TV. Clinical management of potential bioterrorism-related conditions. N Engl J Med 2015;372:954-62.

2. Centers for Disease Control and Prevention. Smallpox. http://emergency.cdc.gov/agent/smallpox/

3. Petersen BW, Damon IK, Pertowski CA, et al. Clinical guidance for smallpox vaccine use in a postevent vaccination program. MMWR Recomm Rep 2015;64:1-26.

4. Cohen J. Smallpox vaccinations: how much protection remains? Science 2001;294:885.

5. Taub DD, Ershler WB, Janowski M, et al. Immunity from smallpox vaccine persists for decades: a longitudinal study. Am J Med 2008;121:1058-64.

6. Imvanex. Summary of product characteristics. http://www.ema.europa.eu/docs/en_GB/document_library/EPAR_-

_Product_Information/human/002596/WC500147896.pdf

7. Haselow D. Vaccination-related side effects, humoral immunity, and adverse events during the civilian smallpox vaccination campaign, Arkansas, 2003. Public Health Nurs 2015 Jun 4. 
8. Engler RJ, Nelson MR, Collins LC Jr, et al. A prospective study of the incidence of myocarditis/pericarditis and new onset cardiac symptoms following smallpox and influenza vaccination. PLoS One 2015;10:e0118283.

9. Badell ML, Meaney-Delman D, Tuuli MG, et al. Risks associated with smallpox vaccination in pregnancy: a systematic review and meta-analysis. Obstet Gynecol 2015;125:1439-51.

10. Zitzmann-Roth EM, von Sonnenburg F, de la Motte S, et al. Cardiac safety of modified vaccinia Ankara for vaccination against smallpox in a young, healthy study population. PLoS One 2015;10:e0122653.

11. Freed ER, Duma RJ, Escobar MR. Vaccinia necrosum and its relationship to impaired immunologic responsiveness. Am J Med 1972;52:411-20

12. Redfield RR, Wright DC, James WD, Jones TS, Brown C, Burke DS. Disseminated vaccinia in a military recruit with human immunodeficiency virus (HIV) disease. N Engl J Med 1987;316:673-6.

13. Tasker SA, Schnepf GA, Lim M et al. Unintended smallpox vaccination of HIV-1-infected individuals in the United States military. Clin Infect Dis 2004; 38:1320-2.

14. Greenberg RN, Overton ET, Haas DW, et al. Safety, immunogenicity, and surrogate markers of clinical efficacy for modified vaccinia Ankara as a smallpox vaccine in HIV-infected subjects. J Infect Dis 2013;207:749-58.

15. Yokote $H$, Shinmura $Y$, Kanehara T, Maruno S, Kuranaga M, Matsui H, Hashizume S. Safety of attenuated smallpox vaccine $\mathrm{LC} 16 \mathrm{~m} 8$ in immunodeficient mice. Clin Vaccine Immunol 2014;21:1261-6.

16. Danon YL, Sutter G. Use of the LC16m8 smallpox vaccine in immunocompromised individuals is still too risky. Clin Vaccine Immunol. 2015;22:604.

17. WHO. Meeting of the Strategic Advisory Group of Experts on Immunization, November 2013 conclusions and recommendations. Wkly Epidemiol Rec 2014;18:1-20. 


\section{TETANUS}

1. Infection and disease: Tetanus is caused by the action of a neurotoxin (tetanospasmin) released by the gram-positive, anaerobic bacterium Clostridium tetani [1,2]. The bacterium and its spores are found primarily in the soil and intestinal tracts of animals and humans. Transmission occurs when spores are introduced into the body, typically through puncture wounds, burns and scratches, but also through trivial, unnoticed wounds, injecting drug use and occasionally abdominal surgery. Tetanus spores are widely distributed in soil or manure and may be introduced to a wound easily following an injury. The spores can also be found on skin surfaces and in contaminated heroin and drug paraphernalia. In the presence of anaerobic conditions, the spores germinate and the toxins are produced and released systemically. Tetanus is not contagious from person to person. Tetanus-prone wounds or burns include those that require surgical intervention and when that treatment is delayed for more than 6 hours; show a significant degree of devitalized tissue; are puncture-type injury particularly in contact with soil or manure; contain foreign bodies; are compound fractures; or occur in patients who have systemic sepsis. In its most common manifestation, tetanus is characterized by generalized rigidity and spasms of skeletal muscles and can lead to respiratory and cardiac failure. The case fatality ratio is $29 \%$ overall, but ranges from $8 \%$ to $90 \%$. Recovery from tetanus may not result in immunity, and vaccination following tetanus is indicated.

2. Epidemiology: Tetanus occurs worldwide but is most common in densely populated regions in hot, damp climates with soil rich in organic matter. Tetanus has occurred only rarely among persons who had previously received a primary vaccine course. The proportions of persons lacking protective levels of circulating antitoxins against tetanus increase with age; at least $40 \%$ of those aged $>60$ years may lack protection. Between 2001 and 2012, 88 cases of tetanus were reported in the UK, mostly in individuals aged $\geq 45$ years who had not been appropriately immunised [2]. In 2003-2004 a first cluster of cases of tetanus occurring in young injecting drug users (IDUs) was identified (case fatality $8 \%$ ). Following this cluster, only sporadic cases of tetanus were reported in IDUs in England to the end of $2014[2,3]$.

3. Tetanus in HIV-positive adults: In a US cohort of HIV-positive patients, $94 \%$ of those born in the US had evidence of tetanus immunity at the time of HIV diagnosis, whereas only $55 \%$ of those born outside of the US had a positive tetanus antibody test [4]. It is not known whether the natural history of tetanus is modified by HIV infection.

4. Tetanus vaccine: The tetanus vaccine is non-replicating and is made from cell-free purified toxin extracted from $C$. tetani and converted into tetanus toxoid. The vaccine is given to adults in combination with diphtheria toxoid and inactivated polio vaccine (Td/IPV). The vaccine is given by parenteral administration. The tetanus vaccine is highly immunogenic and effective. Although antitoxin levels decrease with age, the majority of vaccinated adults maintain protective antitoxin levels for many years. A total of five vaccine doses at the appropriate intervals (as per the UK childhood vaccination schedule) are considered to give lifelong immunity, with reinforcing doses recommended every 10 years for those at risk. The vaccine is well tolerated. Injection site reactions are common but usually self-limited and may occur more frequently following subsequent doses. Fever and other systemic reactions are uncommon. Severe systemic reactions are rare.

General indications: The aim of the UK national vaccination programme is to ensure that all individuals receive at least 5 vaccine doses. Td/IPV is recommended for vaccination of those aged $\geq 10$ years. Adults who are either unvaccinated or have an uncertain vaccination history are advised to receive primary immunization with 3 vaccine doses at either monthly intervals or at 0, 1-2 months, and 6-12 months. Two further doses are scheduled 5 and 10 years after the last dose. Adults who have received partial vaccination are advised to receive the remaining doses, regardless of the interval since the last 
dose and type of vaccine previously received. It is also recommended that travels to areas where access to post-exposure prophylaxis may be limited ensure they are fully vaccinated.

5. Tetanus vaccine in HIV-positive adults: The vaccine has been shown to be immunogenic in a variety of immunocompromised hosts including HIV-positive adults, although less so than in HIV-negative persons [5-10]. In HIV-positive children, serological response rates are 60-100\% after primary vaccination and $75-90 \%$ after booster vaccination [10]. Children show lower serum antitoxin levels compared to controls, and antibody levels deteriorate such that non-immune levels may be reached in less than five years [11]. Adults who received full primary vaccination before acquiring HIV infection may have sufficient humoral immunity for several years and are likely to develop protective levels of antitoxin following a booster dose. However, this response is lower in patients aged $>50$ years and those with a history of AIDS [12]. As a general rule, responses are inversely correlated to the CD4 cell count and immunity improves after successful ART [13]. There is no reported increased risk of side effects or adverse reactions in individuals with HIV infection.

6. Post-exposure prophylaxis: Tetanus vaccine and human tetanus Immunoglobulin (TIG) are used for post-exposure prophylaxis in cases of potential exposure, and used according to the vaccination history and type of wound. Use of TIG is guided by recommendations set out in the Green Book [www.gov.uk/government/uploads/system/uploads/attachment_data/file/148506/Green-BookChapter-30-dh_103982.pdf]. Efficacy in HIV-positive persons has not been established.

\section{Recommendations for HIV-positive adults}

- We recommend that HIV-positive adults that require vaccination against diphtheria, tetanus, or polio be given the Td/IPV vaccine in accordance with general indications, and regardless of CD4 cell count, ART use, and viral load [1B]

- We recommend that individuals who are either unvaccinated or have an uncertain vaccination history receive 3 vaccine doses at 1 month interval, followed by 2 reinforcing doses after 5 and 10 years, whereas partially vaccinated individuals should complete the 5-dose vaccine course [1B]

- We recommend that fully vaccinated individuals ( 5 doses) receive a booster dose every 10 years if at risk of exposure, typically if they are due to travel to areas where they may not be able to receive post-exposure prophylaxis in the event of a tetanus-prone injury [1C]

- We suggest that the interval between booster doses may be shortened to 5 years in patients older than 50 years [2C]

- We recommend that following a potential exposure, HIV-positive contacts receive post-exposure prophylaxis according to the type of exposure, the vaccination history, and the CD4 cell count [1C]

- Subjects with uncertain or incomplete (<3 doses) vaccination history: 3 vaccine doses at monthly intervals, regardless of type of wound and level of risk

- Subjects who have previously received $\geq 3$ vaccine doses with clean wound and negligible risk: 1 vaccine dose if the last dose received was $>10$ years previously

- Subjects who have previously received $\geq 3$ vaccine doses with tetanus-prone wound: 1 vaccine dose if the last dose received was $>10$ years previously or with CD4 count $<200$ cells $/ \mathrm{mL}$

- Subjects with high-risk tetanus-prone wounds should also receive TIG, and it is recommended that a careful assessment is made of the likely immunogenicity of vaccination as the sole mechanism of protection in patients with poor immune function and a significant risk of exposure [1B] 


\section{References}

1. Aronoff DM. Clostridium novyi, sordellii, and tetani: mechanisms of disease. Anaerobe 2013;24:98-101.

2. Public Health England. Tetanus: Information for health professionals. https://www.gov.uk/government/uploads/system/uploads/attachment_data/file/441356/IMW16 6.02_Tetanus_information_for_health_professionals_v1.4_2_.pdf [accessed 06/07/2015].

3. Public Health England. Tetanus in England and Wales. https://www.gov.uk/government/uploads/system/uploads/attachment_data/file/429677/hpr181 5_ttns.pdf [accessed 06/07/2015].

4. Alagappan K, McGowan J, DeClaro D, Ng D, Silverman RA. Tetanus antibody protection among HIV-infected US-born patients and immigrants. Int J Emergency 2008;1:123-6.

5. Kroon FP, van Dissel JT, De Jong JC, Furth RV. Antibody response to influenza, tetanus and pneumococcal vaccines in HIV-seropositive individuals in relation to the number of CD4 lymphocytes. AIDS 1994;8:469-76.

6. Janoff EN, Hardy WD, Smith PD, Wahl SM. Humoral recall responses in HIV infection. Levels, specificity, and affinity of antigen-specific IgG. J Immunol 1991;147:2130-5.

7. Bonetti TC, Succi RC, Weckx LY, Tavares-Lopes L, Moraes-Pinto MI. Tetanus and diphtheria antibodies and response to a booster dose in Brazilian HIV-1-infected women. Vaccine 2004;22:3707-12.

8. Dieye TN, Sow PS, Simonart T, et al. Immunologic and virologic response after tetanus toxoid booster among HIV-1- and HIV-2-infected Senegalese individuals. Vaccine 2001;20:905-13.

9. Rosenblatt HM, Song LY, Nachman SA, et al. Tetanus immunity after diphtheria, tetanus toxoids, and acellular pertussis vaccination in children with clinically stable HIV infection. J Allergy Clin Immunol 2005;116:698-703.

10. Borkowsky W, Steele CJ, Grubman S, Moore T, La Russa P, Krasinski K. Antibody responses to bacterial toxoids in children infected with human immunodeficiency virus. J Pediatr 1987;110:5636.

11. Choudhury SA, Matin F. Subnormal and waning immunity to tetanus toxoid in previously vaccinated HIV-infected children and response to booster doses of the vaccine. Int J Infect Dis 2013;17:e1249-51.

12. Andrade RM, Andrade AFB, Lazaro MA, et al. Failure of highly active antiretroviral therapy in reconstituting immune response to Clostridium tetani vaccine in aged AIDS patients. J Acquir Immune Defic Syndr 2010;54:10-7.

13. Burton CT, Goodall RL, Samri A, et al. Restoration of anti-tetanus toxoid responses in patients initiating highly active antiretroviral therapy with or without a boost immunization: an INITIO substudy. Clin \& Experimental Immunol 2008;152:252-7. 


\section{TICK-BORNE ENCEPHALITIS}

1. Infection and disease: Tick-borne encephalitis (TBE) is an acute febrile syndrome that can become complicated with neurological symptoms ranging from mild meningitis to severe encephalomyelitis [1]. It is caused by the tick-borne encephalitis virus (TBEV), which is a flavivirus. TBEV can be divided into three main subtypes: European (TBEV-Eu), Siberian (TBEV-Sib), and Far Eastern (TBEV-Fe). Other types also circulate [2]. The infection is transmitted to humans by the bite of an infected tick or, less commonly, by ingestion of unpasteurized milk from infected animals, mainly goats. Person-to-person transmission has not been reported. Only about one third of those with symptomatic infection develop neurological complications, which may lead to death (1-2\% or higher with certain subtypes) or sequelae (10-20\%).

2. Epidemiology: TBE is an emerging international public health problem [3]. TBE is the most common tick-transmitted disease in Central and Eastern Europe and Russia, and is endemic in 27 European countries. Infections also occur in the former Soviet Union and Asia [2]. In the UK, Ireland, Belgium, the Netherlands, Luxembourg, Spain, Portugal and Malta no autochthonous TBE cases have been registered to date. Climate, social, economic, and demographic changes are thought to have promoted the expansion of the endemic region of TBE viruses [3]. There are two seasonal peaks in Europe, one in May/June and the second in September/October. Infections are related to either leisure activities such as hiking, walking, and hunting, or working in agriculture and forestry in warm, rural or forested parts of endemic regions. Vaccination remains the most effective protective measure against TBE for people living in risk zones, occupationally exposed subjects, and travellers to endemic areas $[2,4-6]$. The risk of infection among unvaccinated travellers to a highly endemic region is calculated to be 1/10,000 [2]. For countries at very high risk of TBE infection, introduction of universal TBE vaccination in children $>1$ year of age onwards has been advocated. For countries with a very low risk of TBE, vaccine recommendations apply to those traveling to endemic areas $[2,5,6]$.

3. TBE in HIV-positive adults: It is not known whether the natural history of TBE is modified by HIV infection.

4. TBE vaccine: Two non-replicating whole killed vaccines are currently in use in Europe: FSME-Immun and Encepur, which are given by parenteral administration. Three doses are recommended, at 0, 1-3, and 6-12 months [2]. Accelerated schedules can be implemented in emergency situations ( 0 and 14 days, followed by a third dose 5-12 months after the second). Booster doses are indicated every 3-5 years, although immunity is likely to last for longer [2]. The two vaccines are interchangeable. TBE vaccines are highly immunogenic in adults, with seroconversion rates close to $100 \%$ after three doses, and cross-protection against different subtypes [2,4-7]. The rapid vaccination schedule has been shown to elicit similar rates of seroconversion in healthy individuals and is practical for travellers; antibody titres are lower and decline more rapidly than with the conventional schedule and therefore the rapid schedule is best suited for short-term travellers. The TBE vaccine is well tolerated. Injection site reactions are the most frequent side effects. The vaccine however is contraindicated in those with severe allergy to eggs. The vaccine has been suspected of causing an exacerbation of autoimmune diseases, but a cause-and-effect relationship has not been confirmed; a risk assessment should be made before administering the vaccine in these conditions.

5. TBE vaccine in HIV-positive adults: Two published studies have investigated the immunogenicity of TBE vaccination in HIV-positive patients $[8,9]$. These studies suggest that the vaccine is less immunogenic than in HIV-negative persons, particularly at CD4 counts $<400-500$ cells $/ \mu \mathrm{L}$, although a 4-dose vaccine course (given at 0, 1, 2, and 9-12 months) may improve responses. The duration of protection in HIV-positive persons is unknown, but may be reduced compared to healthy individuals; however, there is insufficient evidence to guide a change in boosting recommendations. A neutralizing antibody response $>126$ Vienna Units $/ \mathrm{mL}$ is considered to be protective. Post-vaccination testing is 
not recommended routinely in healthy individuals, but may be considered in some immunocompromised persons at risk of exposure in order to guide booster requirements. Whether rapid schedules are effective in HIV-positive persons is unknown. The TBE vaccine is safe and well tolerated in HIV-positive individuals with CD4 count $>200$ cells $/ \mu \mathrm{L}[8,9 ; \mathrm{H}$. Kollaritsch and $\mathrm{M}$. Peallabauer, personal communications).

\section{Recommendations for HIV-positive adults}

- We recommend that HIV-positive patients who intend to walk, camp, or work in heavily forested regions of TBE-affected countries during late spring or summer be offered TBE vaccination, particularly if staying in areas with heavy undergrowth [1B]. The vaccine is also recommended for expatriates whose principal area of residence is an area where TBE is endemic and this should be according to local vaccination programmes [1B]

- We recommend that 4 vaccine doses be offered in order to improve responses, and these should be given at 0,1 , and 2 months (primary course), followed by a fourth dose at 9-12 months [1B]

- We recommend that the decision to offer a rapid vaccination schedule (2 doses 2 weeks apart, followed by a third dose 5-12 months later) be based upon an evaluation of risk of exposure and urgency, taking into account that responses may be reduced in patients with CD4 counts $<400$ cells $/ \mu \mathrm{L}[1 \mathrm{C}]$

- We recommend that a booster vaccine dose is offered every 3-5 years to those at continued risk, with the shorter interval preferred for patients with CD4 counts $<400$ cells $/ \mu \mathrm{L}[1 \mathrm{C}]$

- We suggest that where available serological testing for specific antibodies may be used to guide boosting requirements $[2 \mathrm{C}]$

\section{References}

1. Zambito Marsala S, Pistacchi M, Gioulis M, Mel R, Marchini C, Francavilla E. Neurological complications of tick borne encephalitis: the experience of 89 patients studied and literature review. Neurol Sci 2014;35:15-21.

2. Amicizia D1, Domnich A, Panatto D, Lai PL, Cristina ML, Avio U, Gasparini R. Epidemiology of tickborne encephalitis (TBE) in Europe and its prevention by available vaccines. Hum Vaccin Immunother 2013;9:1163-71.

3. Jaenson TG, Hjertqvist $M$, Bergström $T$, Lundkvist $A$. Why is tick-borne encephalitis increasing? A review of the key factors causing the increasing incidence of human TBE in Sweden. Parasit Vectors 2012;5:184.

4. Demicheli V, Debalini MG, Rivetti A. Vaccines for preventing tick-borne encephalitis. Cochrane Database Syst Rev 2009;(1):CD000977.

5. Kollaritsch H, Paulke-Korinek M, Holzmann H, Hombach J, Bjorvatn B, Barrett A. Vaccines and vaccination against tick-borne encephalitis. Expert Rev Vaccines 2012;11:1103-19.

6. Zavadska D, Anca I, André F, et al. Recommendations for tick-borne encephalitis vaccination from the Central European Vaccination Awareness Group (CEVAG). Hum Vaccin Immunother 2013;9:362-74.

7. Loew-Baselli A, Poellabauer EM, Pavlova BG, Fritsch S, Firth C, Petermann R, Barrett PN, Ehrlich HJ. Prevention of tick-borne encephalitis by FSME-IMMUN vaccines: review of a clinical development programme. Vaccine 2011;29:7307-19.

8. Panasiuk B, Prokopowicz D, Panasiuk A. Immunological response in HIV-positive patients vaccinated against tick-borne encephalitis. Infection 2003;31:45-6.

9. Wolf HM, Pum M, Jager R, Istvan L, Mannhalter JW, Eibl MM. Cellular and humoral immune responses in haemophiliacs after vaccination against tick-borne encephalitis. British J Haematol 1992;82:374-83. 


\section{TYPHOID FEVER}

1. Infection and disease: Salmonella is a gram-negative bacillus transmitted by the faecal-oral route [1]. Thousands of serotypes are recognised, and most cause non-invasive infections of the gastrointestinal tract. Typhoid fever is an invasive infection caused by S. typhi. S. paratyphi A, B and C, and in HIV-positive individuals other salmonella species, also cause invasive infections which may present as enteric fever. Disease severity varies, but untreated infection carries a $12-30 \%$ risk of mortality. Deaths are rare in treated persons ( $2 \%$ or less). Up to $10 \%$ of patients with typhoid fever excrete the organism for three months following the acute illness. A chronic carrier state, with excretion of S. typhi for more than 1 year, occurs in approximately 1-6\% of individuals.

2. Epidemiology: The incidence of typhoid fever per 100,000 people ranges from $<0.1$ cases/year in Central and Eastern Europe and Central Asia to 725 cases/year in sub-Saharan Africa [3]. Paratyphoid incidence ranges from 0.8 cases/year in North Africa/Middle East to 77 cases/year in sub-Saharan Africa and South Asia. The adjusted estimate for the burden of typhoid fever accounting for the low sensitivity of blood cultures for diagnosis is about 27 million episodes. In the UK most cases follow travel to endemic areas; about $7 \%$ of cases occur in individuals with no relevant travel history. Travellers to Asia, Africa, and Latin America who have prolonged exposure to potentially contaminated food and drink are especially at risk of infection $[1,2,4]$. In these regions, the attack rate for travellers has been estimated at 10 per 100000 travellers. Increasing resistance to available antibiotics, including fluoroquinolones, is being reported. Multidrug-resistant strains of $S$. typhi have become common in the Indian subcontinent, the Middle East and some African countries [5-7]. Typhoid vaccination is an important component of typhoid fever prevention and control, and is recommended for travels and in public health programmes in both endemic and outbreak settings. Vaccination is currently only available against $S$. typhi.

3. Typhoid fever in HIV-positive adults: HIV-positive patients are at increased risk of infection with Salmonella, and immunodeficiency predisposes patients to bacteraemia, antibiotic resistance, relapsing disease, and persistent infection [8-14]. In residents of endemic countries, particularly in Africa, disease is predominately due to non-typhoidal Salmonella (NTS), rather than S. typhi. The burden of NTS in HIV-positive adults is declining with the roll-out of ART [15]. Whether the disease manifestations of typhoid fever among HIV-positive persons differ significantly from those observed in HIV-negative persons is uncertain.

4. Typhoid vaccine: Available vaccines comprise the injectable non-replicating $\mathrm{Vi}$ capsular polysaccharide vaccine (ViCPS), the oral replicating live attenuated Ty21a vaccine, and the injectable non-replicating typhoid conjugate vaccine [TCV] [16-18]. These vaccines do not protect against $S$. paratyphi or NTS infection. A NTS vaccine is under development [17]. TCVs have only recently become available and experience remains limited [16]. ViCPS is $38-80 \%$ protective in healthy people after a single dose $[16,17,19]$, with boosters recommended every three years for those at risk. There are no major safety concerns with the ViPS vaccine in healthy individuals from endemic or non-endemic countries [16-19]. Injection site reactions occur in up to 7\% of ViCPS recipients and usually resolve within 48 hours. Systemic reactions such as headache and fever occur in up to $20 \%$ and $1 \%$ of vaccinees respectively. Anaphylaxis and other serious adverse reactions are rare. There are no major safety concerns with the Ty21a vaccine in healthy people. However, the Ty21a vaccine should not be co-administered with antibacterials or antimalarials as these may impair efficacy.

General indications: The vaccine is indicated for travellers to areas that pose a risk of exposure.

5. Typhoid vaccine in HIV-positive adults: In HIV-positive persons, the induction of protective antibodies is impaired, particularly in patients with CD4 counts $<200$ cells $/ \mu \mathrm{L}$ [20]. The duration of protection may also be reduced in HIV-positive persons. Nonetheless, there is no evidence for dose or 
interval modification. Whether the Vi-conjugate vaccine when it becomes available will be more effective in this population is currently unknown. The ViCPS vaccine is safe for HIV-positive persons. Although there have been no reports of adverse events [21] the Ty21a vaccine is contraindicated in immunocompromised persons, including HIV-positive patients [13].

\section{Recommendations for HIV-positive adults}

- We recommend that HIV-positive patients who are due to travel to areas in which there is a recognized risk of exposure to $S$. typhi be offered the parental ViCPS vaccine [B1]

- Efforts should be made to offer vaccination to those at particularly high risk of exposure: visitors to friends and relatives; long-term travellers; and those with likely exposure to poor sanitary conditions [B1]

- These patients should receive 1 vaccine dose at least 2 weeks before expected exposure [C1]

- We recommend a booster vaccine dose is given every 3 years in those who remain at risk [1C]

\section{References}

1. Wain J, Hendriksen RS, Mikoleit ML, Keddy KH, Ochiai RL. Typhoid fever. Lancet 2015;385:1136-45.

2. Feasey NA, Dougan G, Kingsley RA, Heyderman RS, Gordon MA. Invasive non-typhoidal salmonella disease: an emerging and neglected tropical disease in Africa. Lancet 2012;379:2489-99.

3. Buckle GC, Walker CL, Black RE. Typhoid fever and paratyphoid fever: Systematic review to estimate global morbidity and mortality for 2010. J Glob Health 2012;2:10401.

4. Meltzer E, Schwartz E. Enteric fever: a travel medicine oriented view. Curr Opin Infect Dis 2010;23:432-7.

5. Zaki SA, Karande S. Multidrug-resistant typhoid fever: a review. J Infect Dev Ctries 2011;5:324-72.

6. Feasey NA, Gaskell K, Wong V, et al. Rapid emergence of multidrug resistant, H58-lineage Salmonella typhi in Blantyre, Malawi. PLoS Negl Trop Dis 2015;9:e0003748.

7. Wong VK, Baker S, Pickard DJ, et al. Phylogeographical analysis of the dominant multidrugresistant $\mathrm{H} 58$ clade of Salmonella Typhi identifies inter- and intracontinental transmission events. Nat Genet 2015;47:632-9.

8. Gordon MA. Salmonella infections in immunocompromised adults. J Infect 2008;56:413-22.

9. Gordon MA. Invasive nontyphoidal Salmonella disease: epidemiology, pathogenesis and diagnosis. Curr Opin Infect Dis 2011;24:484-9.

10. Feasey NA, Archer BN, Heyderman RS, Sooka A, Dennis B, Gordon MA, Keddy KH. Typhoid fever and invasive nontyphoid salmonellosis, Malawi and South Africa. Emerg Infect Dis 2010;16:144851.

11. Gordon MA, Kankwatira AM, Mwafulirwa G, et al. Invasive non-typhoid salmonellae establish systemic intracellular infection in HIV-infected adults: an emerging disease pathogenesis. Clin Infect Dis 2010;50:953-62.

12. Nga TV, Parry CM, Le T, et al. The decline of typhoid and the rise of non-typhoid salmonellae and fungal infections in a changing HIV landscape: bloodstream infection trends over 15 years in southern Vietnam.Trans R Soc Trop Med Hyg 2012;106:26-34.

13. Hochberg NS, Barnett ED, Chen LH, et al. International travel by persons with medical comorbidities: understanding risks and providing advice. Mayo Clin Proc 2013;88:1231-40.

14. Biggs HM, Lester R, Nadjm B, et al. Invasive Salmonella infections in areas of high and low malaria transmission intensity in Tanzania. Clin Infect Dis 2014;58:638-47.

15. Feasey NA, Houston A, Mukaka $M$, et al. A reduction in adult blood stream infection and case fatality at a large african hospital following antiretroviral therapy roll-out. PLoS One 2014;9:e92226.

16. Date KA, Bentsi-Enchill A, Marks F, Fox K. Typhoid fever vaccination strategies. Vaccine 2015;33 Suppl 3:C55-C61. 
17. Maclennan CA, Martin LB, Micoli F. Vaccines against invasive Salmonella disease: Current status and future directions. Hum Vaccin Immunother 2014;10:1478-93..

18. Bhutta ZA, Capeding MR, Bavdekar A, et al. Immunogenicity and safety of the Vi-CRM197 conjugate vaccine against typhoid fever in adults, children, and infants in south and southeast Asia: results from two randomised, observer-blind, age de-escalation, phase 2 trials. Lancet Infect Dis 2014;14:119-29.

19. Anwar E, Goldberg E, Fraser A, Acosta CJ, Paul M, Leibovici L. Vaccines for preventing typhoid fever. Cochrane Database Syst Rev 2014;1:CD001261.

20. Kroon FP, van Dissel JT, Ravensbergen E, Nibbering PH, van Furth R. Impaired antibody response after immunization of HIV-infected individuals with the polysaccharide vaccine against Salmonella typhi (Typhim-Vi). Vaccine 1999;17:2941-5.

21. Banda R, Yambayamba V, Lalusha BD, Sinkala E, Kapulu MC, Kelly P. Safety of live, attenuated oral vaccines in HIV-infected Zambian adults: oral vaccines in HIV. Vaccine 2012;30:5656-60. 


\section{TUBERCULOSIS}

1. Infection and disease: The Mycobacterium tuberculosis complex includes $M$. tuberculosis, M. bovis and $M$. africanum. Transmission nearly always occurs through airborne droplets that are expelled when a person with pulmonary tuberculosis (TB) coughs, talks, sings, or sneezes. The most infectious persons are those with cavitary pulmonary disease. Transmission usually requires prolonged exposure and close contact. In some cases transmission can occur through unpasteurized milk or milk products from infected cattle. Depending on host factors, infection may be cleared, remain latent, or progress to active disease over a period of weeks or months. Disease is usually pulmonary (60\% of cases), but non-pulmonary and disseminated disease can occur, especially in young children and immunocompromised persons, and almost every tissue and organ can be affected [1]. Latent infection can re-activate. The lifetime risk of re-activation is $5-15 \%$ for immunocompetent adults. The majority of re-activations occur within two years of primary infection.

2. Epidemiology: In the UK, cases of TB have increased over the last 10 years. A large number of cases are in people born abroad, the rate being higher in certain ethnic groups in the first few years after they enter the country, and rates remain high in the children of these immigrants wherever they are born. The risk of infection is also increased in persons who are close contacts of infectious persons, have HIV infection, are homeless, have hazardous alcohol use, or inject drugs. Risk factors for disease are diabetes mellitus, renal failure, immunodeficiency, latent infection acquired in infancy or early childhood, and therapy with immunomodulators (especially TNF-a antagonists). The mainstay of TB control is identifying and treating infectious cases to stop transmission, skin-testing or interferon gamma release assays (IGRAs) for children and adults who are at high risk for TB, and (where indicated) administering preventive therapy to persons with a positive skin-test result. Vaccination contributes to the prevention and control of TB in limited situations and is contraindicated in HIV infection.

3. TB in HIV-positive adults: HIV infection substantially increases the risk of infection and active TB disease: worldwide, TB is the leading cause of death among HIV-positive people [2]. HIV also suppresses responses to the tuberculin test.

4. Bacille Calmette-Guerin vaccine: The BCG vaccine is a live attenuated vaccine containing a strain of M. bovis isolated in 1908 from a cow, which was sub-cultured 231 times over 13 years resulting in gradual attenuation. Several laboratories produce vaccine derived from the original strain and many different BCG vaccines are available worldwide, with different production techniques and characteristics. BCG Vaccine Statens Serum Institut (SSI) is available in the UK. It is administrated intradermally in the later aspect of the left upper arm. Studies of BCG vaccine are difficult to interpret because they differ in design, location, strains used, vaccine dose, population, presence of mycobacteria in the environment, and diagnostic approach [3]. Protection rates vary widely in different trials. The vaccine appears to prevent the blood-borne spread of $M$. tuberculosis from primary pulmonary foci especially in children, but the protection afforded against pulmonary disease is more uncertain. There remain limited data concerning the protective efficacy of vaccination in adults, but overall efficacy appears to be higher in persons vaccinated during childhood compared with persons vaccinated at older ages. The efficacy of BCG vaccine in children and adults who are infected with HIV has not been determined. New TB vaccines are currently under investigation [4].

General indications: In the UK, a single BCG vaccine dose is given to selected high-risk infants and children, and previously unvaccinated tuberculin-negative close contacts of those with active respiratory TB. The vaccine is also indicated for previously unvaccinated tuberculin-negative adults below the age of 35 years if they are at occupational risk of exposure (e.g. healthcare workers, laboratory staff, veterinarians, prison staff, staff of care homes for the elderly, staff of hostels for homeless people and facilities accommodating refugees and asylum seekers) or intend to live or work 
in countries with an annual incidence of TB of $40 / 100,000$ or greater. The BCG vaccine may also be considered for previously unvaccinated, tuberculin-negative individuals travelling to high-prevalence countries for one month or longer.

5. Vaccine safety: The BCG vaccine often causes local adverse effects, but serious or long-term complications are rare in healthy individuals. Within 10-14 days, $90-95 \%$ of vaccine recipients develop a tender erythematous papule at the injection site, which may ulcerate and then slowly subside over several weeks or months leaving a flat scar of 5-15 mm. There may be enlargement $(<1 \mathrm{~cm})$ of a regional lymph node. Severe injection site reactions may occur, usually as a result of faulty injection technique, excessive dosage, or vaccinating individuals who are tuberculin-positive. Other adverse reactions include headache, fever, lymphadenopathy $(>1 \mathrm{~cm})$, allergic reactions (including anaphylaxis) and, rarely, lymphadenitis, and disseminated BCG (e.g., osteitis or osteomyelitis). Fatal dissemination has been described in immunocompromised individuals and the BCG vaccine is contraindicated in such populations. Case reports indicate that symptomatic HIV-positive persons are at a greater risk of local and systemic complications including disseminated BCG disease than HIV-negative persons or persons with asymptomatic HIV infection [5-12]. These complications can occur several years after BCG vaccination. Overall, there is no evidence of a clear benefit of BCG vaccination in HIV-positive people that may offset the potential risk.

\section{Recommendations for HIV-positive adults}

- We recommend that the BCG vaccine be absolutely contraindicated in all HIV-positive persons regardless of CD4 cell count, AT use, viral load, and clinical status [1C]

\section{References}

1. Zumla A, Raviglione M, Hafner R, von Reyn CF. Tuberculosis. N Engl J Med 2013;368:745-55.

2. Bruchfeld J, Correia-Neves M, Källenius G. Tuberculosis and HIV Coinfection. Cold Spring Harb Perspect Med 2015;5(7).

3. Abubakar I, Pimpin L, Ariti C, et al. Systematic review and meta-analysis of the current evidence on the duration of protection by bacillus Calmette-Guérin vaccination against tuberculosis. Health Technol Assess 2013;17:1-372.

4. Andersen $\mathrm{P}$, Urdahl KB. TB vaccines; promoting rapid and durable protection in the lung. Curr Opin Immunol 2015;35:55-62.

5. Centers for Disease Control and Prevention. Disseminated Mycobacterium bovis infection from BCG vaccination of a patient with acquired immunodeficiency syndrome. Morbid Mortal Wkly Rep 1985;34:227-8.

6. Ninane J, Grymonprez A, Burtonboy G, Francois A, Cornu G. Disseminated BCG in HIV infection. Arch Dis Child 1988;63:1268-9.

7. Boudes $P$, Sobel A, Deforges L, Leblic E. Disseminated Mycobacterium bovis infection from BCG vaccination and HIV infection. JAMA 1989;262:2386.

8. Reynes J, Perez C, Lamaury I, Janbon F, Bertrand A. Bacille Calmette-Guerin adenitis 30 years after immunization in a patient with AIDS. J Infect Dis 1989;160:727.

9. Armbruster C, Junker W, Vetter N, Jaksch G. Disseminated Bacille Calmette-Guerin infection in an AIDS patient 30 years after BCG vaccination. J Infect Dis 1990;162:1216.

10. Lumb R, Shaw D. Mycobacterium bovis (BCG) vaccination: progressive disease in a patient asymptomatically infected with the human immunodeficiency virus. Med J Aust 1992;156: 286-7.

11. Smith E, Thybo S, Bennedsen J. Infection with Mycobacterium bovis in a patient with AIDS: a late complication of BCG vaccination. Scand J Infect Dis 1992;24:109-10.

12. Talbot EA, Perkins MS, Silva SF, et al. Disseminated Bacille Calmette-Guerin disease after vaccination: case report and review. Clin Infect Dis 1997;24:1139-46. 


\section{VARICELLA ZOSTER VIRUS}

1. Infection and disease: VZV is a herpes virus that after primary infection establishes latency within neurons. Primary infection causes varicella or chickenpox. Reactivation causes herpes zoster or shingles. Chickenpox is highly infectious and can be transmitted by respiratory droplets and aerosols up to 48 hours prior to the onset of the rash. The skin lesions of both chickenpox and shingles are infectious until crusted. Chickenpox is usually benign and self-limiting in healthy children; healthy adults are more likely to develop severe and even life-threatening infections. Complications may include severe cutaneous rashes, secondary bacterial infections, visceral involvement (e.g. pneumonia, hepatitis), and neurological disease (meningitis, encephalitis, myelitis). All adults with chickenpox, and especially pregnant women, are at risk of VZV pneumonia. Occasionally, infection in pregnancy leads to foetal injury (congenital varicella syndrome). Shingles is usually self-limiting, although persistent debilitating pain is a frequent complication, particularly in the elderly (post-herpetic neuralgia, PHN); eye involvement may lead to permanent visual impairment.

2. Epidemiology: In temperate climates, primary infection with VZV occurs most commonly during childhood. At least $90 \%$ of adults in England and Wales are VZV IgG seropositive [1], confirming prior infection. In tropical and sub-tropical climates, the mean age of primary VZV infection may be delayed. As a result, a significant proportion of adults raised in those regions remain VZV IgG seronegative and susceptible to primary infection in adulthood. Among HIV-positive adults in the UK, 1.5\% lack evidence of VZV IgG [2]. Shingles is common in the general population, with an overall rate of 2-4 cases per 1000 person-years and higher incidence rates in adults $\geq 50$ years of age and in immunocompromised people, including HIV-positive individuals [3-5].

3. VZV in HIV-positive adults: HIV-positive patients who acquire chickenpox are at increased risk of severe and even fulminant disease [6-8]. Cell-mediated immunity plays a major role in controlling VZV reactivation, and impaired cellular immunity also increases the risk of shingles in people with HIV [9]. Before the introduction of effective ART, incidence rates of shingles were 10-20 times higher in HIVpositive adults than in the age-matched general population [5,10-13]. While disease burden has been reduced by ART, it is has remained 3-5 times higher than in HIV-negative people [5,13-17]. Shingles may occur and may recur at any time during HIV infection, although a low CD4 cell count and a viral load $>400$ copies/mL have been associated with a higher risk $[5,12,18]$. Additional risk factors may include a prior episode of shingles, crack cocaine use, and age $>60$ years ( $>40$ years in crack cocaine users) $[16,18]$. Complications of shingles are also more common in HIV-positive subjects than in the age-matched general population $(27 \%-28 \%$ vs. $10 \%-13 \%)[5,12]$, and may include cutaneous dissemination, chronic atypical skin lesions, ocular and neurological complications, or visceral dissemination. Acute retinal necrosis and neurological syndromes can occur as a result of VZV reactivation in the absence of rash. Both shingles and VZV-mediated cerebral vasculitis causing stroke have also been recognized as a manifestation of the immune reconstitution inflammatory syndrome $[19,20]$.

4. Chickenpox vaccine: Two varicella vaccines are available in the UK - Varilrix and Varivax. Both contain replicating live attenuated VZV (OKA strain). The vaccine strain can establish latent infection in some vaccine recipients, and can reactivate to cause shingles, although less commonly than with wildtype virus. Varilix should only be administered by deep subcutaneous injection. Varivax can be administered by either intramuscular or deep subcutaneous injection. In healthy adults, two doses give $75 \%$ protection against any disease and $95 \%$ protection against severe disease. Waning immunity over time is manifested by mild breakthrough infections with wild-type virus. The need for booster doses is currently under investigation. The vaccine is safe, although up to $10 \%$ of healthy adults develop a vaccine-associated rash, localized at the site of injection or generalized, within one month of immunization [21]. Transmission of vaccine virus from vaccine recipients has been documented 
only rarely and only from individuals with vaccine-associated rashes. Vaccination is not contraindicated and is in fact recommended for close contacts of HIV-positive persons.

General indications: In the UK, the varicella vaccine is currently recommended for susceptible healthcare workers and close contacts of immunocompromised patients. Contraindications include pregnancy and significant Immunocompromise.

5. Chickenpox vaccine in HIV-positive adults: The chickenpox vaccine has been shown to be safe and immunogenic in susceptible children with asymptomatic or mildly symptomatic HIV infection, and a suppressed viral load on ART is associated with improved immunogenicity [22-27]. Severe, but nonfatal vaccine-associated disease has been reported in some children with undiagnosed immunodeficiency [28]. There are limited data in HIV-positive adults. Among VZV IgG seropositive persons with CD4 counts $>400$ cells $/ \mu \mathrm{L}$ and stable on ART for $\geq 3$ months, the vaccine has been shown to boost VZV-specific cellular immune responses, without safety concerns [29]. Expert opinion in the US advises VZV vaccination in susceptible HIV-positive adults with CD4 counts $>200$ cells $/ \mu \mathrm{L}$, based upon evidence of safety and immunogenicity in children, the highly contagious nature of the infection, and the significant risk of severe disease resulting from primary VZV infection [30]. Further, patients who develop complications from the vaccine strain can be managed with antiviral therapy (e.g., aciclovir $800 \mathrm{mg} 5$ times daily, or valaciclovir $1 \mathrm{~g} 3$ times daily).

6. Shingles vaccine: The available shingles vaccine (Zostavax) contains high dose, replicating live attenuated VZV (Oka/Merck strain). The shingles vaccine is at least 14 times more potent than the chickenpox vaccine [31]. It is given as a single dose by subcutaneous injection and is licensed for immunocompetent adults aged $\geq 50$ years [32]. Vaccination of immunocompetent adults aged $\geq 60$ years boosts natural immunity and reduces the incidence of shingles by half and the incidence of PHN by two thirds [33]. The vaccine is also efficacious in immunocompetent adults aged 50-59 years, and protection against shingles lasts for at least 5 years [34-36]. The need for boosting doses has not been clearly determined. A systematic review concluded that there is a clear benefit in vaccinating elderly patients, with no major safety concerns [36]. Inactivated subunit vaccines based on the VZV glycoprotein $\mathrm{E}(\mathrm{gE})$ antigen are in clinical development [37].

General indications: In the UK, shingles vaccination is recommended for adults without a history of immunodeficiency aged 70 years, and a 'catch- up' programme currently targets those aged 70-79 years. Contraindications include pregnancy and breast feeding and significant immunocompromise.

7. Shingles vaccine in HIV-positive adults: The shingles vaccine was safe and immunogenic in a randomised trial (ACTG 5247) of 392 HIV-positive patients who were VZV IgG seropositive and receiving ART with a CD4 count $>200$ cells/ $\mu \mathrm{L}$. There was greater incidence of injection site reactions in the vaccine group (42\%) versus the placebo group (12\%). The greatest antibody response was observed in patients with CD4 counts $>350$ cells/ $\mu \mathrm{L}$ [38]. Duration of response and clinical effectiveness are unknown. Although these data are promising, further studies are required to define the cost-effectiveness of shingles vaccination in HIV-positive adults, including the appropriate age cutoff. Expert opinion is that it is reasonable to vaccinate patients $\geq 60$ years of age (provided the CD4 count is $>200$ cells $/ \mu \mathrm{L}$ ) [39]. Meanwhile, efforts are required to overcome barriers to the vaccination of HIV-positive people with good immune status who meet age-related indications for vaccination based upon general indications [40]. As a future alternative to a replicating vaccine, a recent phase 1/2, randomised, placebo-controlled study evaluated the immunogenicity and safety of a non-replicating adjuvanted subunit shingles vaccine in $123 \mathrm{HIV}$-positive adults that were predominantly on ART with CD4 counts $\geq 200$ cells/ $\mu \mathrm{L}$ [37]. After two doses, the vaccine proved to be strongly immunogenic; no vaccination-related serious adverse events were reported. 
8. Post-exposure prophylaxis: Protective immunity develops within four days of chickenpox vaccination, and Varivax (but not Varilrix) is licensed for post-exposure prophylaxis in susceptible individuals exposed to VZV, when it should be administered within three days and up to five days post-exposure in order to prevent or attenuate the infection. Available evidence supports the use of vaccination as post-exposure prophylaxis in healthy individuals $[41,42]$. There are currently no data in HIV infection, where the risk of any vaccine-related adverse event must be balanced against the risk of severe complications resulting from natural infection. Varicella-zoster immune globulin (VZIG) is indicated for susceptible immunocompromised patients (and pregnant women) who have had a significant exposure to VZV, and this includes symptomatic HIV-positive patients and asymptomatic patients with CD4 count $<400$ cells/ $\mu \mathrm{L}$. VZIG should be given within seven days and up to ten days after exposure by intramuscular injection. The duration of protection is three weeks. In the event of a second exposure after three weeks, repeat administration is recommended. Where intramuscular injection is contraindicated in individuals with bleeding disorders, intravenous immunoglobulin may be given instead. VZIG given within three weeks of a live attenuated vaccine (except Yellow Fever) may interfere with the vaccine immunogenicity. Replicating vaccines should likewise be postponed until three months after the administration of VZIG. Published evidence for the efficacy of aciclovir as post-exposure prophylaxis indicate that chickenpox may be prevented or attenuated in children by administration of aciclovir starting between seven and ten days after exposure, for a total of seven days $[43,44]$. The equivalent dose of aciclovir in adults is $800 \mathrm{mg}$ four times daily. There are no published controlled trials comparing antiviral prophylaxis directly with VZIG.

\section{Recommendations for HIV-positive adults}

- We recommend HIV-positive adults with a negative or uncertain history of chickenpox or shingles undergo VZV IgG testing to determine susceptibility to primary infection and reactivation [1B]

- We recommend VZV IgG seronegative patients who have a CD4 count $>200$ cells $/ \mu \mathrm{L}$ and preferably are established on ART are offered 2 doses of the chickenpox vaccine 3 months apart [1B]

- Serological testing for evidence of VZV IgG seroconversion should be performed 4-6 weeks after the second vaccine dose [GPP]

- We recommend VZV IgG seropositive patients who have a CD4 count $>200 / \mu \mathrm{L}$ and preferably are established on ART be offered 1 dose of the shingles vaccine in line with national age-related indications [1B]

- We recommend prior serological testing for evidence of VZV IgG seropositivity in those lacking a reliable history of chickenpox or shingles [1C]

- We recommend efforts be made to overcome barriers to the vaccination of HIV-positive people with CD4 count $>200$ cells $/ \mu \mathrm{L}$ who meet the age-related indications for shingles vaccination based upon national guidance [1B]

- We suggest that VZV IgG seropositive patients who have a CD4 count $>200 / \mu \mathrm{L}$ and preferably are established on ART may benefit from shingles vaccination from the age of 60 years [2B]

- We recommend HIV-positive recipients of replicating VZV vaccines be advised to report postvaccine rashes or other symptoms promptly, and following medical evaluation, be offered appropriate antiviral therapy against VZV if required [1B]

- We recommend that following a significant exposure to VZV, the VZV IgG status of the HIVpositive contact be ascertained regardless of vaccination history (although prophylaxis should not be delayed waiting for the results) and VZV IgG seronegative patients be considered for postexposure prophylaxis and monitored closely for symptoms to facilitate prompt institution of antiviral therapy $[1 \mathrm{~A}]$

- We recommend VZV IgG seronegative contacts with CD4 counts $<400$ cells $/ \mu \mathrm{L}$ receive post-exposure prophylaxis with VZIG as soon as possible, preferably within 7 days and not later than 10 days after exposure [1B] 
- We recommend that where VZIG is not available VZV IgG seronegative contacts be offered antiviral prophylaxis with aciclovir (800mg 4 times daily) [1B] or valaciclovir (1g 3 times daily) [1C] starting from day 7 after exposure and continuing for 7 days

- We suggest VZV IgG seronegative contacts with CD4 count $<200$ cells $/ \mu \mathrm{L}$ be considered for both VZIG and antiviral prophylaxis with aciclovir (800mg 4 times daily) or valaciclovir ( $1 \mathrm{~g}$ 3 times daily) [2C] starting from day 7 after exposure and continuing for 7 days

- We recommend VZV IgG seronegative contacts with CD4 counts $>400$ cells $/ \mu \mathrm{L}$ receive post-exposure prophylaxis with the Varivax vaccine within 3 and up to 5 days after exposure [1C]. The second dose should normally be scheduled after 3 months

- We recommend that VZV seronegative close contacts of HIV-positive adults with CD4 count $<200$ cells $/ \mu \mathrm{L}$ are proactively offered chickenpox vaccination [1B]

- We recommend that whenever possible HIV-positive patients receiving VZV replicating vaccines are not given treatment doses of antiviral drugs with anti-herpetic activity (e.g., aciclovir) at the time of vaccination and for 4 weeks subsequently as it may reduce vaccine immunogenicity [1D]

\section{References}

1. Vyse AJ, Gay NJ, Hesketh LM, Morgan-Capner P, Miller E. Seroprevalence of antibody to varicella zoster virus in England and Wales in children and young adults. Epidemiol Infect 2004; 132:112934.

2. Molton J, Smith C, Chaytor S, Maple P, Brown K, Johnson M, Geretti AM. Seroprevalence of common vaccine-preventable viral infections in HIV-positive adults. J Infect 2010;61:73-80.

3. Brisson M, Edmunds WJ. Epidemiology of varicella-zoster virus in England and Wales. J Med Virol 2003;70 (Suppl 1):9-14.

4. Yawn BP, Saddier P, Wollan PC, St Sauver JL, Kurland MJ, Sy LS. A population-based study of the incidence and complication rates of herpes zoster before zoster vaccine introduction. Mayo Clin Proc 2007;82:1341-9.

5. Blank LJ, Polydefkis MJ, Moore RD, Gebo KA. Herpes zoster among persons living with HIV in the current antiretroviral therapy era. J Acquir Immune Defic Syndr 2012;61:203-7.

6. Perronne $C$, Lazanas $M$, Leport $C$, et al. Varicella in patients infected with the human immunodeficiency virus. Arch Dermatol 1990;126:1033-6.

7. Grilli E, Baiocchini A, Del Nonno F, Petrosillo N, Galati V. Fulminant VZV infection in an adult AIDS patient treated with steroids: a case report. J Clin Virol 2014;60:63-6.

8. Maves RC, Tripp MS, Dell TG, et al. Disseminated vaccine-strain varicella as initial presentation of the acquired immunodeficiency syndrome: a case report and review of the literature. J Clin Virol 2014;59:63-6.

9. De Castro N, Carmagnat M, Kernéis S, Scieux C, Rabian C, Molina JM. Varicella-zoster virus-specific cell-mediated immune responses in HIV-infected adults. AIDS Res Hum Retroviruses 2011;27:1089-97.

10. Buchbinder SP, Katz MH, Hessol NA, et al. Herpes zoster and human immunodeficiency virus infection. J Infect Dis 1992;166:1153-6.

11. Veenstra J, Krol A, van Praag RM, et al. Herpes zoster, immunological deterioration and disease progression in HIV-1 infection. AIDS 1995;9:1153-8.

12. Glesby MJ, Moore RD, Chaisson RE. Clinical spectrum of herpes zoster in adults infected with human immunodeficiency virus. Clin Infect Dis 1995;21:370-5.

13. Moanna A, Rimland D. Decreasing incidence of herpes zoster in the highly active antiretroviral therapy era. Clin Infect Dis 2013;57:122-5.

14. Gebo KA, Kalyani R, Moore RD, Polydefkis MJ. The incidence of, risk factors for, and sequelae of herpes zoster among HIV patients in the highly active antiretroviral therapy era. J Acquir Immune Defic Syndr 2005;40:169-74. 
15. Vanhems P, Voisin L, Gayet-Ageron A, et al. The incidence of herpes zoster is less likely than other opportunistic infections to be reduced by highly active antiretroviral therapy. J Acquir Immune Defic Syndr 2005;38:111-3.

16. Nacher M, Basurko C, Adenis A, et al. Predictive factors of herpes zoster HIV-infected patients: another adverse effect of crack cocaine. PLoS One 2013;8:e80187.

17. Grabar S, Tattevin P, Selinger-Leneman $H$, et al. Incidence of herpes zoster in HIV-infected adults in the combined antiretroviral therapy era: results from the FHDH-ANRS CO4 cohort. Clin Infect Dis 2015;60:1269-77.

18. Shearer K, Maskew M, Ajayi T, Berhanu R, Majuba P, Sanne I, Fox MP. Incidence and predictors of herpes zoster among antiretroviral therapy-naïve patients initiating HIV treatment in Johannesburg, South Africa. Int J Infect Dis 2014;23:56-62.

19. Tangsinmankong N, Kamchaisatian W, Lugan-Zilbermann J et al. Varicella zoster as a manifestation of immune restoration disease in HIV-infected children. J Allergy Clin Immunol 2004;113:742-6.

20. Teo S, Raha D, Warren D, Hassan A, Monteiro E. Central nervous system-immune reconstitution inflammatory syndrome presenting as varicella zoster virus-mediated vasculitis causing stroke. Int J STD AIDS 2014;25:683-5.

21. Vazquez $M$, Shapiro ED. Varicella vaccine and infection with varicella-zoster virus. $N$ Engl J Med 2005;352:439-40.

22. Levin MJ, Gershon AA, Weinberg A, et al. Immunization of HIV-infected children with varicella vaccine. J Pediatrics 2001;139:305-10.

23. Levin MJ, Gershon AA, Weinberg A, Song LY, Fentin T, Nowak B. Administration of live varicella vaccine to HIV-infected children with current or past significant depression of CD4 T cells. J Infect Dis 2006;194:247-55.

24. Armenian SH, Han JY, Dunaway TM, Church JA. Safety and immunogenicity of live varicella virus vaccine in children with human immunodeficiency virus type 1. Pediatr Infect Dis J. $2006 ; 25: 368$ 70.

25. Bekker V, Westerlaken GHA, Scherpbier H, Alders S, Zaaijerc H, van Baarle D, Kuijpers T. Varicella vaccination in HIV-1-infected children after immune reconstitution. AIDS 2006, 20:2321-2329

26. Son M, Shapiro ED, LaRussa $P$, et al. Effectiveness of varicella vaccine in children infected with HIV. $\mathrm{J}$ Infect Dis 2010; 201:1806-11.

27. Taweesith W, Puthanakit $T$, Kowitdamrong $E$, et al. The immunogenicity and safety of live attenuated varicella-zoster virus vaccine in human immunodeficiency virus-infected children. Pediatr Infect Dis J 2011;30:320-4.

28. Galea S, Sweet A, Beninger P, et al. The safety profile of varicella vaccine: A 10-year review. J Infect Dis 2008;197:S165-9.

29. Weinberg A, Levin MJ MacGregor RR. Safety and immunogenicity of a live attenuated varicella vaccine in VZV-seropositive HIV-infected adults. Hum Vaccin 2010:6;318-21.

30. Rubin LG, Levin MJ, Ljungman $P$, et al. IDSA clinical practice guideline for vaccination of the immunocompromised host. Clin Infect Dis 2014;58:e44.

31. Harpaz F, Ortega-Sanchez IR, Seward JF. Centers for Disease Control and Prevention. Prevention of Herpes Zoster, Recommendations of the Advisory Committee on Immunization Practices (ACIP). Morbid Mortal Wkly Rep 2008;57:RR-5.

32. Centers for Disease Control and Prevention. Update on herpes zoster vaccine: licensure for persons aged 50 through 59 years. MMWR Morb Mortal Wkly Rep 2011;60:1528.

33. Oxman MN, Levin MJ, Johnson GR et al. A vaccine to prevent herpes zoster and postherpetic neuralgia in older adults. N Engl J Med 2005;352:2271-84.

34. Schmader KE, Oxman MN, Levin MJ, et al. Persistence of efficacy of zoster vaccine in the shingles prevention study and the short-term persistence study. Clin Infect Dis 2012;55:1320-8.

35. Schmader KE, Levin M, Gnannet JW, et al. Efficacy, safety and tolerability of herpes zoster vaccine in persons aged 50-59 years. Clin Infect Dis 2012:54:922-8.

36. Gagliardi AMZ, Gomes Silva BN, TorloniMR, Soares BGO. Vaccines for preventing herpes zoster in older adults. Cochrane Database Syst Rev 2012;10:CD008858. 
37. Berkowitz EM, Moyle G, Stellbrink HJ, et al. Safety and immunogenicity of an adjuvanted herpes zoster subunit candidate vaccine in HIV-infected adults: a phase 1/2a randomized, placebocontrolled study. J Infect Dis 2015;211:1279-87.

38. Benson C, Hua L, Anderson J, et al. Zostavax is generally safe and immunogenic in HIV+ adults virologically suppressed on ART: Results of a Phase 2, randomized, double-blind, placebocontrolled trial. Presented at the19th Conference on Retroviruses and Opportunistic Infections, Seattle WA, March 5-8 2012. Oral abstract \#96.

39. Aberg JA, Gallant JE, Ghanem KG, Emmanuel P, Zingman BS, Horberg MA. Primary care guidelines for the management of persons infected with HIV: 2013 update by the HIV medicine association of the Infectious Diseases Society of America. Clin Infect Dis 2014;58:e1.

40. Aziz M, Kessler H, Huhn G. Providers' lack of knowledge about herpes zoster in HIV-infected patients is among barriers to herpes zoster vaccination. Int J STD AIDS 2013;24:433-9.

41. Macartney K, McIntyre P. Vaccines for post-exposure prophylaxis against varicella (chickenpox) in children and adults. Cochrane database Syst Rev 2008;3:CD001833.

42. Souty C, Boos E, Turbelin C, Blanchon T, Hanslik T, Boëlle PY. Vaccination against varicella as postexposure prophylaxis in adults: a quantitative assessment. Vaccine 2015;33:446-50.

43. Asano $Y$, Yoshikawa $T$, Suga $S$, et al. Post exposure prophylaxis of varicella in family contacts by acyclovir. Pediatrics 1993;92:219-22.

44. Suga S, Yoshikawa T, Ozaki T, Asano Y. Effect of oral acyclovir against primary and secondary viraemia in incubation period of varicella. Arch Dis Child 1993;69:639-42. 


\section{YELLOW FEVER VIRUS}

1. Infection and disease: Yellow fever virus (YFV) is a flavivirus spread by the bite of an infected Aedes aegypti mosquito. Severity varies. Most infections are asymptomatic or cause a non-specific, selflimited influenza-like illness. Severe cases are characterised by hepatitis, jaundice, and haemorrhage, and carry a risk of mortality of up to $50 \%$ in non-immune adults travelling to endemic areas [1-3]. There is no specific antiviral treatment available.

2. Epidemiology: YFV is prevalent in tropical and sub-tropical regions of Africa and South America, where it is endemic and intermittently epidemic. It does not occur in Asia. Two forms of YF - urban and jungle - are epidemiologically distinguishable. In South America, sporadic infections occur almost exclusively as a result of occupational exposure in or near forested areas. In Africa, YFV is transmitted mainly in the moist savannah zones of west-central Africa, especially during the late rainy and early dry season (July-October). For travellers to endemic areas the risk of acquiring YF has been estimated to be 0.4-4.3 cases per million travellers [2]. The risk of disease is 10 times lower in South America than in rural West Africa, but varies greatly according to specific location and season. Under regulations set out by the World Health Organization (WHO), anyone travelling to a country or area where the Aedes aegypti mosquito is found must have an International Certificate of Vaccination or Prophylaxis, which is compulsory for entry to several countries in these regions. The certificate is valid for 10 years from the tenth day after primary vaccination and immediately after revaccination [1].

3. Yellow fever in HIV-positive adults: It is not known whether the natural history of YF is modified by HIV infection.

4. YFV vaccine: $Y F$ vaccine is a replicating live attenuated preparation of the YFV 17D strain grown in embryonated chick eggs. The YF vaccine is given as a single dose by deep subcutaneous or intramuscular injection. In healthy recipients, a single dose of the YF vaccine has a protective efficacy of $90 \%$ after 10 days and $99 \%$ after 30 days [3]. The protection lasts for at least 10 years (for which duration the certificate of vaccination is valid), after which a booster is required for those at continued risk. However, with some exceptions, immunity is thought to persist for at least 35 years and probably for life. The Green Book gives recommendations about selected boosting indications [www.gov.uk/government/uploads/system/uploads/attachment_data/file/306941/Green_Book_Chap ter_35_v3_3.pdf]

General indications: The YF vaccine is offered to travellers to specific regions. Vaccination can only be given at designated vaccination centres as established by the International Health Regulations of WHO.

5. Vaccine safety: Adverse reactions are generally mild with headache, myalgia, low-grade fever and/or soreness at the injection site occurring in 10-30\% of vaccine recipients. More serious adverse events are very rare and more likely to occur in persons who have no prior immunity to YFV. These are principally urticarial, bronchospasm or anaphylaxis (occurring in one per 130,000-250,000 vaccine doses), which may be related to reactions to the egg protein in the vaccine. Yellow fever vaccineassociated neurological disease (YEL-AND) has an estimated incidence overall of 0.4-0.8 per 100,000 with a higher rate in person aged over 60 years $(1.4-1.8$ per 100,000) [1]. Presentation is with fever and headache progressing to confusion, focal neurological deficits, coma, and Guillain-Barré syndrome; complete clinical recovery is the usual outcome. Yellow fever vaccine-associated viscerotropic disease (YEL-AVD) was first described in 2001 and has an estimated incidence of 0.4 per 100,000 , increasing to $1-2.3$ per 100,000 in persons aged $\geq 60$ years $[1,4,5]$. It resembles naturally acquired YF clinically and pathologically, and is characterized by multi-organ involvement and $50 \%$ risk of mortality. Studies are being conducted to clarify the cause and risk factors for these rare adverse events associated with the YF vaccines. A history of thymic dysfunction may be a risk factor. 
The main groups of adult people for whom the vaccine is contraindicated are:

- People with severe egg allergy or previous anaphylactic reaction to a previous YF vaccine or to any components of the vaccine

- Pregnant women and breast feeding mothers

- Those with a thymus disorder

- Persons with immunodeficiency caused by disease or treatment

People with any of these conditions can obtain a waiver letter prior to travel, although some countries may not accept waiver documents. Since it is recognised that older recipients are more at risk of developing YF vaccine-associated neurotropic and viscerotropic disease, older travellers are usually advised not to undergo vaccination and instead receive a certificate of exemption when the absolute risk of infection is low.

6. YFV vaccine in HIV-positive adults: A Cochrane review evaluated the risk and benefits of YFV vaccination in HIV-positive patients [6]. The review included 3 cohort studies [7-9] and reported that vaccination can produce protective levels of neutralising antibodies in HIV-positive people, although immunogenicity is less than in HIV-negative people. In one of the included studies, $83 \%$ of HIV-positive people had protective YFV neutralizing antibodies titres (NT) one year after vaccination, compared with $97 \%$ of HIV-negative people [8]. NT were significantly lower and declined more rapidly during follow-up in HIV-positive patients. Another study demonstrated high NT one year after immunization (98\%) with a marginal decrease after 10 years (92\%) [9]. Having a higher CD4 count (>200 cells/ $\mu \mathrm{L}$ ) and lower viral load at the time of vaccination were key associations with development of NT. The Cochrane review reported that none of the 484 HIV positive persons included in the review suffered serious adverse events as a result of vaccination [6]. The data cautiously support the safety of YF vaccination in HIV-positive patients with CD4 counts $>200$ cells $/ \mu \mathrm{L}$ and following viral load suppression on ART. The small numbers of patients included limits conclusions, particularly the very low numbers $(n=21)$ with a CD4 count $<200$ cells $/ \mu \mathrm{L}$. There has been only one report of death after receiving YF 17D vaccine in a Thai man with symptomatic HIV infection and a CD4 count of 108 cells/ $\mu \mathrm{L}$, probably from YEL-AND [10].

\section{Recommendations for HIV positive adults}

- We recommend that HIV-positive persons aged $<60$ years and with CD4 counts $>200$ cells $/ \mu \mathrm{L}$ who are due to travel to countries in which there is a recognized risk of exposure to YFV should be offered the choice of vaccination [1C]

- We recommend patients receive counselling about the benefits and risks of vaccination in relation to the risk of exposure, emphasising that a high CD4 cell count and a suppressed viral load on ART are likely to maximize safety and efficacy of vaccination [1C]

- If international travel requirements and not true exposure risk are the only reasons to vaccinate, a certificate of exemption can be given (some countries may not accepts waiver certificates) [1C]

- We recommend 1 vaccine dose at least 2 weeks before travel. Vaccine recipients should be monitored closely after vaccination [1C]

- We recommend a booster after 10 years for those at continued risk, providing the recipient remains aged $<60$ years, the CD4 count is $>200$ cells $/ \mu \mathrm{L}$, and following risk assessment and counselling [1C]

- We suggest that a serological test may precede vaccination and guide boosting requirements in those at greater risk of side effects [2C]

- We recommend that until more data are available on vaccine safety, HIV-positive adults with CD4 counts $<200$ cells $/ \mu \mathrm{L}$ or $>60$ years of age should not receive YFV vaccination, and should be discouraged from travel to destinations that present a true risk of infection [1C] 


\section{References}

1. Monath TP. Review of the risks and benefits of yellow fever vaccination including some new analyses. Expert Rev Vaccines 2012;11:427-48.

2. Centers for Disease Control and Prevention. Yellow fever vaccination: recommendations of the Advisory Committee on Immunization Practices (ACIP). Morbid Mortal Wkly Rep 2010;59:1-27.

3. Lang J, Zuckerman J, Clarke P, et al. Comparison of the immunogenicity and safety of two 17D yellow fever vaccines. Am J Trop Med Hygiene 1999;60:1045-50.

4. 4Khromava AY, Eidex RB, Weld LH, et al. The Yellow Fever Vaccine Safety Working Group. Yellow fever vaccine: an updated assessment of advanced age as a risk factor for serious adverse events. Vaccine 2005;23:3256-63.

5. Martin M, Weld LH, Tsai TF et al. Advanced age as risk factor for illness temporally associated with yellow fever vaccination. Emerg Infect Dis 2001;7:945-51.

6. Barte H, Horvath TH, Rutherford GW. Yellow fever vaccine for patients with HIV infection. Cochrane Database Syst Rev 2014;1:CD010929.

7. Sibailly TS, Wiktor SZ, Tsai TF, et al. Poor antibody response to yellow fever vaccination in children infected with human immunodeficiency virus type 1. Pediatr Infect Dis J 1997;16:1177-79.

8. Veit $\mathrm{O}$, Niedrig $\mathrm{M}$, Chapuis-Taillard $\mathrm{C}$, et al. Immunogenicity and safety of yellow fever vaccination for 102 HIV-infected patients. Clin Infect Dis 2009;48:659-66.

9. Pacanowski J, Lacombe K, Campa P, et al. Plasma HIV-RNA is the key determinant of long-term antibody persistence after yellow fever immunization in a cohort of 364 HIV-infected patients. J Acquir Immune Defic Syndr 2012;59:360-7.

10. Kengsakul K, Sathirapongsasuti K, Punyagupta S. Fatal myeloencephalitis following yellow fever vaccination in a case with HIV infection. J Med Assoc Thai 2002;85:131-49. 